\title{
Mercury Oxidation via Catalytic Barrier Filters Phase II
}

\section{Final Report}

Period of Performance:

October 1, 2004 through September 30, 2007

\author{
Prepared by: \\ Wayne Seames, PI \\ Michael Mann, co-PI \\ Darrin Muggli, co-PI \\ Jason Hrdlicka, Graduate student \\ Carol Horabik, Graduate student
}

October 2007

Award No. DE-FG26-04NT42188

\author{
Department of Chemical Engineering \\ University of North Dakota \\ P.O. Box 7101 \\ Grand Forks, ND 58202
}

Prepared for the U.S. Department of Energy

National Energy Technology Laboratory 


\section{Mercury Oxidation via Catalytic Barrier Filters}

\section{DISCLAIMER}

This report was prepared as account of work sponsored by an agency of the United States Government. Neither the United States Government nor any agency thereof, nor any of their employee, makes any warranty, express or implied, or assumes any legal liability or responsibility for the accuracy, completeness, or usefulness of any information, apparatus, product, or process disclosed, or represents that its use would not infringe privately owned rights. Reference herein does not necessarily constitute or imply its endorsement, recommendation, or favoring by the United States Government or any agency thereof. The views and opinions of authors expressed herein do not necessarily state or reflect those of the United States Government, the Department of Energy, or the National Energy Technology Laboratory. 


\title{
Mercury Oxidation via Catalytic Barrier Filters
}

\begin{abstract}
In 2004, the Department of Energy National Energy Technology Laboratory awarded the University of North Dakota a Phase II University Coal Research grant to explore the feasibility of using barrier filters coated with a catalyst to oxidize elemental mercury in coal combustion flue gas streams. Oxidized mercury is substantially easier to remove than elemental mercury. If successful, this technique has the potential to substantially reduce mercury control costs for those installations that already utilize baghouse barrier filters for particulate removal. Completed in 2004, Phase I of this project successfully met its objectives of screening and assessing the possible feasibility of using catalyst coated barrier filters for the oxidation of vapor phase elemental mercury in coal combustion generated flue gas streams. Completed in September 2007, Phase II of this project successfully met its three objectives. First, an effective coating method for a catalytic barrier filter was found. Second, the effects of a simulated flue gas on the catalysts in a bench-scale reactor were determined. Finally, the performance of the best catalyst was assessed using real flue gas generated by a $19 \mathrm{~kW}$ research combustor firing each of three separate coal types.
\end{abstract}

\section{ACKNOWLEDGEMENTS}

The authors would like to thank the funding sponsors: U.S. Department of Energy NETL UCR Program (Director: Charles Miller), the North Dakota Lignite Council, MontanaDakota Utilities, Basin Electric Power Cooperative, Great River Energy, Saskatchewan Power Corporation, and Minnkota Power Cooperative, Inc. We would also like to thank General Electric Energy BHA Group, Inc. for providing fabric material, fabric filters, and technical assistance related to the design and operation of baghouse filter systems for this project. We also thank the UND Energy and Environmental Research Center for providing advice and support during this project related to the sample conditioning and analysis of mercury. 


\section{Mercury Oxidation via Catalytic Barrier Filters}

\section{TABLE OF CONTENTS}

EXECUTIVE SUMMARY ............................................... 1

1. BACKGROUND....................................................... 3

Mercury as a Pollutant................................................ 3

Regulatory Status.................................................. 4

Mercury Control Technologies........................................ 5

Mercury Reaction Chemistry.......................................... 7

Coating Technology.................................................. 13

Catalysts and Fabrics.................................................... 17

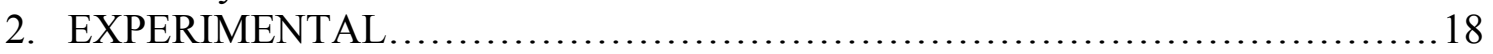

Projective Objective and Scope........................................... 18

Experimental Apparatus and Procedure..................................... 19

3. RESULTS AND DISCUSSION ............................................ 36

Objective 1 - Catalyst Coating........................................... 36

Objective 2 - Bench-Scale Testing.....................................48

Objective 3 - Small Pilot-Scale Testing................................. 73

4. SUMMARY OF PHASE II................................................. 86

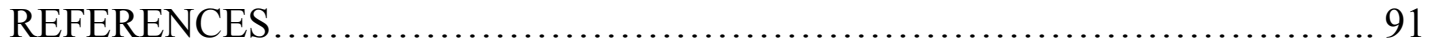

\section{LIST OF FIGURES}

1. Schematic of the dip coating process..................................... 16

2. Schematic of the spray coating process................................. 17

3. Schematic of the lab-scale test apparatus used to assess the adherence of catalyst support material applied to the clean side of typical baghouse fabrics by four separate application methods ............................................... 20

4. Photograph of the complete Horiba unit. The DM-6B analyzer is on the right, the MS-D1 conditioning unit is on the left, the MG-1 mercury generator is in the center, and the $\mathrm{SO}_{2}$ scrubber is located on top of the MG-1............. 23

5. Schematic of the MS-D1 dry catalyst conditioning unit for mercury analysis pretreatment. P1-P4 are pumps used to cycle moisture in and out of the unit...23

6. Schematic of the Horiba DM-6B mercury analyzer. P1 and P2 are vacuum pumps, V1 and V2 are three-way solenoid valves, F1 and F3 are zero gas filters, F2 and F4 are activated carbon filters, FC1 and FC2 are flow controllers, and FM1 and FM2 are rotameters. VR is the reference light signal and VS is the absorbed light signal. ..................................24

7. Schematic of wet solution conditioning system for sample gas pretreatment...25

8. Photograph of wet solution conditioning system for sample gas pretreatment... 26

9. Photograph of PS Analytical 10.534 Mercury Calibration System (PSA Hg

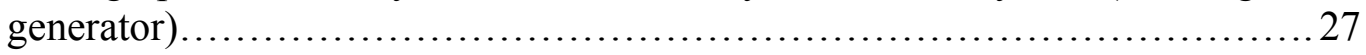

10. Schematic of PS Analytical 10.534 Mercury Calibration System (PSA Hg generator). MFC is mass flow controller. ............................... 27

11. Bench-scale baghouse filter test system for parametric mercury tests ............... 30 
12. Schematic of UND Chemical Engineering $17 \mathrm{~kW}$ research combustor.

13. Photograph of two single-bag baghouses removing ash for the UND Chemical Engineering $17 \mathrm{~kW}$ research combustor..................................... 34

14. Photograph of baghouse filter cage and baghouse filter used in baghouses for UND Chemical Engineering $17 \mathrm{~kW}$ research combustor.................... 35

15. Summary of results for fabric coating. Initial and final mass loadings for each method and both fabrics are shown. 1000 back pulse shocks (400 for the dry coat method) were performed prior to measuring the final catalyst loading....

16. Losses as a function of number of back pulse shocks for spray coated fabric

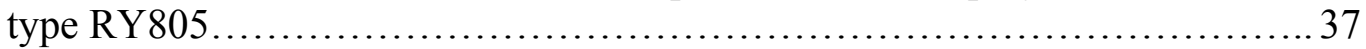

17. Losses from pulsing for spray coating on fabric type PC012 ..................38

18. Losses from pulsing for single dip coating on fabric type RY805 .............. 39

19. Catalyst support losses as a function of number of back pulse shocks for

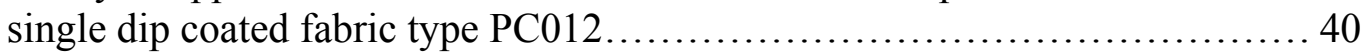

20. Catalyst support losses as a function of number of back pulse shocks for double dip coated fabric type RY805 ................................... 41

21. Catalyst support losses as a function of back pulse shocks for double dip

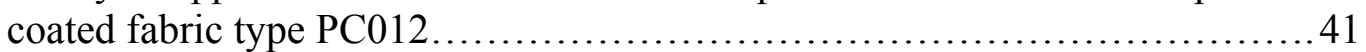

22. Example of an experiment using $\mathrm{TiO}_{2}$ to demonstrate total mercury shift.......49

23. Oxidized mercury spiking system......................................5

24. A comparison of mercury outlet concentrations with and without a $\mathrm{TiO}_{2}$ coated filter using an oxidized mercury $\left(\mathrm{HgCl}_{2}\right)$ spiking system............... 51

25. Typical experiment using $\mathrm{Au} / \mathrm{TiO}_{2}$ to demonstrate the different types of

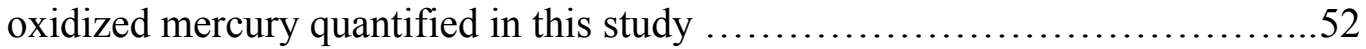

26. The effect of $\mathrm{Cl}_{2}$ on mercury oxidation for uncoated (bare) filter type RY805 (baseline gas is $4 \% \mathrm{O}_{2}, 10 \% \mathrm{H}_{2} \mathrm{O}, 20-30 \mu \mathrm{g} / \mathrm{m}^{3} \mathrm{Hg}^{0}$, and balance $\mathrm{N}_{2}$ ).........53

27. The effect of $\mathrm{HCl}$ on mercury oxidation for uncoated (bare) filter type $\mathrm{RY} 805$ (baseline gas is $4 \% \mathrm{O}_{2}, 10 \% \mathrm{H}_{2} \mathrm{O}, 20-30 \mu \mathrm{g} / \mathrm{m}^{3} \mathrm{Hg}^{0}$, and balance $\mathrm{N}_{2}$ ) ......... 53

28. The effect of $\mathrm{SO}_{2}$ on mercury oxidation for uncoated (bare) filter type $\mathrm{RY} 805$ (baseline gas is $4 \% \mathrm{O}_{2}, 10 \% \mathrm{H}_{2} \mathrm{O}, 20-30 \mu \mathrm{g} / \mathrm{m}^{3} \mathrm{Hg}^{0}$, and balance $\mathrm{N}_{2}$ )..........5 54

29. The effect of $\mathrm{NO}$ on mercury oxidation for uncoated (bare) filter type RY805 (baseline gas is $4 \% \mathrm{O}_{2}, 10 \% \mathrm{H}_{2} \mathrm{O}, 20-30 \mu \mathrm{g} / \mathrm{m}^{3} \mathrm{Hg}^{0}$, and balance $\mathrm{N}_{2}$ )......... 54

30. The effect of $\mathrm{Cl}_{2}$ on mercury oxidation for filter type $\mathrm{RY} 805$ coated with $\mathrm{TiO}_{2}$ (baseline gas is $4 \% \mathrm{O}_{2}, 10 \% \mathrm{H}_{2} \mathrm{O}, 20-30 \mu \mathrm{g} / \mathrm{m}^{3} \mathrm{Hg}^{0}$, and balance $\mathrm{N}_{2}$ )......... 56

31. The effect of $\mathrm{HCl}$ on mercury oxidation for filter type RY805 coated with $\mathrm{TiO}_{2}$ (baseline gas is $4 \% \mathrm{O}_{2}, 10 \% \mathrm{H}_{2} \mathrm{O}, 20-30 \mu \mathrm{g} / \mathrm{m}^{3} \mathrm{Hg}^{0}$, and balance $\mathrm{N}_{2}$ ).... 57

32. The effect of $\mathrm{SO}_{2}$ on mercury oxidation for filter type $\mathrm{RY} 805$ coated with $\mathrm{TiO}_{2}$ (baseline gas is $4 \% \mathrm{O}_{2}, 10 \% \mathrm{H}_{2} \mathrm{O}, 20-30 \mu \mathrm{g} / \mathrm{m}^{3} \mathrm{Hg}^{0}$, and balance $\mathrm{N}_{2}$ ).... 57

33. The effect of $\mathrm{NO}$ on mercury oxidation for filter type RY805 coated with $\mathrm{TiO}_{2}$ (baseline gas is $4 \% \mathrm{O}_{2}, 10 \% \mathrm{H}_{2} \mathrm{O}, 20-30 \mu \mathrm{g} / \mathrm{m}^{3} \mathrm{Hg}^{0}$, and balance $\mathrm{N}_{2}$ )......58

34. The effect of $\mathrm{Cl}_{2}$ on mercury oxidation for filter type $\mathrm{RY} 805$ coated with $\mathrm{Au} / \mathrm{TiO}_{2}$ (baseline gas is $4 \% \mathrm{O}_{2}, 10 \% \mathrm{H}_{2} \mathrm{O}, 20-30 \mu \mathrm{g} / \mathrm{m}^{3} \mathrm{Hg}^{0}$, and balance $\mathrm{N}_{2}$ ). 
35. The effect of $\mathrm{HCl}$ on mercury oxidation for filter type RY805 coated with $\mathrm{Au} / \mathrm{TiO}_{2}$ (baseline gas is $4 \% \mathrm{O}_{2}, 10 \% \mathrm{H}_{2} \mathrm{O}, 20-30 \mu \mathrm{g} / \mathrm{m}^{3} \mathrm{Hg}^{0}$, and balance $\mathrm{N}_{2}$ ).

36. The effect of $\mathrm{SO}_{2}$ on mercury oxidation for filter type RY805 coated with $\mathrm{Au} / \mathrm{TiO}_{2}$ (baseline gas is $4 \% \mathrm{O}_{2}, 10 \% \mathrm{H}_{2} \mathrm{O}, 20-30 \mu \mathrm{g} / \mathrm{m}^{3} \mathrm{Hg}^{0}$, and balance $\mathrm{N}_{2}$ ).

37. The effect of $\mathrm{NO}$ on mercury oxidation for filter type RY805 coated with $\mathrm{Au} / \mathrm{TiO}_{2}$ (baseline gas is $4 \% \mathrm{O}_{2}, 10 \% \mathrm{H}_{2} \mathrm{O}, 20-30 \mu \mathrm{g} / \mathrm{m}^{3} \mathrm{Hg}^{0}$, and balance $\mathrm{N}_{2}$ ).....

38. The effect of $\mathrm{Cl}_{2}$ on mercury oxidation using filter type $\mathrm{RY} 805$ coated with $\mathrm{Pd} / \mathrm{Al}_{2} \mathrm{O}_{3}$ (baseline gas is $4 \% \mathrm{O}_{2}, 10 \% \mathrm{H}_{2} \mathrm{O}, 20-30 \mu \mathrm{g} / \mathrm{m}^{3} \mathrm{Hg}^{0}$, and balance $\mathrm{N}_{2}$ ).

39. Oxidation promotion by $\mathrm{SO}_{2}$ in the presence of $\mathrm{Cl}_{2}$ and $\mathrm{Pd} / \mathrm{Al}_{2} \mathrm{O}_{3}$ (filter type RY805).

40. Spike in elemental mercury concentration with $\mathrm{Cl}_{2}$ and $\mathrm{HCl}$ addition using filter type $\mathrm{RY} 805$ coated with $\mathrm{Pd} / \mathrm{Al}_{2} \mathrm{O}_{3}$

41. Spike in elemental mercury concentration with $\mathrm{Cl}_{2}$ and $\mathrm{NO}$ addition using filter type $\mathrm{RY} 805$ coated with $\mathrm{Pd} / \mathrm{Al}_{2} \mathrm{O}_{3}$

42. The effect of $\mathrm{HCl}$ on mercury oxidation using filter type $\mathrm{RY} 805$ coated with $\mathrm{Pd} / \mathrm{Al}_{2} \mathrm{O}_{3}$ (baseline gas is $4 \% \mathrm{O}_{2}, 10 \% \mathrm{H}_{2} \mathrm{O}, 20-30 \mu \mathrm{g} / \mathrm{m}^{3} \mathrm{Hg}^{0}$, and balance $\mathrm{N}_{2}$ ).

43. The effect of $\mathrm{SO}_{2}$ on mercury oxidation using filter type $\mathrm{RY} 805$ coated with $\mathrm{Pd} / \mathrm{Al}_{2} \mathrm{O}_{3}$ (baseline gas is $4 \% \mathrm{O}_{2}, 10 \% \mathrm{H}_{2} \mathrm{O}, 20-30 \mu \mathrm{g} / \mathrm{m}^{3} \mathrm{Hg}^{0}$, and balance $\mathrm{N}_{2}$ ).

44. The effect of NO on mercury oxidation using filter type RY805 coated with $\mathrm{Pd} / \mathrm{Al}_{2} \mathrm{O}_{3}$ (baseline gas is $4 \% \mathrm{O}_{2}, 10 \% \mathrm{H}_{2} \mathrm{O}, 20-30 \mu \mathrm{g} / \mathrm{m}^{3} \mathrm{Hg}^{0}$, and balance $\mathrm{N}_{2}$ )....

45. A comparison of mercury oxidation achieved for the three study catalysts under experimental conditions 1-6.

46. A comparison of mercury oxidation achieved for the three study catalysts under experimental conditions 7-11...

47. A comparison of mercury oxidation achieved with the two study filter fabric types under various experimental conditions

48. Typical measurement spiking profile for experiments with fabric type RY805 coated with $\mathrm{Au} / \mathrm{TiO}_{2}$

49. Typical measurement spiking profile for experiments with fabric type RY805 coated with $\mathrm{Pd} / \mathrm{Al}_{2} \mathrm{O}_{3}$

50. Typical measurement spiking profile for experiments with fabric type PC012 coated with $\mathrm{Au} / \mathrm{TiO}_{2}$. Note the relateive smoothness of the measurements compared to figures 48 and 49 ....

51. Elemental and total mercury concentrations at the outlet of a baghouse fitted with uncoated (no catalyst) filters attached to a $19 \mathrm{~kW}$ combustor firing Illinois \#6 coal (doping results are based on injecting $\mathrm{Hg}^{0}$ directly into the baghouse at a concentration of $\left.6 \mu \mathrm{g} / \mathrm{m}^{3}\right)$.

52. Elemental and total mercury concentrations at the outlet of a baghouse fitted with uncoated (no catalyst) filters attached to a $19 \mathrm{~kW}$ combustor firing 
Falkirk lignite (doping results are based on injecting $\mathrm{Hg}^{0}$ directly into the baghouse at a concentration of $10 \mu \mathrm{g} / \mathrm{m}^{3}$ ).

53. Elemental and total mercury concentrations at the outlet of a baghouse fitted with $\mathrm{Pd} / \mathrm{Al}_{2} \mathrm{O}_{3}$ catalyst coated filters attached to a $19 \mathrm{~kW}$ combustor firing Falkirk lignite (doping results are based on injecting $\mathrm{Hg}^{0}$ directly into the baghouse at a concentration of $10 \mu \mathrm{g} / \mathrm{m}^{3}$ ).

54. A comparison of mercury measurements for the DM-6B mercury analyzer method and the Ontario-Hydro $(\mathrm{OH})$ method for Falkirk tests with and without the $\mathrm{Pd} / \mathrm{Al}_{2} \mathrm{O}_{3}$ catalyst

55. Elemental and total mercury concentrations at the outlet of a baghouse fitted with uncoated (no catalyst) filters attached to a $19 \mathrm{~kW}$ combustor firing Eagle Butte coal (doping results are based on injecting $\mathrm{Hg}^{0}$ directly into the baghouse at a concentration of $10 \mu \mathrm{g} / \mathrm{m}^{3}$ )

56. Elemental and total mercury concentrations at the outlet of a baghouse fitted with $\mathrm{Pd} / \mathrm{Al}_{2} \mathrm{O}_{3}$ catalyst coated filters attached to a $19 \mathrm{~kW}$ combustor firing Eagle Butte coal (doping results are based on injecting $\mathrm{Hg}^{0}$ directly into the baghouse at a concentration of $\left.10 \mu \mathrm{g} / \mathrm{m}^{3}\right)$

57. A comparison of mercury measurements for the DM-6B mercury analyzer method and the Ontario-Hydro $(\mathrm{OH})$ method for Eagle Butte tests with and without the $\mathrm{Pd} / \mathrm{Al}_{2} \mathrm{O}_{3}$ catalyst

58. Verification test for Eagle Butte using $\mathrm{Pd} / \mathrm{Al}_{2} \mathrm{O}_{3}$ catalyst during small pilotscale testing $\left(\mathrm{Hg}^{0}\right.$ is injected directly into the baghouse at a concentration of $\left.10 \mu \mathrm{g} / \mathrm{m}^{3}\right)$.

59. Mercury measurement at baghouse outlet for Eagle Butte during small pilotscale testing with $\mathrm{Cl}_{2}$ doping $\left(\mathrm{Hg}^{0}\right.$ is injected directly into the baghouse at a concentration of $10 \mu \mathrm{g} / \mathrm{m}^{3}$ and $\mathrm{Cl}_{2}$ is injected at a concentration of $10 \mathrm{ppm}$ )...83

60. Mercury measurement at baghouse outlet for Eagle Butte using $\mathrm{Pd} / \mathrm{Al}_{2} \mathrm{O}_{3}$ catalyst during small pilot-scale testing with $\mathrm{Cl}_{2}$ doping $\left(\mathrm{Hg}^{0}\right.$ is injected directly into the baghouse at a concentration of $10 \mu \mathrm{g} / \mathrm{m}^{3}$ and $\mathrm{Cl}_{2}$ is injected at a concentration of $10 \mathrm{ppm}$ )

\section{LIST OF TABLES}

1. Simulated flue gas composition and experimental conditions................... 30

2. Design of experiments for bench-scale parametric mercury tests................ 31

3. Coal analysis for test coals used in small pilot-scale testing................... 35

4. Pressure drop across filters for spray coating method........................ 44

5. Pressure drop across filters for double dip coating method...................44

6. Results for uncoated filter tests using filter type RY805 (baseline gas is $4 \%$

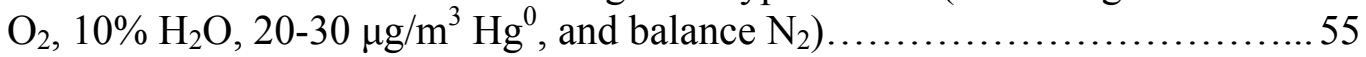

7. Results for filter type RY805 coated with $\mathrm{TiO}_{2}$ (baseline gas is $4 \% \mathrm{O}_{2}, 10 \%$

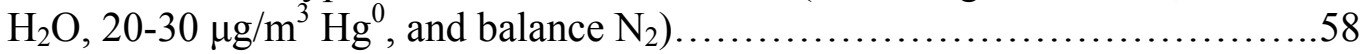

8. Results for filter type RY805 coated with $\mathrm{Au} / \mathrm{TiO}_{2}$ (baseline gas is $4 \% \mathrm{O}_{2}$, $10 \% \mathrm{H}_{2} \mathrm{O}, 20-30 \mu \mathrm{g} / \mathrm{m}^{3} \mathrm{Hg}^{0}$, and balance $\mathrm{N}_{2}$ ).......................... 62

9. Results for filter type RY805 coated with $\mathrm{Pd} / \mathrm{Al}_{2} \mathrm{O}_{3}$ (baseline gas is $4 \% \mathrm{O}_{2}$, $10 \% \mathrm{H}_{2} \mathrm{O}, 20-30 \mu \mathrm{g} / \mathrm{m}^{3} \mathrm{Hg}^{0}$, and balance $\mathrm{N}_{2}$ ).... 
10. Summary of results from Falkirk and Eagle Butte coals, short test is 6 hours and long test is 35 hours (All tests have $\mathrm{Hg}^{0}$ doping of $10 \mu \mathrm{g} / \mathrm{m}^{3}$ and $\mathrm{Cl}_{2}$ doping is $10 \mathrm{ppm}$ for Eagle Butte) 


\section{Mercury Oxidation via Catalytic Barrier Filters}

\section{EXECUTIVE SUMMARY}

The emission of mercury from pulverized coal combustion has drawn attention due to potential dangers for the ecosystem. Coal-fired utility boilers account for about one-third of the total U.S. anthropogenic mercury emission (40 to 50 tons annually). ${ }^{[1]}$ Although oxidized gaseous and particulate forms of mercury are deposited near their source, the lifetime of elemental mercury in the atmosphere is estimated to be up to two years. Moreover, elemental mercury can transport over trans-continental distances. While equilibrium calculations predict that elemental mercury should be almost completely converted to oxidized forms of gas or solid phase mercury $\left(\mathrm{Hg}^{2+}\right)$ upon cooling, measurements of flue gas from boilers burning a variety of coals typically show only $35 \%$ to $95 \%$ oxidation. $^{[1]}$

In order to further explore the feasibility of oxidizing elemental mercury in coal combustion flue gas, a project was initiated to study the oxidation of mercury using catalytic material impregnated onto fabric barrier filters. Barrier filtration is a wellknown and accepted method for separating fly ash particles from a flue gas stream. In fabric filtration, the fly ash-loaded gas flows through a number of microporous filter bags placed in parallel, removing the ash particles by the fabric. ${ }^{[2]}$ The excellent gas-catalyst contact that can be provided by barrier filters is expected to overcome the current gasdiffusion limitations of competing technologies, i.e. packed beds and entrained injection. This should substantially reduce the amount of catalyst required to accomplish removal of elemental mercury. Further, for existing and planned facilities utilizing barrier filters, this oxidation can be accomplished with virtually no additional capital expense.

The objectives of this project were 1) to screen potential catalyst coating methods and determine their ability to maintain ample and uniform loading under back-pulse cleaning cycles similar to those experienced in a baghouse, 2) to test the impact of important flue gas constituents on the performance of catalyst coated filters in a benchscale reactor using a simulated flue gas stream, and 3) to test the performance of catalyst coated filters under actual combustion conditions in a baghouse that services a $19 \mathrm{~kW}$ downflow laboratory combustor.

Phase $\mathrm{I}$ of this project screened three potential catalysts, $\mathrm{Al}_{2} \mathrm{O}_{3}, \mathrm{TiO}_{2}$, and $\mathrm{Pd} / \mathrm{Al}_{2} \mathrm{O}_{3}$ and found that $\mathrm{Pd} / \mathrm{Al}_{2} \mathrm{O}_{3}$ was the most attractive candidate with elemental mercury oxidation rates on the order of $90 \%$. $\mathrm{TiO}_{2}$ also shows possible potential with oxidation rates on the order of $70 \%$. By contrast, $\mathrm{Al}_{2} \mathrm{O}_{3}$ was found to be completely ineffective for elemental mercury oxidation under the experimental conditions utilized. The use of gold in oxidation processes has shown promise, ${ }^{[3,4]}$ so Phase II of this project included an investigation of the oxidation performance of $\mathrm{Au} / \mathrm{TiO}_{2}$. $\mathrm{TiO}_{2}$ and $\mathrm{Pd} / \mathrm{Al}_{2} \mathrm{O}_{3}$ were also further considered.

In Phase II we studied different fabric filter catalyst coating techniques. A test apparatus was constructed to automatically simulate back pulses of the filters. Filter samples were back pulsed up to 1000 times to determine the long term integrity of the catalyst loading. A simple spray coating process appears to be the most simple and 
effective technique. A double dip coating method is also effective but involves a more complex process than spray coating. Increases in pressure drop across a catalyst-coated filter were found to be insignificant when compared to a bare filter. We also found that UV light can damage the types of fabric filters we used when $\mathrm{TiO}_{2}$ was applied to them. Therefore $\mathrm{UV}$ activated $\mathrm{TiO}_{2}$ is not a viable option for this technology.

The oxidation performance of the catalyst-coated filters was tested using a simulated flue gas stream in a bench-scale reactor under conditions similar to those in a commercial coal-fired power plant baghouse. The impact of important flue gas constituents on mercury oxidation was investigated parametrically using $\mathrm{Cl}_{2}, \mathrm{HCl}, \mathrm{SO}_{2}$, and NO. Mercury measurement was accomplished using a Horiba DM-6B continuous emissions monitor type atomic absorption spectrometry-based mercury analyzer. The sample gas was pretreated using a wet conditioning system consistent with the OntarioHydro method. $\mathrm{Au} / \mathrm{TiO}_{2}$ and $\mathrm{Pd} / \mathrm{Al}_{2} \mathrm{O}_{3}$ performed well in the presence of $\mathrm{Cl}_{2}$. $\mathrm{Pd} / \mathrm{Al}_{2} \mathrm{O}_{3}$ performed the best with the addition of $\mathrm{Cl}_{2}$ and $\mathrm{SO}_{2}$. $\mathrm{Pd} / \mathrm{Al}_{2} \mathrm{O}_{3}$ had the best overall performance and was selected for use in the small pilot-scale testing.

The third objective of this project involved testing the performance of $\mathrm{Pd} / \mathrm{Al}_{2} \mathrm{O}_{3}$ in a single-bag baghouse that services a $19 \mathrm{~kW}$ research combustor. The bag in this baghouse is $76 \mathrm{~cm}$ (30 in.) long with a $15 \mathrm{~cm}$ (6 in.) diameter. Three study coals were used: Illinois \#6 bituminous, Eagle Butte subbituminous, and Falkirk lignite. Tests were performed for 4 to 6 hours. Very little elemental mercury could be measured in the Illinois \#6 flue gas because of its high chlorine and sulfur content. Eagle Butte and Falkirk flue gases were tested with $\mathrm{Pd} / \mathrm{Al}_{2} \mathrm{O}_{3}$ and $90 \%$ mercury oxidation was achieved. Ontario-Hydro verification of the on-line $\mathrm{Hg}$ measurements was also successfully performed during these tests.

A longer verification test was performed with the Eagle Butte. After 36 hours, the high level of mercury oxidation previously witnessed was reduced to $<20 \%$. This is expected to be the result of the catalyst mostly adsorbing mercury and reaching saturation over time, the catalyst being deactivated by some component, or the catalyst not properly adhering to the fabric filter and is being lost to the flue gas over time, possibly due to the pulse-jet cleaning cycles. However, this single longer term test is insufficient to properly ascertain the performance of catalytically coated filter bags under realistic conditions and additional future tests are warranted to determine the ultimate feasibility of the technology. 


\section{BACKGROUND}

\section{Mercury as a Pollutant}

The Clean Air Act Amendments of 1990 (CAAA) address 189 hazardous air pollutants (HAPs) believed to be detrimental to human health and the environment and highlighted mercury and its compounds as one of the highest priority pollutants to investigate. The CAAA required the U.S. Environmental Protection Agency (EPA) to conduct a mercury emissions study, including those from electric utility steam generating units. In 1997, EPA released the Mercury Study Report to Congress which analyzed mercury emissions from power plants and investigated control technologies. In 1998, EPA released the Utility Air Toxics Study which also showed mercury as a top priority pollutant due to its multi-pathway exposure potential and its ability to bio-accumulate and persist in the environment as methyl mercury. ${ }^{[5,6]}$

Mercury can exist in the environment in three forms: elemental mercury $\left(\mathrm{Hg}^{0}\right)$, oxidized mercury (mercurous $\left[\mathrm{Hg}_{2}{ }^{2+}\right]$ or mercuric $\left[\mathrm{Hg}^{2+}\right]$ ), and particulate-bound mercury $\left(\mathrm{Hg}^{\mathrm{P}}\right) .{ }^{[7]}$ Much of the mercury released into the atmosphere is in the form of elemental mercury. Elemental mercury can persist in the atmosphere for up to two years ${ }^{[8]}$ and travel thousands of miles, thus creating a global issue. Most of the oxidized and particulate-bound mercury will deposit in nearby water and soils, thus creating a local or regional issue. Bacteria can convert all forms of mercury to organic mercury, namely methyl mercury, most efficiently in the aquatic food chain. Once methyl mercury enters water, it can bio-accumulate in fish and other aquatic animals. Humans are primarily exposed to mercury through the consumption of fish and other aquatic animals that come from contaminated lakes and streams. ${ }^{[5]}$ 


\section{Regulatory Status}

On March 15, 2005, EPA issued the final Clean Air Mercury Rule (CAMR), which builds on EPA's Clean Air Interstate Rule (CAIR) to significantly reduce mercury emissions from coal-fired power plants. When fully implemented, these rules will reduce utility emissions of mercury from 48 to 15 tons per year, a reduction of nearly 70 percent.

The Clean Air Mercury Rule establishes "standards of performance" limiting mercury emissions from new and existing utilities and creates a market-based cap-andtrade program that will reduce nationwide utility emissions of mercury in two distinct phases. In the first phase, due by 2010 , emissions will be reduced by taking advantage of "co-benefit" reductions - that is, mercury reductions achieved while reducing sulfur dioxide and nitrogen oxides under CAIR. In the second phase, due in 2018, utilities will be subject to a second cap, which will reduce emissions to 15 tons per year upon full implementation. ${ }^{[9]}$

EPA was asked to reconsider the CAMR by several states and organizations. On May 31, 2006, EPA issued a final rule to reconsider its regulatory finding on utility emissions and on the CAMR. EPA reaffirmed its regulatory decision and made small technical changes and clarifications to the CAMR.

As of June 2006, seven states (Connecticut, Maryland, Massachusetts, Minnesota, New Hampshire, New Jersey, and Virginia) have established more stringent emission limits. ${ }^{[10]}$ These limits require reductions ranging from 80 to 95 percent and will be implemented sooner than the federal limits set by the CAMR. The state regulations also prohibit sources from trading mercury credits. Ten more states (Delaware, Florida, 
Georgia, Illinois, Michigan, Montana, New York, North Carolina, Pennsylvania, and Washington) are in the process of proposing similar standards.

\section{Mercury Control Technologies}

While there are a significant number of possible approaches to control mercury emissions, there is presently no single best technology that can be broadly applied. Therefore, a technology based standard would be very difficult to implement nation wide. Based on the current state of development, costs for mercury control are estimated to range from $\$ 11,000$ to $\$ 150,000$ per $\mathrm{kg}$ ( $\$ 5000$ to $\$ 70,000$ per pound) of mercury removed which may add up to $\$ 0.005$ per kWh to power cost. ${ }^{[1]}$ Remediation costs range from $\$ 2500$ to $\$ 1.1$ million per $\mathrm{kg}$ ( $\$ 1100$ to $\$ 500,000$ per pound) of mercury isolated from the environment, generally making mercury control at the source a better option. ${ }^{[12]}$

A variety of potential mercury oxidation catalysts have been investigated under experimental conditions ranging from short laboratory-scale tests using simulated flue gas to full-scale tests performed over several months. ${ }^{[13]}$ Gold has been used to catalyze mercury oxidation ${ }^{[3,4]}$ and has been shown to be very useful since it adsorbs mercury and chlorine, but does not adsorb other species such as nitric oxide, sulfur dioxide, and water. ${ }^{[3]}$ Gold has also demonstrated its ability to adsorb mercury and form an amalgam as a means of control in large-scale facilities. ${ }^{[14]}$ Palladium is a promising candidate that has been shown to oxidize $>95$ percent of elemental mercury in pilot-scale testing. ${ }^{[4]}$ 
Iron oxides, $\mathrm{Fe}_{2} \mathrm{O}_{3}$ and $\mathrm{Fe}_{3} \mathrm{O}_{4}$ in fly ash, have been shown to promote mercury oxidation. ${ }^{[15,16]}$ While fly ash seems to promote mercury oxidation, studies have shown that only a small amount of the active surface area ( 1 to 3 percent) plays a role in the process. ${ }^{[17,18]} \mathrm{Fe}_{2} \mathrm{O}_{3}$ has also been used as an effective catalyst in small-scale systems. ${ }^{[19}$, 20] Two components of refractory, $\mathrm{Al}_{2} \mathrm{O}_{3}$ and $\mathrm{TiO}_{2}$, have been shown to oxidize a portion of elemental mercury. ${ }^{[21,22]}$ Other metal catalysts shown to promote mercury oxidation include iridium ${ }^{[23]}, \mathrm{MnO}_{2}^{[20]}$, and $\mathrm{CuO}{ }^{[20]}$ Photochemical oxidation of mercury using ultraviolet irradiation, with particular promise in the presence of $\mathrm{TiO}_{2}$, is another emerging technology being investigated for use in coal-fired power plants. ${ }^{[24-27]}$

Selective catalytic reduction (SCR) technology, which achieves high levels of $\mathrm{NO}_{\mathrm{x}}$ emission reduction ( $\left.>90 \%\right)$ for power plants, has been found to oxidize mercury at rates as high as 70 percent in lab-scale studies. ${ }^{[28]}$ The application of SCR technology also affects the speciation of mercury in coal combustion flue gases. Mercury oxidation is generally low $(<20 \%)$ for lignite and subbituminous coals and high $(>70 \%)$ for bituminous coals. ${ }^{[29-31]}$ This most likely occurs because of the high chlorine content in most bituminous coals, which assists in catalytic oxidation, and low chlorine content in lignite and subbituminous coals.

Flue gas desulfurization (FGD) systems are primarily used to remove $\mathrm{SO}_{2}$ emissions from boiler flue gases. However, they can also be effective in removing mercury from boiler flue gas. Wet FGD systems, those that use a scrubbing solution, are installed on about 25 percent of the coal-fired utility generating capacity. ${ }^{[32]}$ The efficiency of a FGD system to remove mercury depends on the form of mercury present in the incoming flue gas. Oxidized mercury is much more water soluble than elemental 
mercury which allows oxidized mercury to be scrubbed from the flue gas, whereas essentially zero elemental mercury is removed.

The reduction of oxidized mercury back to its elemental form is a concern in wet FGD units. The presence of aqueous S(IV) species (as sulfite and/or bisulfite) can reduce oxidized mercury to elemental mercury in a wet FGD system. ${ }^{[33]}$ One full-scale study focused on the use of additives at two locations to inhibit the reduction of oxidized mercury across wet FGD units. ${ }^{[32]}$ One location averaged 77 percent mercury removal efficiency over a four month duration, while the other location showed significant chemical reduction and a mercury removal efficiency of 50 percent.

In a full-scale study where an SCR and FGD unit were present, greater than 90 percent mercury removal was obtained at a plant firing a bituminous coal. ${ }^{[34]}$ Selective catalytic reduction and FGD units will play a major role in meeting mercury emission requirements for utility boilers that employ their use which warrants further study of their mercury capture capabilities.

\section{Mercury Reaction Chemistry}

Significant advances in control technology will depend on an improved understanding of the chemical mechanisms of mercury oxidation and capture. The United States Geological Survey's (USGS) COALQUAL database indicates average mercury content in coal in the range of 0.08 to $0.22 \mathrm{ppmw}$, or 2.1 to $16 \mathrm{~kg} / 10^{15} \mathrm{~J}$ (4.8 to $36.4 \mathrm{lb}$ of $\left.\mathrm{Hg} / 10^{12} \mathrm{Btu}\right)$ on an energy basis. ${ }^{[35]}$ In the high temperature region of the 
combustion zone, all mercury is expected to vaporize into the elemental form $\left(\mathrm{Hg}^{0}\right)$ regardless of its original form in the coal. ${ }^{[36]}$

The coal combustion flue gas will typically contain vapor concentrations of mercury in the range of 1 to $30 \mu \mathrm{g} / \mathrm{Nm}^{3} \cdot{ }^{[37,38]}$ As flue gas cools in the post-combustion zone, mercury can undergo many transformations including oxidation and/or adsorption on materials such as fly ash or it can remain as elemental mercury. The range of oxidized mercury $\left(\mathrm{Hg}^{2+}\right)$ can vary from 10 percent to $>90$ percent of the total mercury in the flue gas and depends on several factors such as coal type, concentration of $\mathrm{Hg}$, flue gas temperature and composition, concentration and physical characteristics of entrained ash, and residence time in the flue gas duct. ${ }^{[1,7]}$

$\mathrm{Hg}^{2+}$ and particulate-bound mercury $\left(\mathrm{Hg}^{\mathrm{P}}\right)$ are relatively easy to remove from flue gas using typical air pollution control devices (APCD). $\mathrm{Hg}^{\mathrm{P}}$ is captured in electrostatic precipitators (ESP) and/or baghouses. $\mathrm{Hg}^{2+}$ is soluble in water and is removed with high efficiency by wet FGD equipment. However, $\mathrm{Hg}^{0}$ is difficult to capture. It is insoluble in water and is therefore not removed by FGD.

It is generally agreed that oxidation of mercury with chlorine containing species $\left(\mathrm{Cl}, \mathrm{HCl}\right.$, and $\left.\mathrm{Cl}_{2}\right)$ is the most important oxidation mechanism with mercuric chloride $\left(\mathrm{HgCl}_{2}\right)$ being the most likely product. Coal chlorine converts to $\mathrm{HCl}$ in the combustion zone. ${ }^{[37]} \mathrm{Cl}_{2}$ is considered to be much more reactive than $\mathrm{HCl}$ but the conversion to $\mathrm{Cl}_{2}$ is kinetically limited, most likely by the Deacon process in the presence of a catalyst ${ }^{[21]}$ :

$$
2 \mathrm{HCl}+1 / 2 \mathrm{O}_{2} \rightarrow \mathrm{Cl}_{2}+\mathrm{H}_{2} \mathrm{O}
$$


Sliger et al. ${ }^{[39]}$ described the transformation of $\mathrm{Hg}^{0}$ first with $\mathrm{Cl}$ to form $\mathrm{HgCl}$, and then with $\mathrm{Cl}, \mathrm{Cl}_{2}$, or $\mathrm{HCl}$ to the more stable $\mathrm{HgCl}_{2}$ ( $\mathrm{M}$ stands for intermediate):

$$
\begin{aligned}
& \mathrm{Hg}^{0}+\mathrm{Cl}+\mathrm{M} \rightarrow \mathrm{HgCl}+\mathrm{M} \\
& \mathrm{HgCl}+\mathrm{Cl} \rightarrow \mathrm{HgCl}_{2} \\
& \mathrm{HgCl}+\mathrm{Cl}_{2} \rightarrow \mathrm{HgCl}_{2}+\mathrm{Cl} \\
& \mathrm{HgCl}+\mathrm{HCl} \rightarrow \mathrm{HgCl}_{2}+\mathrm{H}
\end{aligned}
$$

Sliger et al ${ }^{[39]}$ found that virtually all of the oxidation occurred through equations 2 and 3 through a super-equilibrium $\mathrm{Cl}$ concentration process. Widmer et al. ${ }^{[40]}$ expanded this mechanism by introducing other possible initiation reactions with $\mathrm{HCl}, \mathrm{Cl}_{2}$, and $\mathrm{HOCl}$ :

$$
\begin{aligned}
& \mathrm{Hg}^{0}+\mathrm{Cl}_{2} \rightarrow \mathrm{HgCl}+\mathrm{Cl} \\
& \mathrm{Hg}^{0}+\mathrm{HCl} \rightarrow \mathrm{HgCl}+\mathrm{H} \\
& \mathrm{Hg}^{0}+\mathrm{HOCl} \rightarrow \mathrm{HgCl}+\mathrm{OH} \\
& \mathrm{HgCl}+\mathrm{HOCl} \rightarrow \mathrm{HgCl}_{2}+\mathrm{OH}
\end{aligned}
$$

Niksa et al. ${ }^{[41]}$ suggested that the essential reaction sequence for mercury oxidation involves a $\mathrm{Cl}$-atom recycle process. Once a pool of $\mathrm{Cl}$ atoms is established, $\mathrm{Hg}^{0}$ is first oxidized by $\mathrm{Cl}$ into $\mathrm{HgCl}$ (equation 2) which is then oxidized by $\mathrm{Cl}_{2}$ into $\mathrm{HgCl}_{2}$ (equation 4) with an associated regeneration of $\mathrm{Cl}$ atoms. In addition, Edwards et al. ${ }^{[42]}$ suggested that there is a competition between $\mathrm{Cl}$ atoms and $\mathrm{Hg}^{0}$. If the recombination reaction:

$$
2 \mathrm{Cl} \rightarrow \mathrm{Cl}_{2}
$$


is fast enough, then $\mathrm{Hg}^{0}$ will react directly with $\mathrm{Cl}_{2}$ to form $\mathrm{HgCl}_{2}$, although this is a much slower reaction.

$$
\mathrm{Hg}^{0}+\mathrm{Cl}_{2} \rightarrow \mathrm{HgCl}_{2}
$$

Frandsen et al. ${ }^{[43]}$ showed that $\mathrm{HgCl}_{2}$ is stable in the temperature range of 105 to $425^{\circ} \mathrm{C}\left(224\right.$ to $\left.800{ }^{\circ} \mathrm{F}\right)$. Below this range $\mathrm{Hg}$ is expected to transform to crystalline sulfate, which is more stable at lower temperatures:

$$
\mathrm{HgCl}_{2}+\mathrm{SO}_{2}+\mathrm{O}_{2} \rightarrow \mathrm{HgSO}_{4}+\mathrm{Cl}_{2}
$$

Above this range $\mathrm{Hg}$ is expected to transform to an oxide:

$$
\mathrm{HgCl}_{2}+\mathrm{H}_{2} \mathrm{O} \rightarrow \mathrm{HgO}+2 \mathrm{HCl}
$$

The concentration of $\mathrm{HgO}$ reaches a maximum around $525^{\circ} \mathrm{C}\left(980^{\circ} \mathrm{F}\right)$. Above this temperature, $\mathrm{HgO}$ is predicted to decompose to $\mathrm{Hg}^{0}{ }^{[43]}$ Several studies ${ }^{[43-45]}$ have shown that $\mathrm{HgO}$ makes up only 1 to 10 percent of the total mercury in flue gas at any give time in the flue gas duct.

$\mathrm{O}_{2}$ is a weak promoter of homogenous mercury oxidation ${ }^{[22,41,42,44]}$ due to kinetic limitations and short residence time in the flue gas duct and therefore plays a small role in Hg oxidation (equation 14).

$$
\mathrm{Hg}^{0}+1 / 2 \mathrm{O}_{2} \rightarrow \mathrm{HgO}
$$

However, equation 14 has been shown to be heterogeneously catalyzed, possibly in the presence of refractory materials such as $\mathrm{Al}_{2} \mathrm{O}_{3}$ and $\mathrm{TiO}_{2}{ }^{[21,22]}$

Nitric oxide (NO) has been shown to either have no effect on homogenous oxidation with mercury $^{[19,41]}$ or has been shown to play an inhibitory role in homogenous 
oxidation. $^{[41,46,47]}$ Niksa et al. ${ }^{[41]}$ concluded that the inhibitory role of NO was due to its consumption of $\mathrm{OH}$ radicals as shown in equation 15. The depletion of $\mathrm{OH}$ radicals did not allow for the formation of $\mathrm{HOCl}$, one of the important oxidizing species.

$$
\mathrm{NO}+\mathrm{OH}+\mathrm{M} \rightarrow \mathrm{HONO}+\mathrm{M}
$$

Agarwal et al. ${ }^{[48]}$ suggest that $\mathrm{NO}$ can react with $\mathrm{Cl}_{2}$, thereby reducing the amount of $\mathrm{Cl}_{2}$ available for mercury oxidation as shown in equation 16.

$$
2 \mathrm{NO}+\mathrm{Cl}_{2} \rightarrow 2 \mathrm{NOCl}
$$

Zhao et al. ${ }^{[47]}$ also propose that $\mathrm{NO}$, in the presence of $\mathrm{H}_{2} \mathrm{O}$, can react with $\mathrm{Cl}_{2}$ and $\mathrm{Cl}$, forming $\mathrm{HCl}$ which has much less oxidizing capability than $\mathrm{Cl}_{2}$ possibly through equations 17 and 18 .

$$
\begin{aligned}
& \mathrm{NO}+\mathrm{Cl}_{2}+\mathrm{H}_{2} \mathrm{O} \rightarrow \mathrm{NO}_{2}+2 \mathrm{HCl} \\
& \mathrm{NO}+\mathrm{Cl}+\mathrm{H}_{2} \mathrm{O} \rightarrow \mathrm{HONO}+\mathrm{HCl}
\end{aligned}
$$

Nitrogen dioxide $\left(\mathrm{NO}_{2}\right)$ is expected to promote mercury oxidation. ${ }^{[49]}$ Hall et al. propose a mechanism for mercury oxidation by $\mathrm{NO}_{2}$ :

$$
\mathrm{Hg}^{0}+\mathrm{NO}_{2} \rightarrow \mathrm{HgO}+\mathrm{NO}
$$

However, this is a slow reaction and since $\mathrm{HgO}$ decomposes above temperatures around $525^{\circ} \mathrm{C}\left(980{ }^{\circ} \mathrm{F}\right)$ this mechanism is not expected to be important. Several intermediate nitrites and nitrates may occur here, but they are generally unstable above $100{ }^{\circ} \mathrm{C}(212$ $\left.{ }^{\circ} \mathrm{F}\right)$. Overall, nitrogen oxides $\left(\mathrm{NO}_{\mathrm{x}}\right)$ have been shown to oxidize mercury in the presence of fly ash and thus may be important. ${ }^{[19,38,46]}$ 
Similar to NO, sulfur dioxide $\left(\mathrm{SO}_{2}\right)$ generally plays an inhibitory role in mercury oxidation. $\mathrm{SO}_{2}$ can consume $\mathrm{OH}$ radicals, which is an important species in the oxidizing intermediate $\mathrm{HOCl}$ as is shown in equations 20 and 21. ${ }^{[47]}$

$$
\begin{aligned}
& \mathrm{SO}_{2}+\mathrm{OH}+\mathrm{M} \rightarrow \mathrm{HOSO}_{2}+\mathrm{M} \\
& \mathrm{SO}_{2}+\mathrm{OH}+\mathrm{M} \rightarrow \mathrm{SO}_{3}+\mathrm{H}+\mathrm{M}
\end{aligned}
$$

Agarwal et al. ${ }^{[48]}$ suggest that $\mathrm{SO}_{2}$ can react with $\mathrm{Cl}_{2}$, thereby reducing the amount of $\mathrm{Cl}_{2}$ available for mercury oxidation as shown in equation 22 .

$$
\mathrm{SO}_{2}+\mathrm{Cl}_{2} \rightarrow \mathrm{SO}_{2} \mathrm{Cl}_{2}
$$

Several studies ${ }^{[15,21,47]}$ have suggested that $\mathrm{SO}_{2}$, in the presence of $\mathrm{H}_{2} \mathrm{O}$, can deplete $\mathrm{Cl}_{2}$ and $\mathrm{Cl}$, forming $\mathrm{HCl}$ which has a lesser oxidizing capability.

$$
\begin{aligned}
& \mathrm{SO}_{2}+\mathrm{Cl}_{2}+\mathrm{H}_{2} \mathrm{O} \rightarrow 2 \mathrm{HCl}+\mathrm{SO}_{3} \\
& \mathrm{SO}_{2}+\mathrm{Cl}+\mathrm{H}_{2} \mathrm{O} \rightarrow \mathrm{HCl}+\mathrm{HOSO}_{2}
\end{aligned}
$$

Heterogeneous mercury oxidation is of particular interest in mercury transformations that occur in the flue gas duct. Gas phase interactions alone are not enough to account for the observed extents of mercury oxidation. ${ }^{[50]}$ There are still many unknowns for how mercury and other flue gas constituents react on different particle surfaces. There are two possible mechanisms that occur between two species adsorbed to a surface. The first is a Langmuir-Hinshelwood mechanism ${ }^{[51]}$.

$$
\begin{aligned}
& \mathrm{A}(\mathrm{g}) \rightarrow \mathrm{A}(\text { ads }) \\
& \mathrm{B}(\mathrm{g}) \rightarrow \mathrm{B}(\text { ads }) \\
& \mathrm{A}(\text { ads })+\mathrm{B}(\text { ads }) \rightarrow \mathrm{AB}(\text { ads })
\end{aligned}
$$




$$
\mathrm{AB}(\mathrm{ads}) \rightarrow \mathrm{AB}(\mathrm{g})
$$

For mercury oxidation, $\mathrm{A}$ is $\mathrm{Hg}^{0}$ and $\mathrm{B}$ is either $\mathrm{HCl}$ or $\mathrm{Cl}_{2}$. The second considers the possibility that one of the components does not adsorb (or is weakly adsorbed) to the surface and is an Eley-Rideal mechanism ${ }^{[51]}$ :

$$
\begin{aligned}
& \mathrm{A}(\mathrm{g}) \rightarrow \mathrm{A}(\text { ads }) \\
& \mathrm{A}(\mathrm{ads})+\mathrm{B}(\mathrm{g}) \rightarrow \mathrm{AB}(\mathrm{g})
\end{aligned}
$$

Depending on the surface, $\mathrm{A}$ in equation 29 could be either $\mathrm{Hg}^{0}$ or a chlorine containing component such as $\mathrm{HCl}$ or $\mathrm{Cl}_{2}$.

\section{Coating Technology}

Catalyst coating on a surface is a function of several factors including: solution viscosity, coating the fabric surface or fabric penetration, surface properties, desired coating uniformity, production speed, and drying conditions. ${ }^{[52]}$ For the case of coating bag house fabric, the catalyst must penetrate into the fabric to provide for more contact surface between the catalyst and elemental mercury, but must also leave sufficient porosity to keep the bag open to flue gas flow. The catalyst must also resist poisoning from constituents in the flue gas and/or fly ash. The surface and open areas of the fabric will factor into the catalyst loading of the fabric by either trapping the catalyst particles or allowing the catalyst to be removed by normal flue gas flow or the cleaning back pulse.

The insolubility of the catalyst substrate (e.g. alumina) in water is another factor in selecting a coating method. A commercially feasible technology will not require the use of expensive, environmentally deleterious, or hazardous solvents to apply the catalyst 
and substrate to the fabric. Keeping the catalyst slurry in suspension is necessary to facilitate a uniform penetration and to prevent clogging of the final process equipment.

The drying capacity of the coating limits the production speed of the coater while fabric composition will set an upper temperature limit that can be used in the dryer to prevent fabric damage. The calcination temperature of the catalyst will be much higher than the temperature the baghouse fabric can withstand. Therefore the catalyst must be calcined before it is applied to the fabric. The process necessary to drive off the catalyst solvent (water) and open the active sites on the catalyst may also limit fabric coating production speed; increasing the minimum required time for drying. Thus the coating process is expected to be dryer speed limited.

Several coating methods are standard practice in the industry depending on the factors listed above. These methods include: dip coating, rod coating, blade or air knife coating, spray coating, curtain or slide coating, gravure coating, reverse roll coating, and extrusion coating. The objective of catalyst loading will be to penetrate into the fiber web while minimizing the pressure loss across the filter thus maintaining fly ash removal as the primary function of the filter.

Surface coating methods are used to provide a smooth even coating on a substrate. Surface coating methods are eliminated from the options considered in this study because they will inhibit stack gas flow by closing up the web surface to air flow. Coating methods that provide an even smooth surface include: rod coating, knife coating, blade coating, gravure coating, and air knife coating. These methods are all eliminated from consideration in order to maintain flue gas flow, keep fabric pressure losses to a minimum, and reduce boiler fan electrical costs. 
Curtain and slide coaters are used for application of several layers on to the web surface usually with layers being of different composition for various purposes. Curtain and slide coatings are eliminated from consideration since only a single catalyst application is considered in this work. Extrusion coating is used with high fluid viscosities like hot melts. This technique is eliminated since the catalyst slurry does not match the hot melt fluid properties in terms of viscosity behavior, temperature, and coating thickness. The reverse roll coater is used for application of thick films to the web and again is not applicable for web penetration of the flue gas through the fabric.

The remaining two commonly utilized options for penetrating the catalyst solids into the fabric are dip coating and spray coating. The oldest method of coating is dip coating and can be used when the web is strong enough to be pulled through the coating solution without breaking. Figure 1 shows a dip coating schematic. For the catalyst application, the challenge will not be the fabric strength, but will be keeping the catalyst in suspension and the ability of the fabric to absorb the catalyst slurry. As the catalyst particles are drawn away into the fabric, additional catalyst will have to be added to the dip tank in order to maintain catalyst concentration and a uniform application to the fabric.

This coating method was modeled in the lab by dip coating fabric samples in a catalyst/water slurry followed by rolling the fabric sample with a rolling pin to facilitate penetration throughout the fabric depth. 


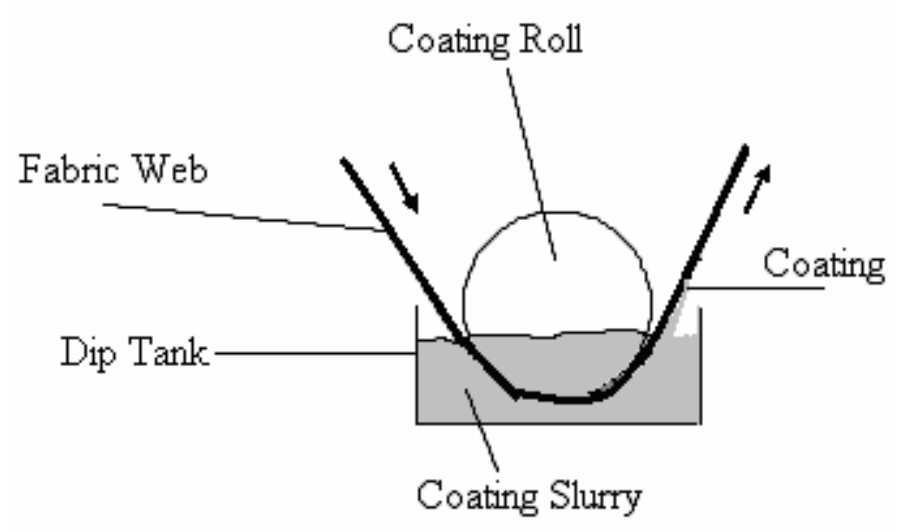

Figure 1: Schematic of the dip coating process

Spray coating, the second option, provides more opportunity to keep an even slurry concentration in the spray and more penetration options by varying the spray pressure. The catalyst loading in the fabric may be more uniform using this method than dip coating because the suspension problem is eliminated. Figure 2 presents a spray coating schematic. The spray method could be limited by plugging tendencies of the spray nozzle and the ability of the fabric to absorb to saturation to provide sufficient catalyst loading. The spray coat was modeled by 1) applying the spray coat with an art sprayer using commercially canned air at approximately $205 \mathrm{kPa}$ (15 psig), 2) a surface scrape using a lab scoop to provide an even distribution of the slurry puddle on the fabric surface, 3) a second spray coat, and 4) a second scrape.

In addition to the wet coating processes listed above, a dry coat method was used. When starting with new bags, a bag house is pretreated with a conditioning agent. The conditioning agent is a powdered material that acts as a filter cake on the fabric to assist in initial fly ash collection. If the dry powder stays on the bag surface, the application of the catalyst can be achieved simply by normal bag pretreatment procedures. The process 
was simulated in the laboratory using just the catalyst support to see what levels of doping could be achieved with a dry application and how well it would stay on the bag surface. The catalyst support is the base alumina or titanium dioxide that the metal catalyst will be deposited on.

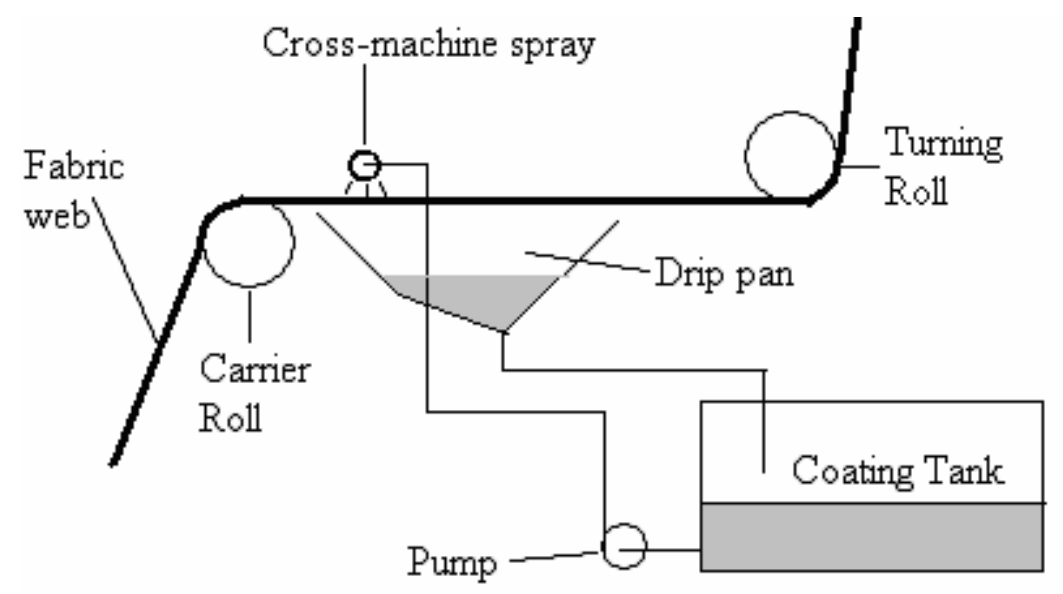

Figure 2: Schematic of the spray coating process

\section{Catalysts and Fabrics}

Three noble metal catalysts were chosen for the oxidation of mercury. $\mathrm{TiO}_{2}$ and $\mathrm{Pd} / \mathrm{Al}_{2} \mathrm{O}_{3}$ were identified as promising catalysts during the Phase I work. Gold has also been shown to oxidize mercury ${ }^{[3,4]}$ and was studied in this work as $\mathrm{Au} / \mathrm{TiO}_{2}$. The two fabrics tested in this project were both provided by GE Energy BHA Group, Inc. RY805 is a yellow felt and is composed of a proprietary blend of Procon and Torcon. PC012 is a white woven fabric and is composed of $100 \%$ Procon. According to the vendor, both of these fabrics are considered to be common in coal-fired utilities. 


\section{EXPERIMENTAL}

\section{Project Objective and Scope}

The objective of this project was to explore the feasibility of oxidizing elemental mercury in coal combustion flue gas using catalytic material impregnated onto barrier filters. Barrier filters provide excellent contact between the mercury and catalyst and reduce the gas-film transport limitations observed for other contacting configurations. The excellent gas/catalyst contact that can be provided by barrier filters is expected to overcome the current gas-diffusion limitations of competing technologies, i.e. packed beds and entrained injection. This should substantially reduce the amount of catalyst required to accomplish removal of elemental mercury. Further, for existing and planned facilities utilizing barrier filters, this oxidation can be accomplished with virtually no additional capital expense.

Accomplishment of Phase II involved achieving three objectives:

1) Determine the best method of catalyst coating and evaluate the effectiveness of coating under simulated back pulse cleaning cycles.

2) Perform parametric bench-scale tests to determine catalyst performance using simulated flue gas.

3) Perform small pilot-scale testing using a $19 \mathrm{~kW}$ combustor firing a wide range of coals to determine the performance of the most promising catalyst. 


\section{Experimental Apparatus and Procedure}

\section{Objective 1- Catalyst Coating}

The goal of this research was to determine the catalytic coating method for the baghouse fabric. The noble metals, $\mathrm{Au}$ and $\mathrm{Pd}$, considered as catalysts are expensive compared to the alumina or titanium dioxide catalyst supports. Since the weight of the noble metal was 0.5 to $1 \mathrm{wt} \%$ on the support, the preliminary coating methods were tested only using the supporting alumina or titanium dioxide. The catalyst support was tested in a bench scale reactor for coating stability, assessed by the fraction of catalyst support mass that remained on the fabric after experiencing a substantial number back pulse shocks.

$3.2 \mathrm{~m}^{3} / 10^{5} \mathrm{~s}(4 \mathrm{~L} / \mathrm{min})$ of air was fed into the bench reactor to simulate the flue gas flow. This flow rate yielded an air-to-cloth ratio of $0.03 \mathrm{~m} / \mathrm{s}(6 \mathrm{ft} / \mathrm{min})$ compared to a power industry average of $0.02 \mathrm{~m} / \mathrm{s}(4 \mathrm{ft} / \mathrm{min})$. A higher air-to-cloth ratio was used to insure that the conditions experienced in the test system were more rigorous than those typically encountered commercially. A counter-current pulse-jet flow using $780 \mathrm{kPa}$ (113 psig) air was used to simulate the back pulse cleaning cycle of a commercial baghouse. These pulses of air were electronically controlled using a solenoid valve and lasted for a duration of 30 to 100 milliseconds. A schematic of the bench reactor system is shown in Figure 3. The purpose of this work was to determine the fraction of catalyst that remained on the fabric when exposed to the continuous flow of flue gas through the fabric and to numerous back pulse shocks experience in typical baghouse cleaning cycles. The weight of the catalyst on the fabric was checked in intervals after a set number of cleaning pulses and a loss was calculated. 


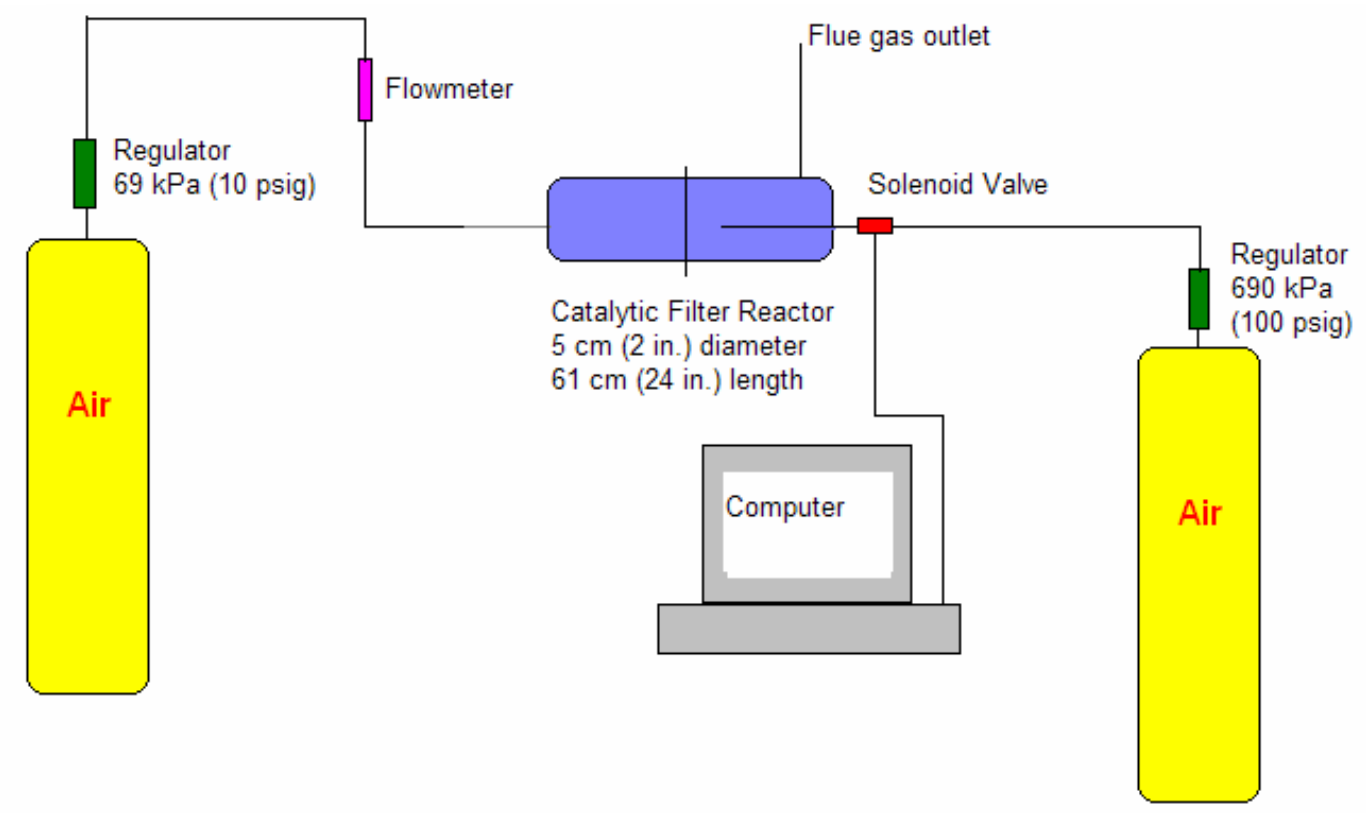

Figure 3: Schematic of the lab-scale test apparatus used to assess the adherence of catalyst support material applied to the clean side of typical baghouse fabrics by four separate application methods

Four methods of fabric coating were considered. The dip coat method consisted of soaking the filter sample in a slurry of alumina or titanium dioxide, removing it from the slurry, and then squeezing it with a rolling pin. Since the catalyst substrates chosen were not water soluble, a slurry was formed and kept agitated in order for the solids to remain in suspension for filter application. Slurries of $17.5 \mathrm{wt} \%$ were used. The filter sample was placed on the bottom of a $1000 \mathrm{~mL}$ beaker that allowed the filter sample to lie flat. The fabric was oriented with the "clean" side of the up so that this side was exposed to the slurry suspension which was added to the beaker over the fabric. By applying the catalyst to the "clean side", the back pulse shocks tend to force the catalyst into the fabric instead of out of the fabric (if applied from the "dirty" side). A magnetic stirrer was used to keep the solids in suspension. The fabric was removed by holding it in a horizontal position while it was placed in a plastic tray. 
A weighted rolling pin was used to provide a consistent force to press the slurry into a more even distribution on the fabric surface and possibly through its pores. This simulates what a fabric would experience on a production coater since it would go through a nip between two rolls to squeeze excess water out of the sample. The samples were dried over night in a $375 \mathrm{~K}\left(216^{\circ} \mathrm{F}\right)$ oven.

The second method was a double dip coat method. The single dip coating method was modified to obtain a double dip coating method. Fabric samples were soaked in 17.5 $\mathrm{wt} \%$ water slurry of substrate for 120 seconds. After the dip, the sample was rolled six times under a custom rolling pin filled with lead weight. The dip procedure was repeated a second time and samples were dried overnight in a $375 \mathrm{~K}\left(216^{\circ} \mathrm{F}\right)$ oven.

The third method was a spray coating method using an artist's hobby sprayer with canned propellant to spray the "clean" side surface of the filter fabric. The pressure in the propellant can varied with the contents of the can but started out at approximately 203 $\mathrm{kPa}(2 \mathrm{~atm})$. The slurry was agitated with a magnetic stirrer during spraying to keep the catalyst support in suspension. The slurry tended to puddle on the surface of the filter so a laboratory scoop was used as a blade to gently scrape the filter surface and evenly distribute the slurry. A second coat was immediately applied until the sample was saturated as determined by the wetness of a paper towel located under the sample. The sample was then dried over night in a $375 \mathrm{~K}\left(216^{\circ} \mathrm{F}\right)$ oven.

The fourth method was a dry method of application using a Buchner funnel under vacuum generated by a vacuum pump. The catalyst support was sprinkled over the "clean" side of the filter fabric with a saltshaker and induced into the fabric under a 17 
$\mathrm{kPA}(125 \mathrm{~mm} \mathrm{Hg})$ vacuum. Excess powder was shaken off and vacuum was applied for a second time. The vacuum was applied for one minute during each vacuum cycle.

Objective 2- Bench-Scale Testing

A Horiba DM-6B Dry-Mercury Speciation Continuous Emission Monitor (DM6B) was used to measure elemental and total mercury. The DM-6B comes equipped with a MS-D1 Dry-Mercury Speciation Conditioning Unit (MS-D1), a MG-1 Mercury Standard Gas Generator (MG-1), and a $\mathrm{SO}_{2}$ Scrubbing Unit. Figure 4 shows a photograph of the complete Horiba unit. Figures 5 and 6 show schematics of the MS-D1 and $\mathrm{DM}-6 \mathrm{~B}$, respectively.

The DM-6B analyzer uses cold-vapor atomic absorption spectrometry (CVAAS) for measurement. It is equipped with two separate detecting lamps: one each for measuring elemental and total mercury. In order to maintain accurate measurements, the DM-6B is calibrated daily using a mercury standard generated by the MG-1 unit. A zero adjustment is also performed hourly during measurement.

The MS-D1 unit first conditions the sample gas by passing it through a dust filter and then separating it into two samples: elemental and total mercury. In the elemental mercury side, the sample is separated into gas and liquid fractions in a gas-liquid separation tube where any interfering substances are removed in the liquid phase. The gas sample is then dehumidified and sent to an absorption column which removes any oxidized mercury $\left(\mathrm{Hg}^{2+}\right)$ from the sample. The gas then passes through a potassium hydroxide (KOH) scrubbing solution in the scrubbing unit (to capture $\mathrm{SO}_{2}$ ) before being sent to the DM-6B for measurement. 


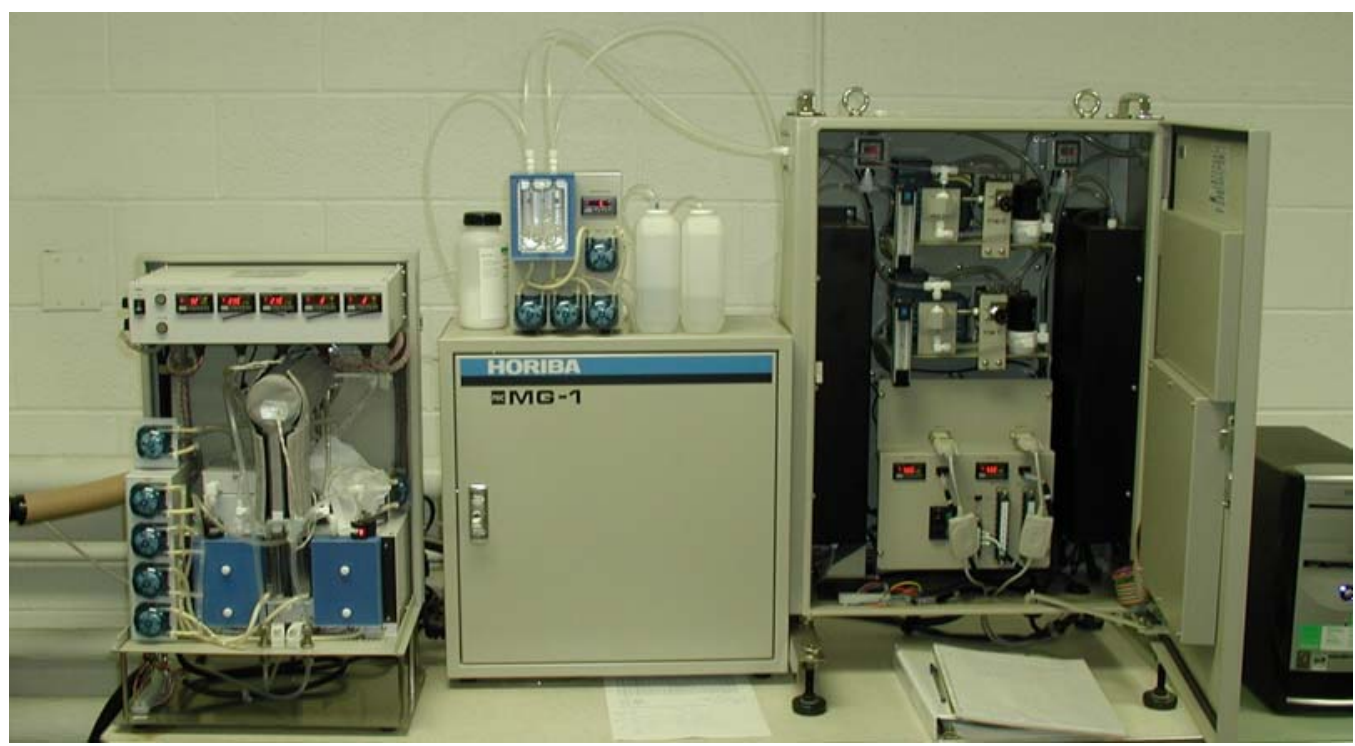

Figure 4: Photograph of the complete Horiba unit. The DM-6B analyzer is on the right, the MS$\mathrm{D} 1$ conditioning unit is on the left, the MG-1 mercury generator is in the center, and the $\mathrm{SO}_{2}$ scrubber is located on top of the MG-1

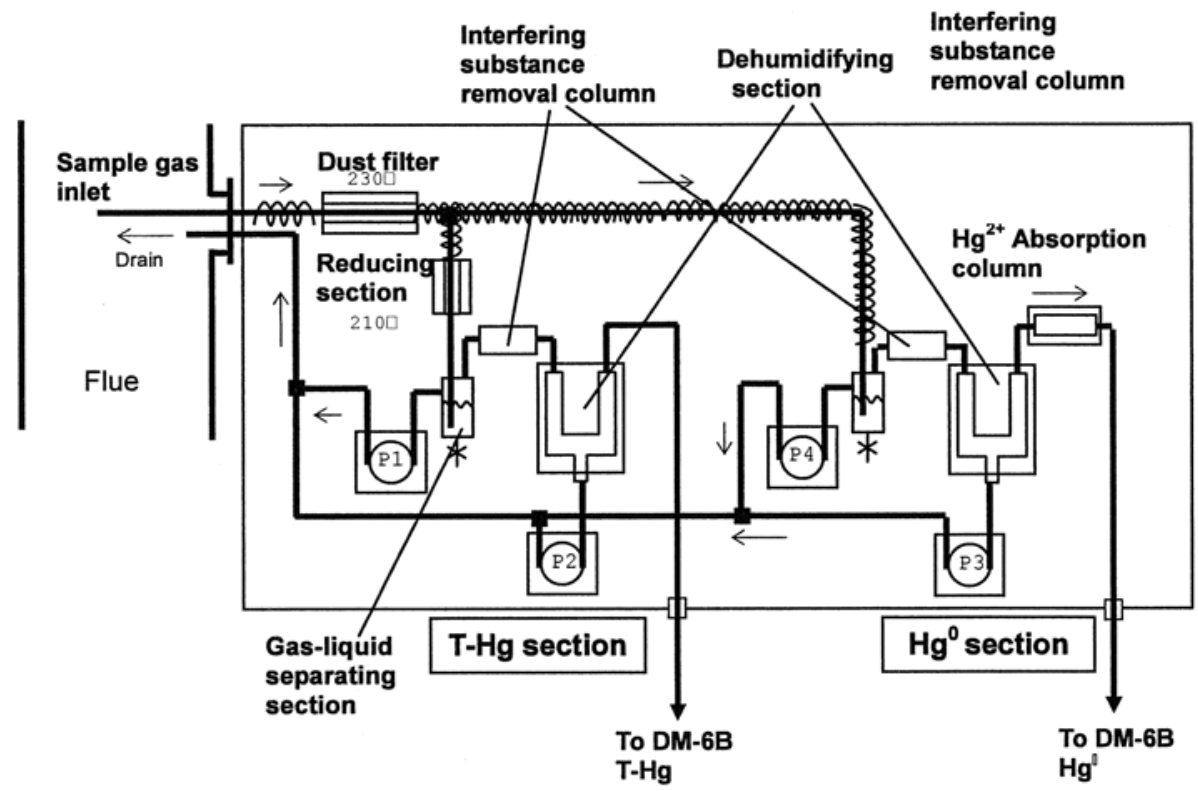

Figure 5: Schematic of the MS-D1 dry catalyst conditioning unit for mercury analysis pretreatment. P1-P4 are pumps used to cycle moisture in and out of the unit. ${ }^{[53]}$ 


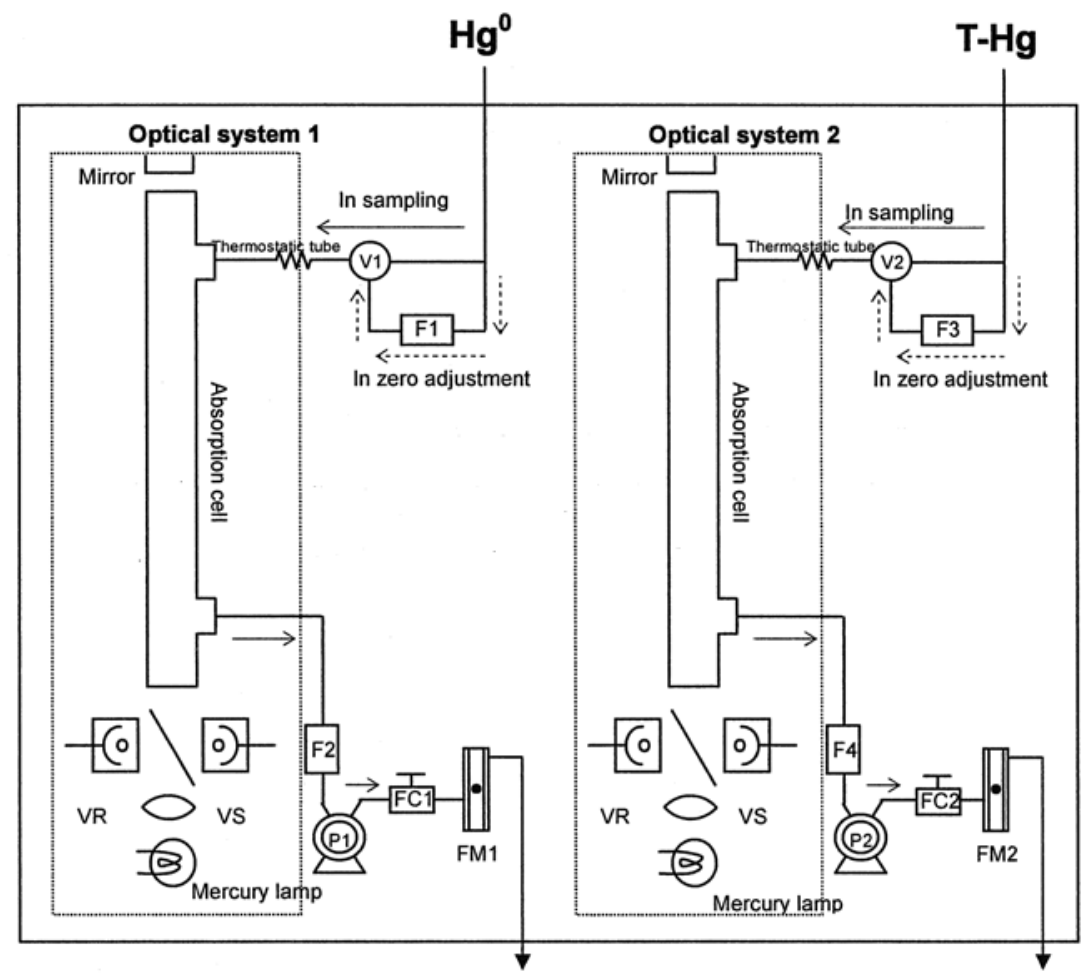

Figure 6: Schematic of the Horiba DM-6B mercury analyzer. P1 and P2 are vacuum pumps, V1 and V2 are three-way solenoid valves, F1 and F3 are zero gas filters, F2 and F4 are activated carbon filters, FC1 and FC2 are flow controllers, and FM1 and FM2 are rotameters. VR is the reference light signal and VS is the absorbed light signal. ${ }^{[53]}$

On the total mercury side, the sample is first sent to a catalytic reduction column which reduces any $\mathrm{Hg}^{2+}$ to $\mathrm{Hg}^{0}$. The sample is then separated into gas and liquid fractions in a gas-liquid separation tube where any interfering substances are removed in the liquid phase. The gas sample is dehumidified and sent to the scrubbing unit where it passes through a $\mathrm{KOH}$ scrubbing solution (to capture $\mathrm{SO}_{2}$ ) before being sent to the DM$6 \mathrm{~B}$ for measurement. The DM-6B analyzer continuously transmits mercury concentrations to a desktop PC via RS-232 communication cable.

It was very difficult to obtain consistent results with the dry conditioning unit packaged with the analyzer, so a wet conditioning unit was assembled and utilized instead. We found the wet conditioning unit to be much more reliable since the 
conditioning catalyst is continuously regenerated. In addition, the wet conditioning unit appears to be the method used almost exclusively for research purposes. Figure 7 shows a schematic, and figure 8 a photograph, of the wet solution conditioning system. This system uses two impingers containing chemical solutions in order to condition the sample gas.
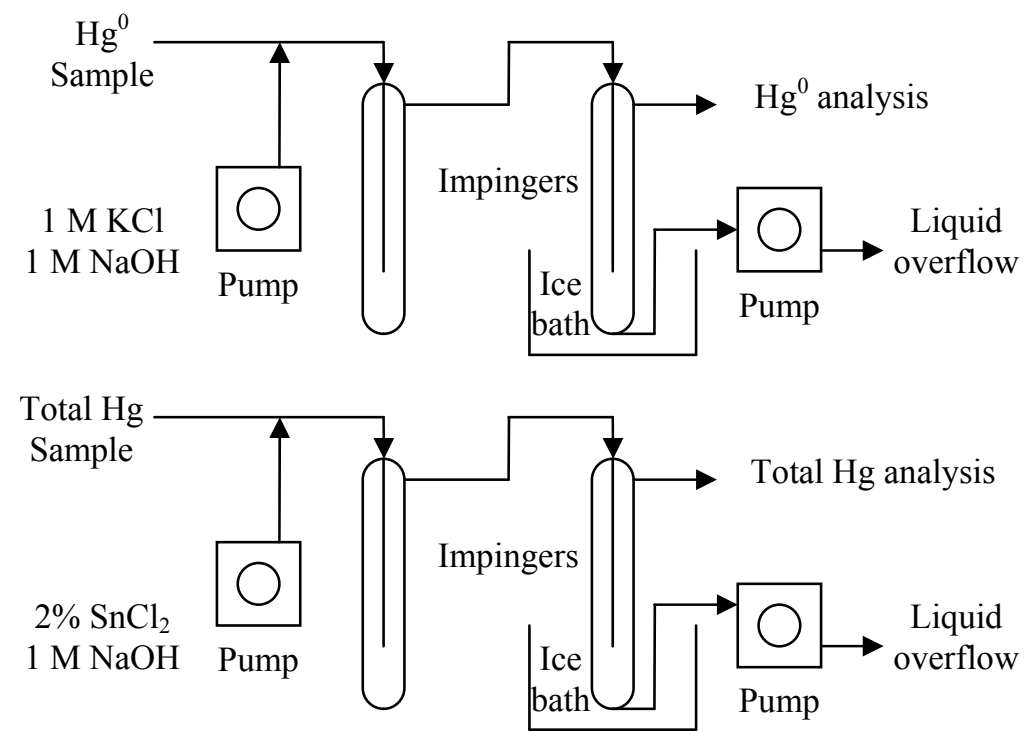

Figure 7: Schematic of wet solution conditioning system for sample gas pretreatment

The elemental mercury impinger contains a solution of $1 \mathrm{M}$ potassium chloride $(\mathrm{KCl})$ and $1 \mathrm{M}$ sodium hydroxide $(\mathrm{NaOH})$. The $\mathrm{KCl}$ captures oxidized mercury and the $\mathrm{NaOH}$ captures $\mathrm{SO}_{2}$. The total mercury impinger contains a solution of $2 \%$ stannous chloride $\left(\mathrm{SnCl}_{2}\right)$ and $1 \mathrm{M} \mathrm{NaOH}$. The $\mathrm{SnCl}_{2}$ reduces the oxidized mercury in order to obtain a total mercury measurement. The $\mathrm{NaOH}$ captures $\mathrm{SO}_{2}$.

Fresh solutions are continuously fed to the impingers at a rate of about 1.5 $\mathrm{mL} / \mathrm{min}$ by using peristaltic pumps. This is done to avoid any residual buildup in the 
impinger system. Both of these impingers are followed by an empty impinger held in an ice bath to collect liquid overflow before being sent to the DM-6B analyzer.

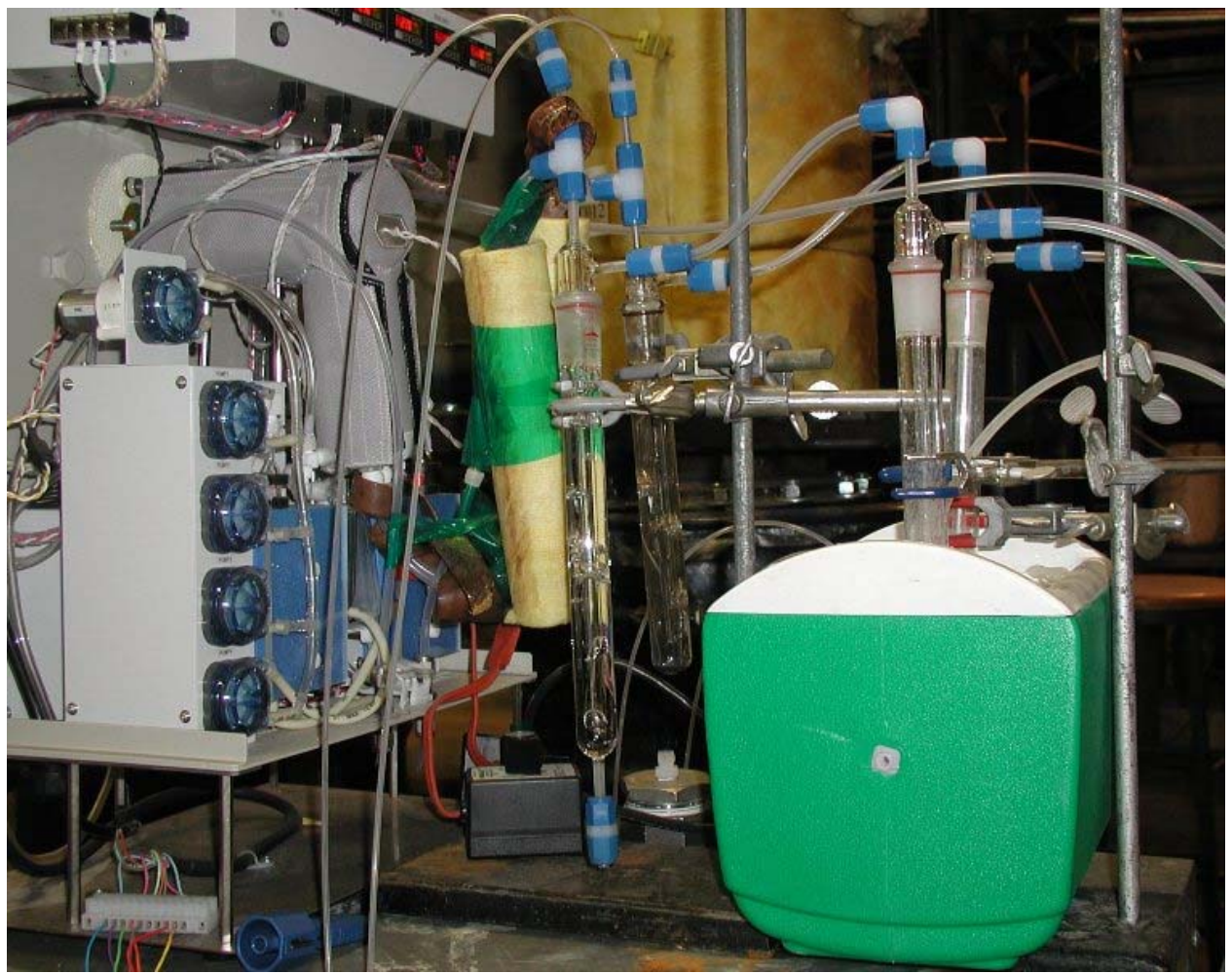

Figure 8: Photograph of wet solution conditioning system for sample gas pretreatment

A PS Analytical 10.534 Mercury Calibration System was used as a defined mercury source in these experiments. This unit works on the principle of diluting a saturated $\mathrm{Hg}^{0}$ vapor at known temperature. A low flowrate $(0-20 \mathrm{~mL} / \mathrm{min})$ is delivered over a $\mathrm{Hg}^{0}$ reservoir using a mass flow controller. A dilution gas $(0-20 \mathrm{~L} / \mathrm{min})$ is supplied using a mass flow controller and dilutes the $\mathrm{Hg}^{0}$ vapor to the concentration of interest. Cylinder air or nitrogen is used with the unit. Figure 9 shows a photograph of the PS Analytical 10.534 Mercury Calibration System while a schematic is shown in Figure 10. 


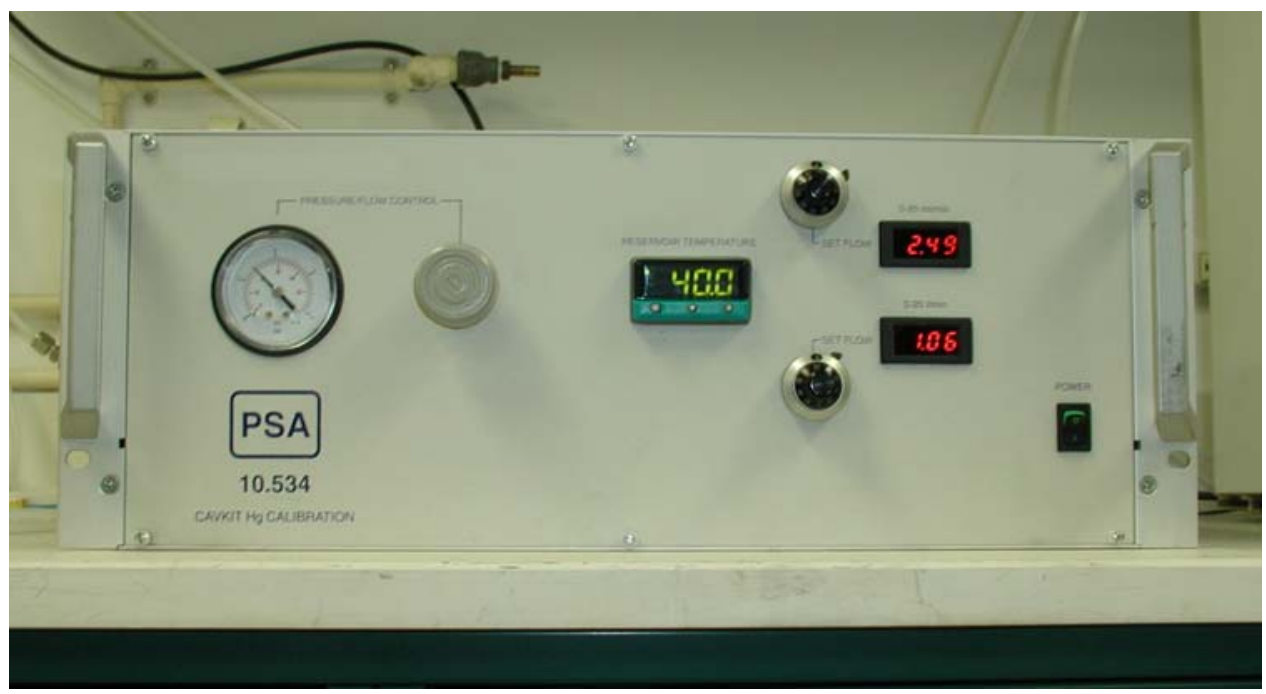

Figure 9: Photograph of PS Analytical 10.534 Mercury Calibration System (PSA Hg generator)

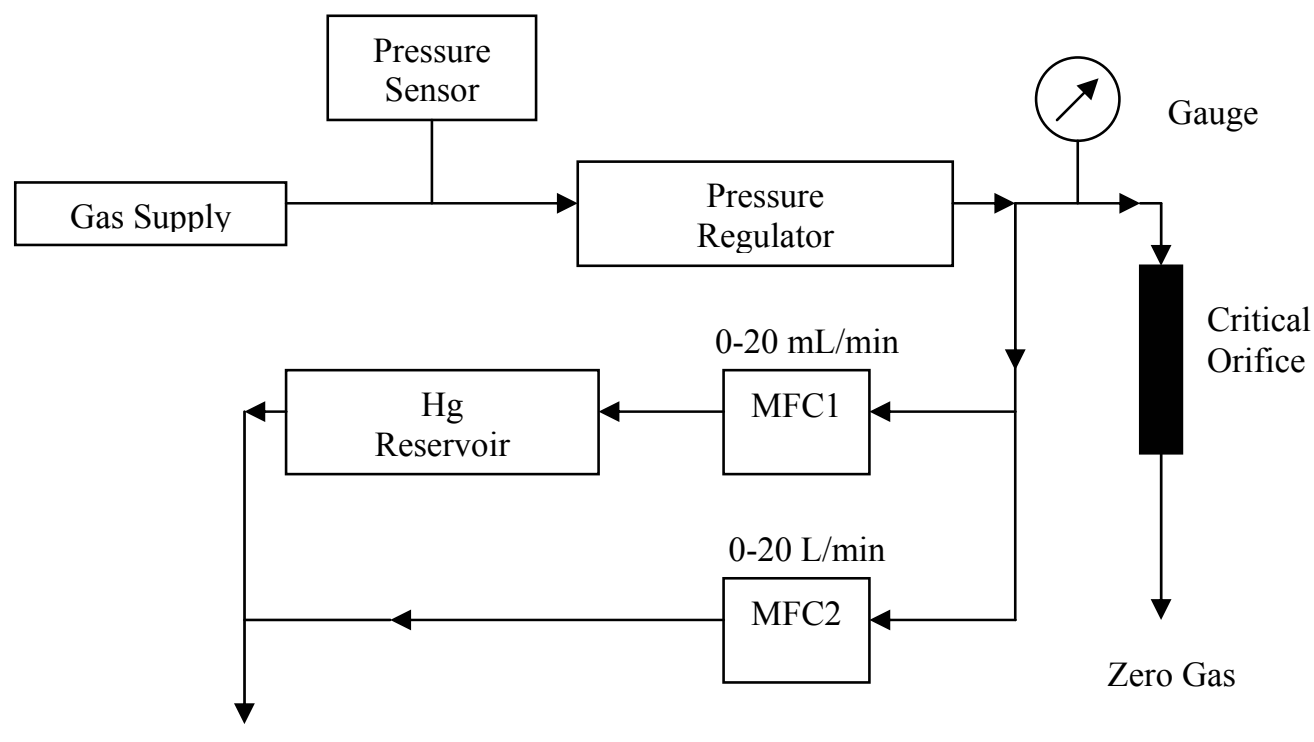

Calibration Gas

Figure 10: Schematic of PS Analytical 10.534 Mercury Calibration System (PSA Hg generator). MFC is mass flow controller. ${ }^{[54]}$ 
This project investigated the mercury oxidation performance of three catalysts. Two of the catalysts, titanium dioxide $\left(\mathrm{TiO}_{2}\right)$ and palladium on alumina $\left(\mathrm{Pd} / \mathrm{Al}_{2} \mathrm{O}_{3}\right)$, were identified in Phase I as promising catalysts. The third, gold on titanium dioxide $\left(\mathrm{Au} / \mathrm{TiO}_{2}\right)$, was shown to be a possible catalyst for mercury oxidation in other work ${ }^{[3,4]}$

The $\mathrm{TiO}_{2}$ used was Aeroxide $\mathrm{TiO}_{2} \mathrm{P} 25$ (Degussa). The $\mathrm{Pd} / \mathrm{Al}_{2} \mathrm{O}_{3}$ (SigmaAldrich) contains $1 \%$ wt $\mathrm{Pd}$ on $\mathrm{Al}_{2} \mathrm{O}_{3}$ substrate. The $\mathrm{Au} / \mathrm{TiO}_{2}$ was produced in the lab using a method developed by Mallick et al. ${ }^{[55]}$ This method produces nano-sized Au particles on a $\mathrm{TiO}_{2}$ substrate $(1.0 \% \mathrm{wt} \mathrm{Au})$ by using sodium borohydride $\left(\mathrm{NaBH}_{4}\right)$, hydrogen tetrachloroaurate(III) trihydrate $\left(\mathrm{HAuCl}_{4} \cdot 3 \mathrm{H}_{2} \mathrm{O}\right)$, and $\mathrm{TiO}_{2}$ as precursors. $\mathrm{NaBH}_{4}$ and $\mathrm{HAuCl}_{4} \cdot 3 \mathrm{H}_{2} \mathrm{O}$ were purchased from Sigma-Aldrich.

The bench-scale testing primarily used filter type RY805 with some spot testing performed using filter type PC012. The small pilot-scale testing used filter type PC012 because this is the type that the manufacturer recommended and supplied to this project. To coat the fabric, a slurry solution is first prepared with deionized water to yield a concentration of $15 \mathrm{wt} \%$ of catalyst/catalyst support. An art-style paint sprayer and cylinder air at a pressure of $275 \mathrm{kPa}$ (40 psig) was used to spray the catalyst solution onto the fabric filters until the fabric was thoroughly coated with solution. The filters were then oven dried at $380 \mathrm{~K}\left(221^{\circ} \mathrm{F}\right)$ for 12 hours.

A bench-scale test system was built to determine the effects of prominent flue gas constituents on mercury oxidation as shown in Figure 11. This system was used to test the performance of each type of catalytically impregnated fabric filter. A designed set of experiments was performed to test the significance of each of the flue gas components on mercury oxidation capabilities. 
A baseline model simulated combustion flue gas was generated using $\mathrm{N}_{2}, \mathrm{O}_{2}$, $\mathrm{H}_{2} \mathrm{O}$, and $\mathrm{Hg}^{0}$. Additional flue gas components tested during the parametric study include $\mathrm{SO}_{2}, \mathrm{NO}, \mathrm{HCl}$, and $\mathrm{Cl}_{2}$. The $\mathrm{Hg}^{0}$ was generated using the PSA Hg Generator with the carrier gas consisting of cylinder quality air. The moisture was generated by pumping a low flow of water into a heated stream of nitrogen and air. Table 1 gives the simulated flue gas concentration and experimental conditions of the reactor.

The simulated flue gas was routed at a flow rate of $4 \mathrm{~L} / \mathrm{min}\left(0.14 \mathrm{ft}^{3} / \mathrm{min}\right)$ to the heated reactor, which was maintained at $425 \mathrm{~K}\left(300{ }^{\circ} \mathrm{F}\right)$ using a rope heater (Omega FGR), PFA-lined thermocouple (Omega), and controller (Watlow 935A). This flowrate yielded a filtering velocity of $0.03 \mathrm{~m} / \mathrm{s}(6.1 \mathrm{ft} / \mathrm{min})$, which is near the high range of filtering velocities in the utility industry.

The reactor was constructed of a $45.7 \mathrm{~cm}$ (18 in) length by $6 \mathrm{~cm}$ ( 2 in nominal) diameter NPS steel pipe with a pair of $6 \mathrm{~cm}$ pipe flanges installed approximately $23 \mathrm{~cm}$ from each end of the pipe. These flanges were used to hold the test fabric filter samples in the reactor. The reactor was internally coated with Teflon to minimize mercury adsorption onto the walls of the reactor. PFA Teflon tubing and fittings (Swagelok) were used where mercury was present in the simulated flue gas in order to prevent any mercury surface adsorption. Sample tubing was heated to $425 \mathrm{~K}\left(300^{\circ} \mathrm{F}\right)$ using heating tape (Omega HWTC).

The Horiba CEM measured the mercury concentration of the simulated flue gas at the outlet of the reactor. The simulated flue gas was then dehumidified using an impinger held in an ice bath and then filtered by activated carbon (Pall) before being vented to the atmosphere. 


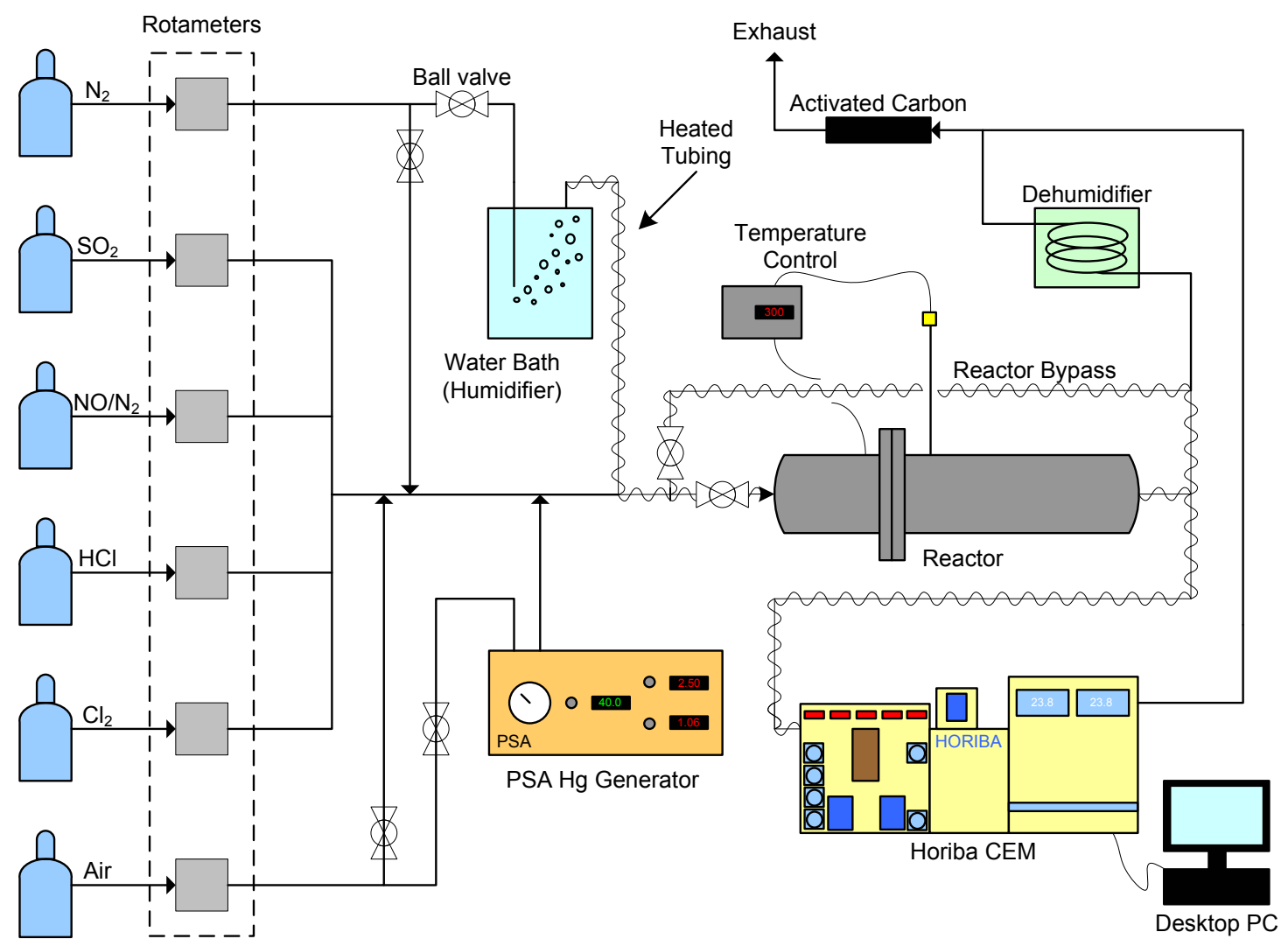

Figure 11: Bench-scale baghouse filter test system for parametric mercury tests

Table 1: Simulated flue gas composition and experimental conditions

\begin{tabular}{llll}
\hline $\mathrm{Gas}$ & Concentration & Conditions & \\
\hline \hline $\mathrm{Cl}_{2}$ & $10 \mathrm{ppm}$ & Reactor temperature & $425 \mathrm{~K}\left(300^{\circ} \mathrm{F}\right)$ \\
$\mathrm{HCl}$ & $50 \mathrm{ppm}$ & Heated tubing & $425 \mathrm{~K}\left(300^{\circ} \mathrm{F}\right)$ \\
$\mathrm{SO}_{2}$ & $1000 \mathrm{ppm}$ & Total gas flow rate & $4 \mathrm{~L} / \mathrm{min}(0.14 \mathrm{ft} / \mathrm{min})$ \\
$\mathrm{NO}$ & $100 \mathrm{ppm}$ & Filtering velocity & $0.03 \mathrm{~m} / \mathrm{s}(6.1 \mathrm{ft} / \mathrm{min})$ \\
$\mathrm{O}_{2}$ & $4 \%$ & Catalyst mass & $0.2 \mathrm{~g}$ \\
$\mathrm{H}_{2} \mathrm{O}$ & $10 \%$ & & \\
$\mathrm{~N}_{2}$ & Balance & & \\
$\mathrm{Hg}^{0}$ & $20-30 \mu \mathrm{g} / \mathrm{m}^{3}$ & & \\
\hline
\end{tabular}

A screening design was used to determine the extent of significance for each of the flue gas constituents being tested. Table 2 shows the experimental design that was 
used for each combination of catalyst and bag type. An " $x$ " denotes the respective gas was added in the experiment. Run order was randomized to reduce systematic error. Results from the bench-scale testing were used to determine which catalyst is best suited for additional testing under full combustion conditions.

Table 2: Design of experiments for bench-scale parametric mercury tests

\begin{tabular}{|c|c|c|c|c|}
\hline Condition & $\mathrm{Cl}_{2}$ & $\mathrm{HCl}$ & $\mathrm{SO}_{2}$ & $\mathrm{NO}$ \\
\hline 1 & $\mathrm{x}$ & & & \\
\hline 2 & & $\mathrm{x}$ & & \\
\hline 3 & & & $\mathrm{x}$ & \\
\hline 4 & & & & $\mathrm{x}$ \\
\hline 5 & $\mathrm{x}$ & $\mathrm{x}$ & & \\
\hline 6 & $\mathrm{x}$ & & $\mathrm{x}$ & \\
\hline 7 & $\mathrm{x}$ & & & $\mathrm{x}$ \\
\hline 8 & & $\mathrm{x}$ & $\mathrm{x}$ & \\
\hline 9 & & $\mathrm{x}$ & & $\mathrm{x}$ \\
\hline 10 & & & $\mathrm{x}$ & $\mathrm{x}$ \\
\hline 11 & $\mathrm{x}$ & $\mathrm{x}$ & $\mathrm{x}$ & $\mathrm{x}$ \\
& & & & \\
\hline
\end{tabular}

\section{Objective 3- Small Pilot-Scale Testing}

The UND Department of Chemical Engineering operates a $19 \mathrm{~kW}$ laminar downflow research combustor. This combustor is equipped with two single-bag pulse-jet baghouses in parallel. The combustor is described in detail elsewhere. ${ }^{[56]}$ Figure 12 shows a detailed schematic of the research combustor. The baghouse filters are $15.2 \mathrm{~cm}$ (6 in) in diameter and $76.2 \mathrm{~cm}$ (30 in) in length. The baghouse filter is cleaned with pulses of house air at a pressure of $690 \mathrm{kPa}(100 \mathrm{psig})$. The pulses are manually controlled at a length of about $0.1 \mathrm{~s}$ and are performed once the pressure drop across the 
filter bag is above $1.3 \mathrm{kPa}\left(5\right.$ in $\left.\mathrm{H}_{2} \mathrm{O}\right)$. Figure 13 shows a photograph of the baghouses. Figure 14 shows a photograph of the baghouse filter cage and baghouse filter used in the baghouse.

Three coals were studied in this work: Illinois \#6 (eastern bituminous), Eagle Butte (Powder River Basin subbituminous), and Falkirk (North Dakota lignite). Table 3 gives the ultimate and proximate analyses as well as the mercury and chlorine content of each coal, as determined at the UND Energy and Environmental Research Center. For each coal, a 4 hour experiment was performed with a bare filter to determine the baseline outlet mercury concentration. Then, for each coal, a 6 hour experiment was performed with a catalyst coated filter. The baghouse outlet mercury concentration was continuously monitored during these experiments. The Eagle Butte coal was chosen for use in a 24-48 hour test to investigate the integrity of the catalyst over time.

In order to verify the mercury measurements given by the DM-6B analyzer, the Ontario Hydro method was performed in selected experiments using a special impinger train. The first impinger contained $1 \mathrm{M} \mathrm{KCl}$ to absorb oxidized mercury. A second impinger contained $4 \% \mathrm{KMnO}_{4}$ and $10 \% \mathrm{H}_{2} \mathrm{SO}_{4}$ to absorb all remaining mercury. These two solutions were analyzed for mercury at the UND Environmental Analytical Research Laboratory (EARL) using cold vapor atomic absorption spectrometry (CVAAS) equipped with a mercury conditioning unit. 


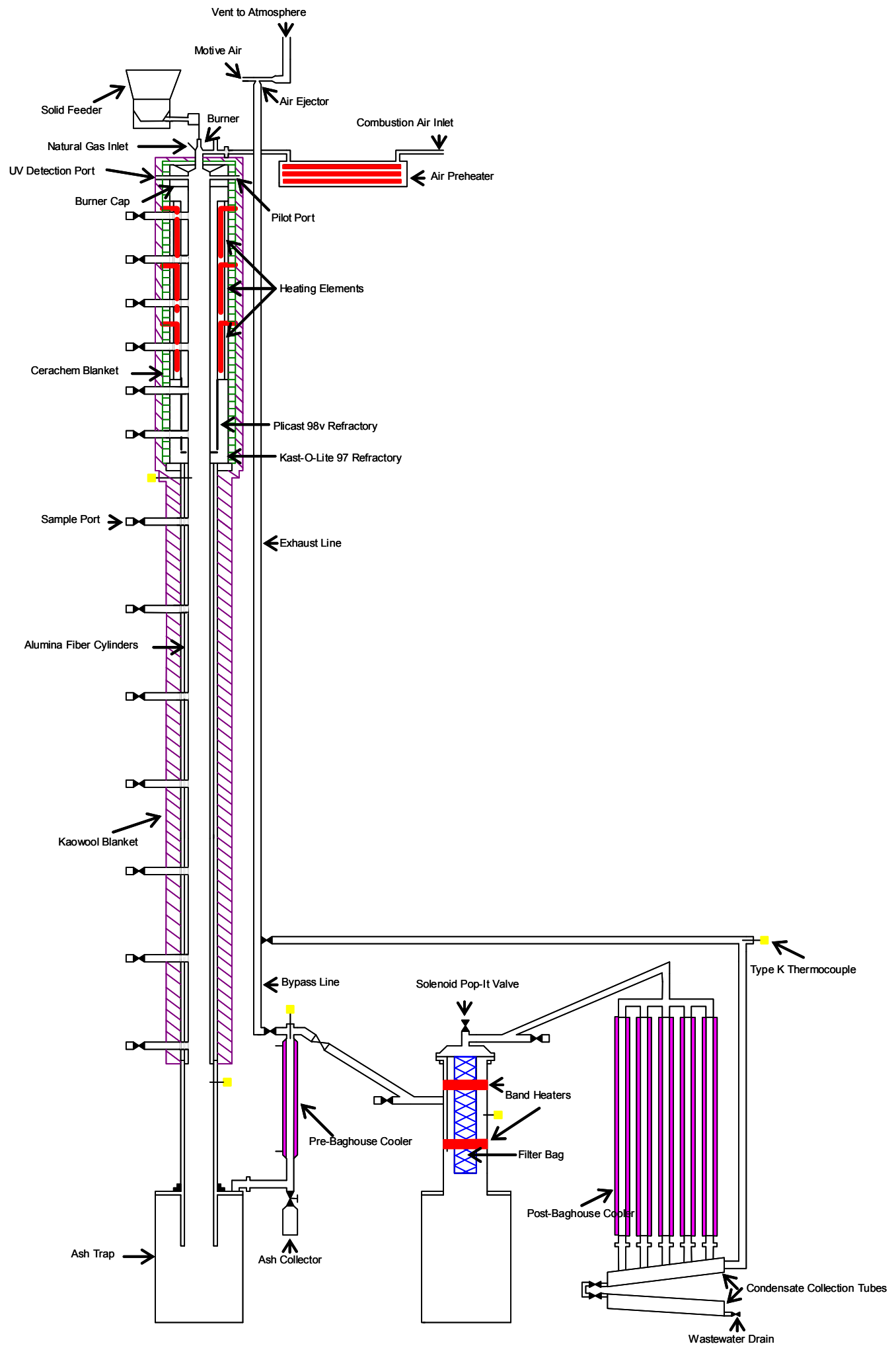

Figure 12: Schematic of UND Chemical Engineering $19 \mathrm{~kW}$ research combustor ${ }^{[56]}$ 


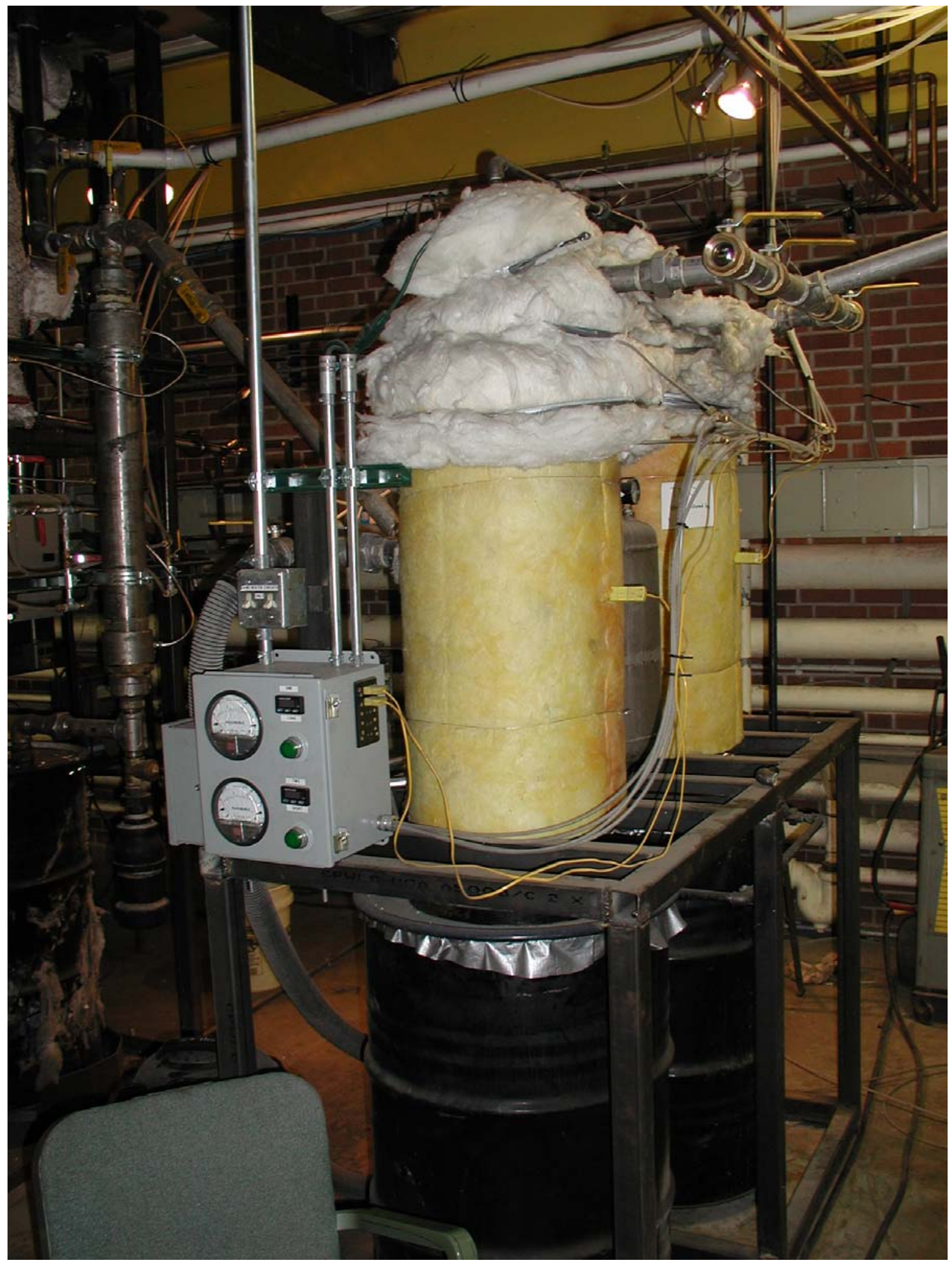

Figure 13: Photograph of two single-bag baghouses removing ash for the UND Chemical Engineering $19 \mathrm{~kW}$ research combustor 


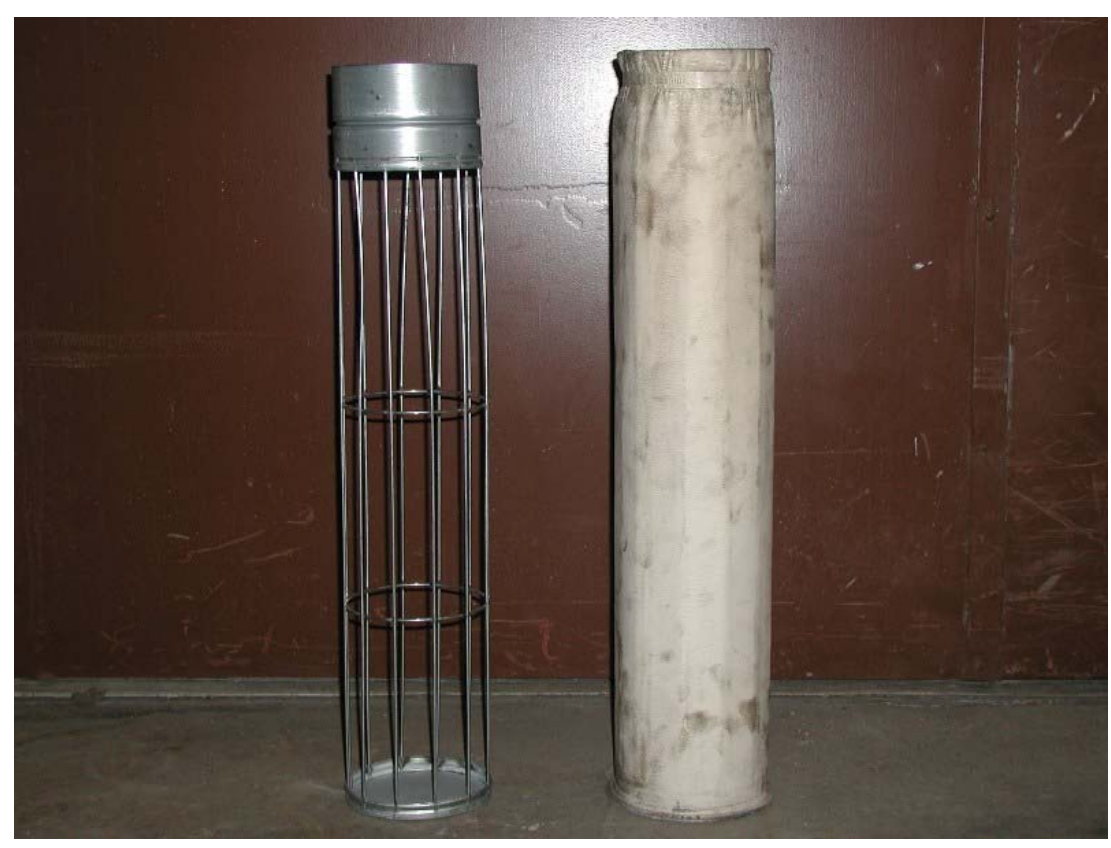

Figure 14: Photograph of baghouse filter cage and baghouse filter used in baghouses for UND Chemical Engineering $19 \mathrm{~kW}$ research combustor

Table 3: Coal analysis for test coals used in small pilot-scale testing

\begin{tabular}{|l|c|c|c|}
\hline & Illinois \#6 & Eagle Butte & Falkirk \\
\hline Proximate analysis (wt\%) & & & \\
\hline Moisture & 7.5 & 24.9 & 23.8 \\
\hline Volatile matter & 38.8 & 33.3 & 36.2 \\
\hline Fixed carbon & 43.7 & 36.7 & 33.7 \\
\hline Ash & 10.0 & 5.0 & 6.3 \\
\hline & & & \\
\hline Ultimate analysis (wt\%) & & & \\
\hline Hydrogen & 4.7 & 5.0 & 4.5 \\
\hline Carbon & 67.5 & 67.0 & 63.6 \\
\hline Nitrogen & 1.5 & 1.3 & 1.2 \\
\hline Sulfur & 3.3 & 0.8 & 0.8 \\
\hline Oxygen & 12.1 & 19.2 & 21.6 \\
\hline & & & \\
\hline $\begin{array}{l}\text { Higher heating value } \\
\text { (kJ/kg) }\end{array}$ & 26,300 & 20,300 & 17,200 \\
\hline (Btu/lb) & 11,300 & 8700 & 7400 \\
\hline Mercury $(\mu \mathrm{g} / \mathrm{g})$ & 0.061 & 0.075 & 0.035 \\
\hline Chlorine $(\mu \mathrm{g} / \mathrm{g})$ & 96 & 8.5 & 13 \\
\hline
\end{tabular}




\section{RESULTS AND DISCUSSION}

\section{Objective 1- Catalyst Coating}

\section{Initial Catalyst Loading}

Figure 15 summarizes the initial and final catalyst loadings for both fabric types as well as each of the coating methods: spray, single dip, double dip, and dry. Catalyst loading was measured by determining the weight of the fabric filter before and after coating. These weights were then used to calculate the mass fraction of the total weight of the filter sample due to the catalyst support. The initial loading was measured after the filter was coated and the fabric was dried, as described for each coating method in the experimental section, above. The final loading was measured after $400-1000$ back pulse shocks (depending on the method) had been applied to the sample.

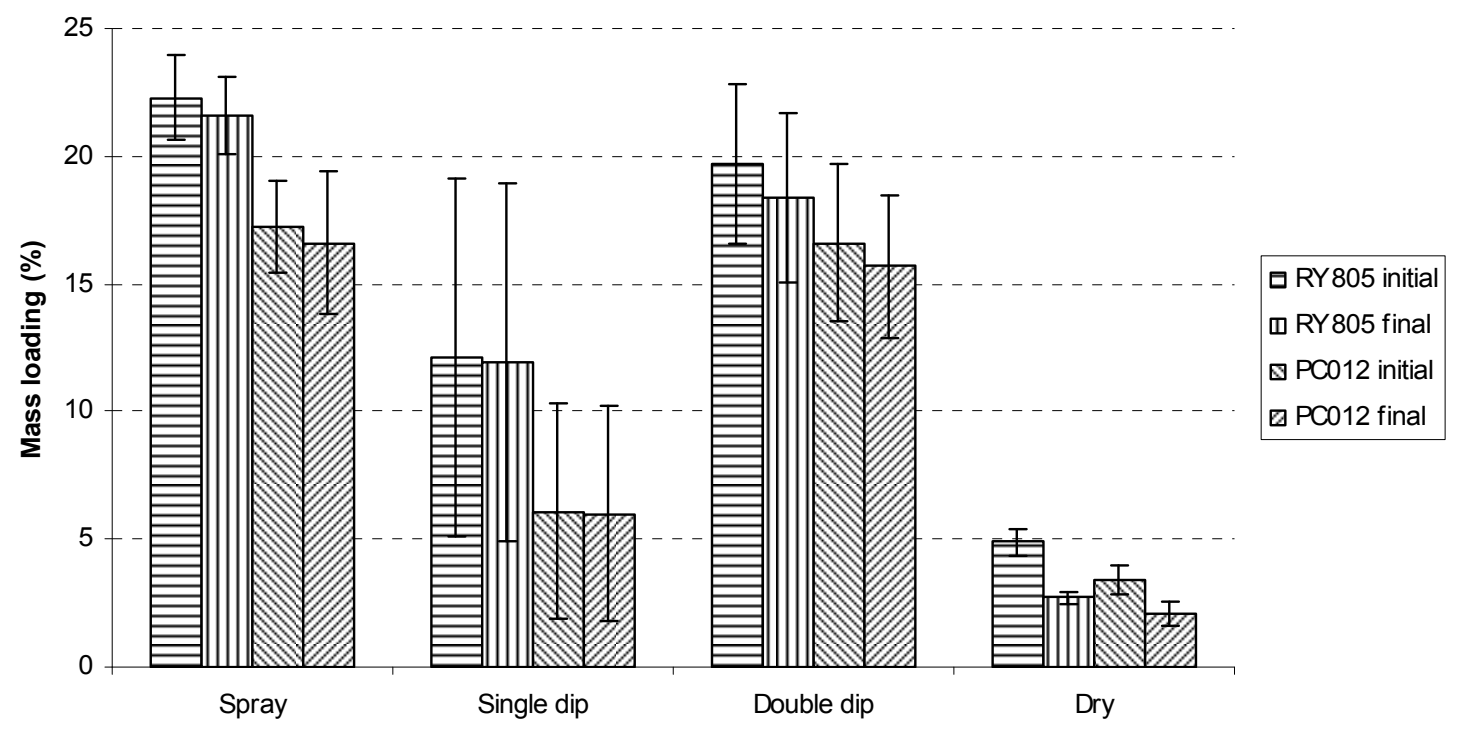

Figure 15: Summary of results for fabric coating. Initial and final mass loadings for each method and both fabrics are shown. 1000 back pulse shocks ( 400 for the dry coat method) were performed prior to measuring the final catalyst loading 


\section{Spray Coating}

Spraying gave the highest average initial catalyst loadings of any of the methods. Type RY805 fabric averaged $22.3 \pm 1.7 \mathrm{wt} \%$ initial catalyst support loading rate. The final loading rate averaged $21.6 \pm 1.5 \mathrm{wt} \%$ after 1000 cleaning pulses. Figure 16 summarizes the catalyst loss as a function of pulses for the spray coated RY805 blended fabric. Each run is defined by its initial catalyst loading. Catalyst support loss appears to be a simple linear function of the number of back pulses with a moderate slope of the function line suggesting that this method of catalyst loading is feasible.

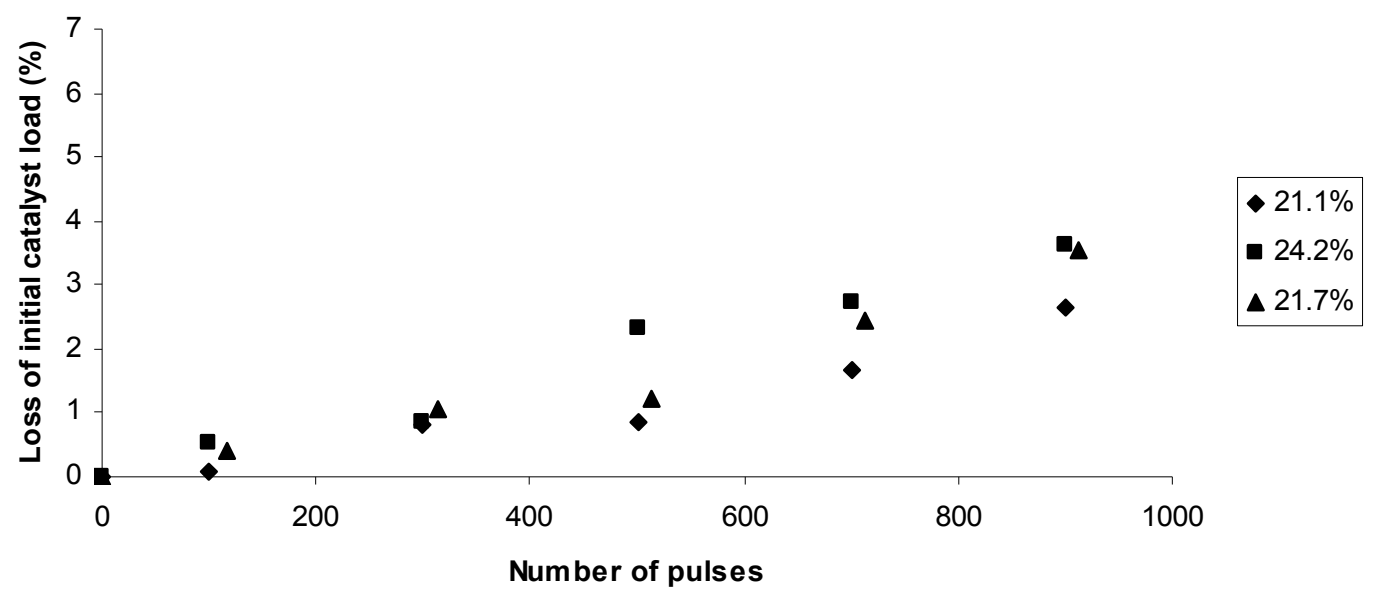

Figure 16: Losses as a function of number of back pulse shocks for spray coated fabric type RY805

The initial loading rate of type PC012 averaged $17.2 \pm 1.8 \mathrm{wt} \%$. The net average final loading after 1000 pulses was $16.6 \pm 2.8 \mathrm{wt} \%$. Figure 17 summarizes the catalyst loss as a function of pulses for the spray coated PC012 fabric. In general the same trend is seen as for the RY805, although the loss appears to level off for at least one test and the slope of the loss regression line is a bit steeper than for RY805. Again, these results suggest that this method of catalyst loading is feasible. 


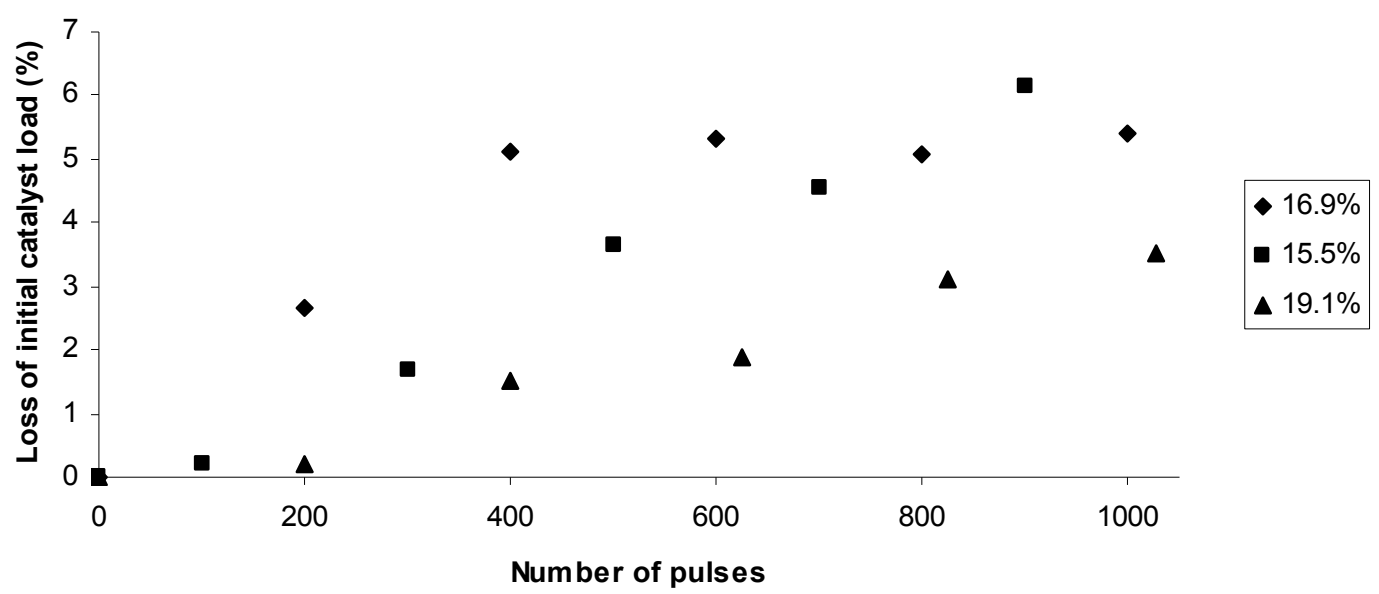

Figure 17: Losses from pulsing for spray coating on fabric type PC012

Inspection of the reactor in between the sample runs showed that the catalyst was coming out on the "dirty" side of the felt sample. This means that the flue gas flow rate had very little to do with the loss of catalyst in the fabric. The catalyst loss came from the $780 \mathrm{kPa}$ air pulses blowing the catalyst through the fabric and out on the "dirty" side of the reactor where the flue gas would enter. In an actual test, where the dirty side of the fabric will become coated with a layer of the collected ash, this effect should be inhibited somewhat. Thus these results represent a worst case scenario.

\section{Single Dip Coating}

A single dip coat in a $20 \mathrm{wt} \%$ alumina slurry was used on the fabrics followed by a "nip" roll using an empty piece of two-inch pipe. A nip roll is commonly used in web processes to force a fluid through the web and to distribute the fluid evenly through the web. Figure 18 shows the losses of catalyst as a function of the number of back pulse shocks for fabric type RY805. Two of the three trials showed a low catalyst loss but the 
third was not consistent with the behavior of the other. The one with the highest loss was the sample that had the lowest initial loading. This test is considered an anomaly.

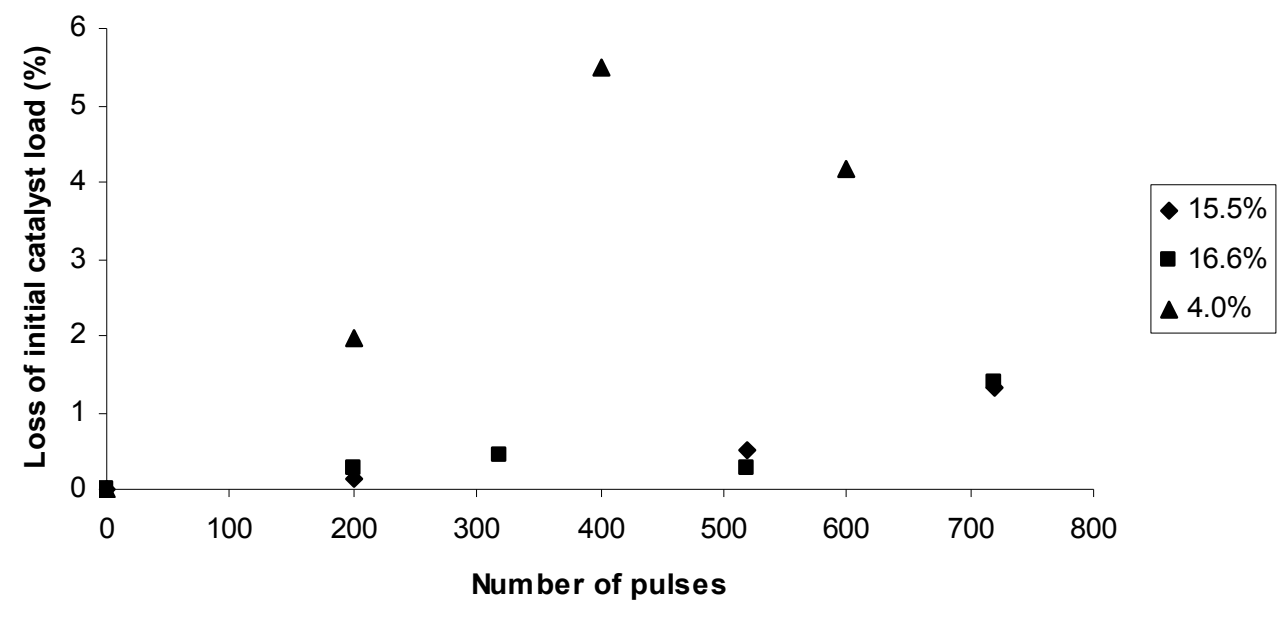

Figure 18: Losses from pulsing for single dip coating on fabric type RY805

Figure 19 shows that the losses for fabric type PC012 varied from less than 1\% to $4 \%$ overall. The starting catalyst doses on all of these runs varied widely and were low compared to the spray coat method. In all of the runs, the catalyst load was only the weight of alumina, the support material. 


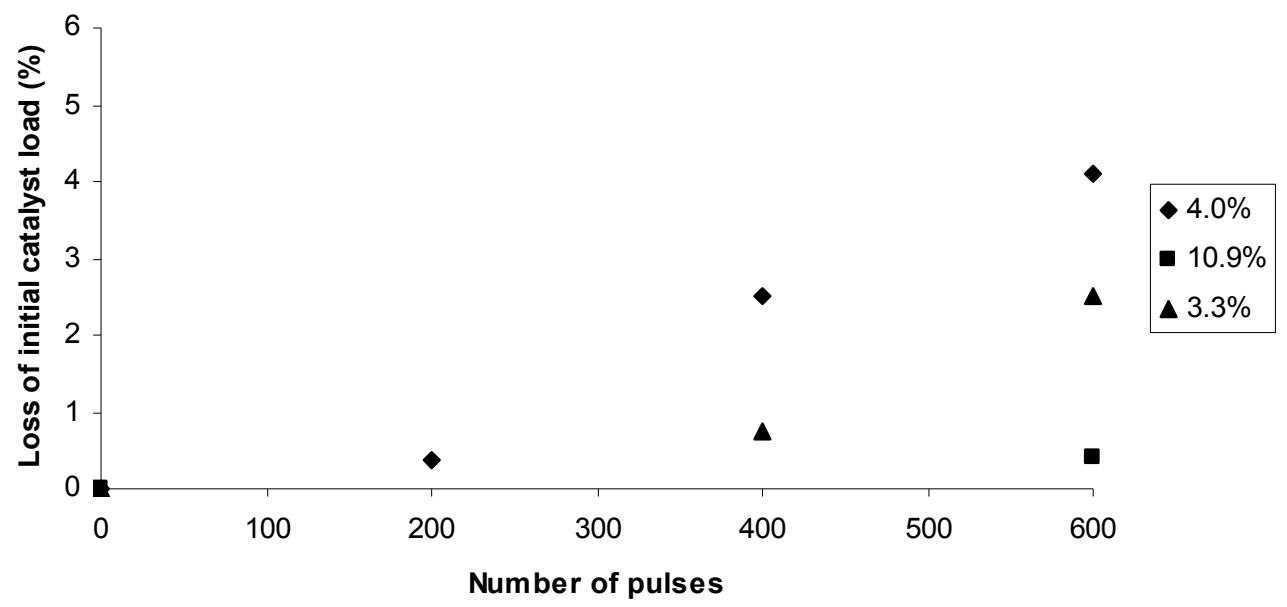

Figure 19: Catalyst support losses as a function of number of back pulse shocks for single dip coated fabric type PC012

\section{Double Dip Coating}

The single dip coating method was modified to obtain a double dip coating method. Fabric samples were soaked in $17.5 \mathrm{wt} \%$ water slurry of substrate for 2 minutes. After the dip, the sample was rolled six times under a custom rolling pin filled with lead weight. The dip procedure was repeated a second time and samples were dried overnight in a $375 \mathrm{~K}\left(216^{\circ} \mathrm{F}\right)$ oven. The heavier weight was added to properly saturate the fabric. Modification to the slurry concentration, mixing pressure, and nip pressures applied after each dip were all required to obtain consistent dosing between samples.

Figures 20 and 21 show the catalyst lost as a function of number of back pulse shocks for the double dip coated fabrics. The initial catalyst loadings were higher than the single coat and approached the spray coat loadings as shown in Figure 15. The double dip coat averaged $19.7 \pm 3.1 \mathrm{wt} \%$ on fabric RY805 and $16.6 \pm 3.1 \mathrm{wt} \%$ on fabric PC012. The average losses were $6.6 \%$ for fabric RY805 and $4.9 \%$ for fabric PC012. The 
double dip method for catalyst loading on the fabric provides the closest loading to the spray coat method. Higher loadings are desirable to provide the highest catalyst concentration for mercury oxidation to occur.

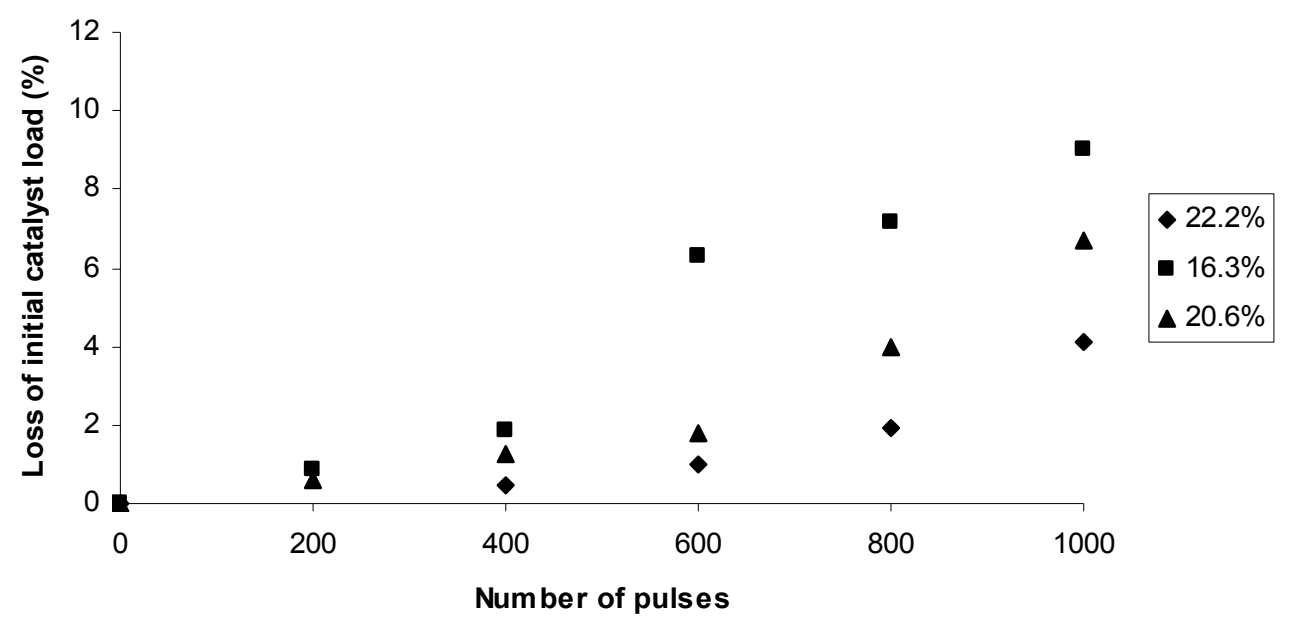

Figure 20: Catalyst support losses as a function of number of back pulse shocks for double dip coated fabric type RY805

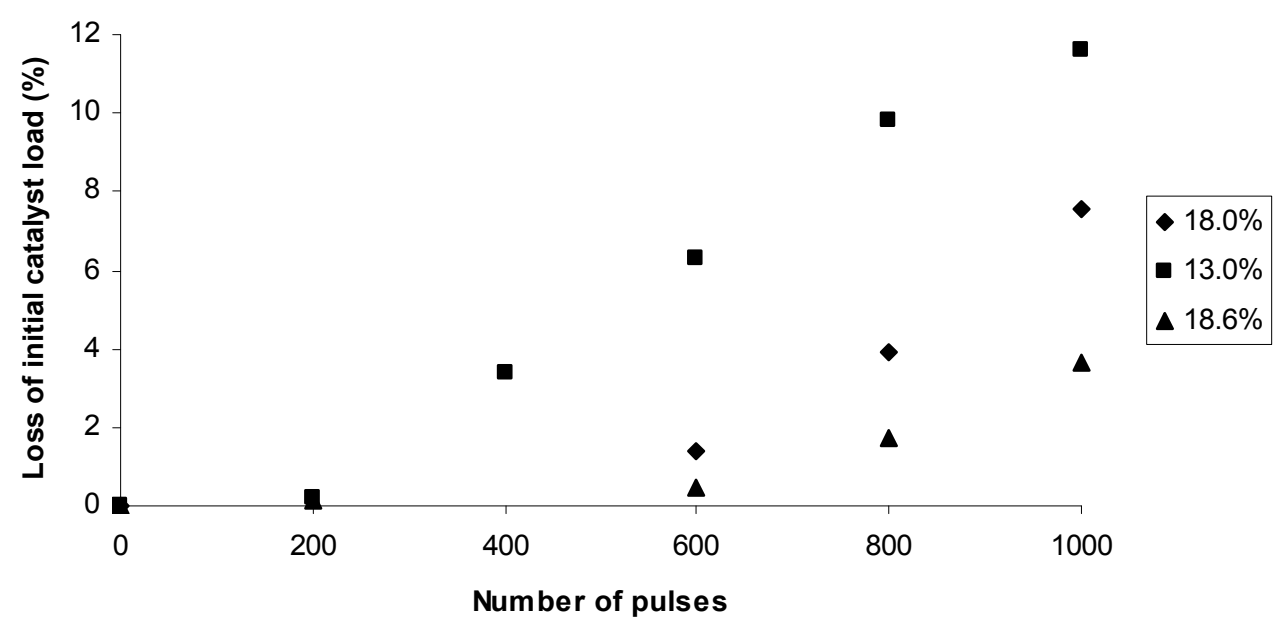

Figure 21: Catalyst support losses as a function of back pulse shocks for double dip coated fabric type $\mathrm{PC} 012$ 


\section{Dry Coating}

Starting up a baghouse with new filter bags requires the application of a pre-coat to protect the new bags from plugging with fine fly ash particulate. The pre-coat consists of a conditioning powder that when deposited on the bag actually filters the fly ash with support from the bag. The hypothesis was made that if the catalyst could be mixed with the conditioning agent or applied as a precursor to the conditioning agent, the simplest method to apply the catalyst would be a dry application method similar to applying the conditioning agent. A laboratory dry trial was attempted to determine potential loading rates and losses.

All of the runs were discontinued after only 400 back pulse shocks due to excessive losses. Dry coat dosing resulted in the lowest catalyst loading of all the methods investigated. Loading averaged only $4.9 \pm 0.5 \mathrm{wt} \%$ for fabric RY805 and $3.4 \pm$ $0.6 \mathrm{wt} \%$ for fabric PC012. Not only did the dry coat method have the lowest initial loads, it also gave the highest catalyst losses in the shortest number of pulses. Fabric RY805 losses averaged $44.2 \pm 8.2 \%$ and fabric PC012 losses averaged $39.4 \pm 3.7 \%$. The excessive application losses, cleaning pulse losses, and low dosing capabilities suggest that the dry coat method is not feasible. No further testing was performed using this method.

\section{Pressure Drop across Filter}

The pressure drop across the filter bags in a baghouse is important because it impacts the power consumption of the boiler's induced draft fan and the frequency of the jet-pulse used for cleaning. The operating cost of the power plant is affected by increased electrical cost and increased air consumption for cleaning with increasing pressure drop 
across the bag. Adding the catalyst to the filter fabric increases the pressure drop across the filter and assessing this impact was an important parameter in our tests.

As part of the laboratory testing program the differential pressure was logged at the beginning of each run with the catalytic filters. The differential pressure for bare fabrics was logged at the operating conditions of the bench reactor. The flue gas flow rate was $4 \mathrm{~L} / \mathrm{min}$ corresponding to a $0.03 \mathrm{~m} / \mathrm{s}(6 \mathrm{ft} / \mathrm{min})$ face velocity with a supply pressure of $179 \mathrm{kPa}(10 \mathrm{psig})$ to the flow meter. The bare fabrics both had a pressure drop of $0.025 \mathrm{kPa}\left(0.1\right.$ inches of $\left.\mathrm{H}_{2} \mathrm{O}\right)$ under the bench reactor operating conditions. Table 4 summarizes the differential pressure data for the spray coating method. Each run is defined by its initial catalyst loading.

The $24.2 \%$ initial load RY805 fabric run showed the same differential pressure at zero pulses as the bare fabric at $0.1 " \mathrm{H}_{2} \mathrm{O}$. All the other runs showed a slight increase of 0.025-0.05 $\mathrm{kPa}\left(0.1\right.$ to 0.2 inches of $\mathrm{H}_{2} \mathrm{O}$ ) in the differential pressure except the $15.5 \%$ initial load PC012 sample which showed an increase of $0.17 \mathrm{kPa}\left(0.7\right.$ inches of $\left.\mathrm{H}_{2} \mathrm{O}\right)$ over the bare fabric drop. The initial load of the catalyst does not directly correlate to increasing pressure drop. In general, the pressure drop of the catalytic filter can be expected to be slightly higher than the bare filter.

Two of the type RY805 fabric runs showed pressure drop increases across the filter of $0.025 \mathrm{kPA}\left(0.1\right.$ inches of $\left.\mathrm{H}_{2} \mathrm{O}\right)$ which remained constant as a function of the number of pulses applied. Two of the type PC012 fabric runs showed an increase of 0.05 kPA ( 0.2 inches of $\left.\mathrm{H}_{2} \mathrm{O}\right)$ over the bare fabric pressure drop, even though they had lower initial loadings than type RY805 fabric. The pressure drop remained constant over the 1000 pulses applied to the fabric. The $15.5 \%$ initial load run on PC012 showed a larger 
Table 4: Pressure drop across filters for spray coating method

\begin{tabular}{|c|c|c|c|c|c|c|}
\hline $\begin{array}{c}\text { Init. Load } \\
\text { Fabric } \\
\text { Pulses }\end{array}$ & $\begin{array}{c}21.7 \% \\
\mathrm{RY} 805 \\
\Delta \mathrm{P}\left({ }^{“} \mathrm{H}_{2} \mathrm{O}\right) \\
\end{array}$ & $\begin{array}{c}24.2 \% \\
\mathrm{RY} 805 \\
\Delta \mathrm{P}\left({ }^{(“} \mathrm{H}_{2} \mathrm{O}\right)\end{array}$ & $\begin{array}{c}21.1 \% \\
\mathrm{RY} 805 \\
\Delta \mathrm{P}\left({ }^{“} \mathrm{H}_{2} \mathrm{O}\right)\end{array}$ & $\begin{array}{c}16.9 \% \\
\mathrm{PC} 012 \\
\Delta \mathrm{P}\left({ }^{(“} \mathrm{H}_{2} \mathrm{O}\right) \\
\end{array}$ & $\begin{array}{c}15.5 \% \\
\mathrm{PC} 012 \\
\Delta \mathrm{P}\left({ }^{(“} \mathrm{H}_{2} \mathrm{O}\right) \\
\end{array}$ & $\begin{array}{c}19.1 \% \\
\mathrm{PC} 012 \\
\Delta \mathrm{P}\left({ }^{(“} \mathrm{H}_{2} \mathrm{O}\right)\end{array}$ \\
\hline 0 & 0.2 & 0.1 & 0.2 & 0.3 & 0.8 & 0.3 \\
\hline 100 & 0.3 & 0.1 & 0.3 & & 0.7 & \\
\hline 200 & & & & 0.3 & & 0.3 \\
\hline 300 & 0.2 & 0.2 & 0.2 & & & \\
\hline 400 & & & & 0.2 & & 0.3 \\
\hline 500 & 0.2 & 0.2 & 0.3 & & 0.4 & \\
\hline 600 & & & & 0.1 & & 0.3 \\
\hline 700 & 0.2 & 0.2 & 0.3 & & 0.3 & \\
\hline 800 & & & & 0.3 & & 0.3 \\
\hline 900 & & & & & & \\
\hline 1000 & & & & 0.3 & & \\
\hline $\mathrm{AVG}$ & 0.2 & 0.2 & 0.3 & 0.3 & 0.6 & 0.3 \\
\hline STD DEV & 0.04 & 0.05 & 0.05 & 0.08 & 0.24 & 0.00 \\
\hline
\end{tabular}

Note: 1 ' $\mathrm{H}_{2} \mathrm{O}$ (inches of $\mathrm{H}_{2} \mathrm{O}$ ) pressure drop $=0.25 \mathrm{kPa}$

initial increase in pressure drop of $0.2 \mathrm{kPa}\left(0.8\right.$ inches of $\left.\mathrm{H}_{2} \mathrm{O}\right)$ but the filter pressure drop decreased to $0.07 \mathrm{kPa}\left(0.3\right.$ inches of $\left.\mathrm{H}_{2} \mathrm{O}\right)$ after 700 pulses. The pressure drop trends cannot be explained by any of the laboratory observations noted during this run.

Table 5 summarizes the pressure drop data for the double dip coat method of catalyst application. The zero pulse differential pressure drop for all runs was equal to or showed only a $0.025 \mathrm{kPa}\left(0.1\right.$ inches of $\left.\mathrm{H}_{2} \mathrm{O}\right)$ increase over the bare fabric pressure drop. No trend for pressure drop with increasing pulses for the double dip coat method was apparent. The $0.025-0.075 \mathrm{kPa}\left(0.1-0.3\right.$ inches of $\left.\mathrm{H}_{2} \mathrm{O}\right)$ increase in pressure drop observed in both the dip coat and spray application trials indicate that a slight increase in pressure drop can be expected in commercial applications. This increase is not expected to play a significant role in commercial applications. 
Table 5: Pressure drop across filters for double dip coating method

\begin{tabular}{ccccccc} 
Init. Load & $22 \%$ & $16.3 \%$ & $20.6 \%$ & $18.6 \%$ & $18.0 \%$ & $13.00 \%$ \\
Fabric & $\mathrm{RY} 805$ & $\mathrm{RY} 805$ & $\mathrm{RY} 805$ & $\mathrm{PC} 012$ & $\mathrm{PC} 012$ & $\mathrm{PC} 012$ \\
Pulses & $\Delta \mathrm{P}\left(\right.$ " $\left.\mathrm{H}_{2} \mathrm{O}\right)$ & $\Delta \mathrm{P}\left(\right.$ " $\left.\mathrm{H}_{2} \mathrm{O}\right)$ & $\Delta \mathrm{P}\left(\right.$ " $\left.\mathrm{H}_{2} \mathrm{O}\right)$ & $\Delta \mathrm{P}\left(\right.$ " $\left.\mathrm{H}_{2} \mathrm{O}\right)$ & $\Delta \mathrm{P}\left(\right.$ "“ $\left.\mathrm{H}_{2} \mathrm{O}\right)$ & $\Delta \mathrm{P}$ (" $\left.\mathrm{H}_{2} \mathrm{O}\right)$ \\
\hline 0 & 0.1 & 0.1 & 0.2 & 0.1 & 0.2 & 0.1 \\
200 & 0.2 & 0.2 & 0.1 & 0.1 & 0.20 & 0.1 \\
400 & 0.2 & 0.2 & 0.2 & & 0.10 & - \\
600 & 0.1 & 0.2 & 0.2 & 0.1 & 0.10 & 0.1 \\
800 & 0.2 & 0.1 & 0.1 & 0.1 & 0.10 & 0.1 \\
1000 & & 0.1 & & 0.1 & & \\
\hline AVG & 0.2 & 0.2 & 0.2 & 0.1 & 0.1 & 0.1 \\
STD DEV & 0.05 & 0.05 & 0.05 & 0.00 & 0.05 & 0.00 \\
Note: 1 " $\mathrm{H} 2 \mathrm{O}$ pressure drop $=0.25 \mathrm{kPa}$ & & &
\end{tabular}

\section{UV Exposure to Titania}

Kon Corporation of Japan makes an anatase sol, TPX-220, which is primarily used as a building coating to prevent dirt and degradation by air pollution. The coating is applied like paint to the building exterior and by exposure to sunlight acts to clean the building by oxidizing the contaminants. TPX-220 is a $2.2 \%$ by weight solution of peroxotitanic acid and titanium dioxide and was sprayed onto the fabrics using the spray bottle's internal pump.

Two coats were applied to the "clean" side of the fabric. After each of the coats, a lab spatula was used as a knife blade for even distribution of the solution over the fabric surface. The samples were then dried over night in a $375 \mathrm{~K}\left(212^{\circ} \mathrm{F}\right)$ oven. In the morning the samples looked splotchy and appeared to be not quite dry. The oven temperature was then increased to $398 \mathrm{~K}\left(257^{\circ} \mathrm{F}\right)$ to complete the drying for 3 hours. After this second drying, the samples had a reverse "grilled" appearance; white where the oven grill impacted the sample and light brown in the air-exposed areas.

We postulated that the sol-gel had not been completely removed and was taking up some of the catalyst active sites. The samples were then exposed to ultraviolet light in 
order to clean up the active sites. The samples were treated overnight which darkened the lighter colored spots and lightened the dark areas to even out the color. The cleaning appeared to be working so the samples were left under ultraviolet light for an entire weekend. The samples then turned a darker medium brown instead of cleaning up to the white color of the fabric. Obviously, a reaction was taking place.

At this point it was uncertain if a large source of residual sol-gel was reacting with the catalyst or if the catalyst was oxidizing the fabric. The side of the fabric that was not being treated with the ultraviolet light remained at the fabric's original color. In the oven, the sample only turned color on the side toward the bottom of the oven, not the topside of the fabric. The topside of the fabric was the side of the fabric that had been sprayed with the sol-gel. Further ultraviolet testing of the top side was done and it also turned brown showing signs of reaction. The heat emanating from the oven bottom must have been sufficiently different on the bottom surface compared to the top of the fabric to facilitate the reaction. Also, only the side of the fabric exposed to the ultraviolet light showed signs of color change (reaction).

Since the samples were degraded, no weighing for dosage was made. A water slurry with $\mathrm{TiO}_{2}$ as a catalyst was then prepared to determine if the catalyst was oxidizing the fabric or if the sol-gel reacted with the catalyst. Since water is inert to the fabrics, if the samples turn brown during oven drying this would indicate that the fabric was oxidized by the catalyst application. After coating with the $\mathrm{TiO}_{2}$ slurry, overnight drying of the fabric did not cause the samples to turn brown. These fabric samples were dosed at an average level of $8.7 \mathrm{wt} \%$ on fabric PC012 and $9.5 \mathrm{wt} \%$ on fabric RY805. However, 
when the samples were subjected to ultraviolet light the samples turned brown indicating oxidation takes place with titanium dioxide as a catalyst.

Fabric type RY805 is reported to have poor collection efficiency above $15 \%$ oxygen. ${ }^{[57]}$ This performance is predicted without catalyst application. Even though the sample did not oxidize in an overnight thermal drying cycle, the titanium dioxide catalyst can be expected to oxidize the fabric itself under ultraviolet light and shorten the life cycle of the fabric.

\section{Summary of Coating Methods}

Spray coating the fabrics with a $25 \mathrm{wt} \%$ slurry under approximately $138 \mathrm{kPa}$ pressure and a cone shaped spray gave the highest catalyst loadings. The spray method is easier to control to a constant slurry concentration than the dip coating method because of free mixing in the slurry (the fabric is not in the slurry to interfere with the mixing). As long as the spray pressure and flow rate to the spray nozzle remain constant the coating process is simple. This also applies to the commercial scale of the project. If a proper nozzle is chosen for the desired spray pattern and design pressure, the spray coat method will provide the highest catalyst loading and have the simplest operation. The best scenario for a coating method is to spray the catalyst on at a low pressure (under $345 \mathrm{kPa}$ ) and to use a felted fabric.

Dip coat application can achieve relatively high dosage levels approaching doses of $20 \mathrm{wt} \%$. The dip coat method has more variables that can give inconsistent dosing from sample to sample compared to the spray coating method. The highest coating levels (approaching $20 \mathrm{wt} \%$ ) were achieved with two successive dip coats with each dip followed by rolling the sample under a weighted rolling pin. If two coats were required 
in production this would require two successive dip tanks with each dip followed by pressing in a low pressure roll press to assure distribution of the slurry into the fabric.

Since the catalyst support is not water soluble, the coating is a slurry not a solution. The dip tanks require adequate mixing to keep the catalyst in suspension and since catalyst is continually removed with the fabric, the catalyst concentration is not constant. Maintaining a constant slurry concentration in the dip tank will require a makeup stream of catalyst slurry. The challenge becomes monitoring a process variable that will allow the proper control of the make-up stream.

The pressure applied to the nip roll may also become a variable dependent on fabric properties. If too much pressure is applied, more water will be squeezed out of the fabric acting much like a paper machine press. Fine particles will come with the water; how much will depend on the fabric structure, fiber size, and composition. If more than one type of fabric would be run on a coating line, adjustments to the nip roll might have to be made based on the fabric type running at the time. A danger exists in applying too much pressure such that the fabric compresses and is less permeable to air flow.

The dry method of application attempted to simulate the application of the catalyst as a pre-coat to the bag. The dry application was done under vacuum. The particle size was so small that the catalyst support was pulled directly through the fabric or formed a splotchy buildup that readily fell off during sample handling. The dosing was very low at less than $5 \mathrm{wt} \%$ and $40 \%$ of that fell off after 400 cleaning pulses. Dry application is not considered a viable option due to the excessive application and pulsing losses. 


\section{Objective 2- Bench-Scale Testing}

The main filter fabric type for the bench-scale testing is type RY805. For the gold catalyst, random spot tests were also performed using fabric type PC012 to test for any differences between bag types. The baseline gas consists of $4 \% \mathrm{O}_{2}, 10 \% \mathrm{H}_{2} \mathrm{O}, 20-30$ $\mu \mathrm{g} / \mathrm{m}^{3} \mathrm{Hg}^{0}$, and a balance of $\mathrm{N}_{2}$. All of the experiments performed in this project were performed using the wet solution conditioning system on the DM-6B mercury analyzer. We were not able to get the manufacturer's dry catalyst conditioning system to work properly for any significant amount of time. It has been determined that the acid gases used in this research significantly interfere with the conditioning catalyst's ability to function properly.

\section{Data Interpretation}

This section will explain how figures and graphs are used in this chapter. Figure 22 shows an example of an experiment using $\mathrm{TiO}_{2}$. The dashed line in the figure represents the concentration of mercury that is added to the reactor. The numbers above the gases listed are experimental condition numbers. These experimental condition numbers are unique for each combination of gases and are consistent throughout the entire set of bench-scale tests. From the figure, the total mercury concentration very closely follows that of the elemental mercury concentration. It was first assumed that the addition of various gases resulted in changes in elemental mercury adsorption rates. However, it was suggested that $\mathrm{TiO}_{2}$ might adsorb oxidized mercury. To test for this, an oxidized mercury spiking system was constructed. Figure 23 shows the oxidized 


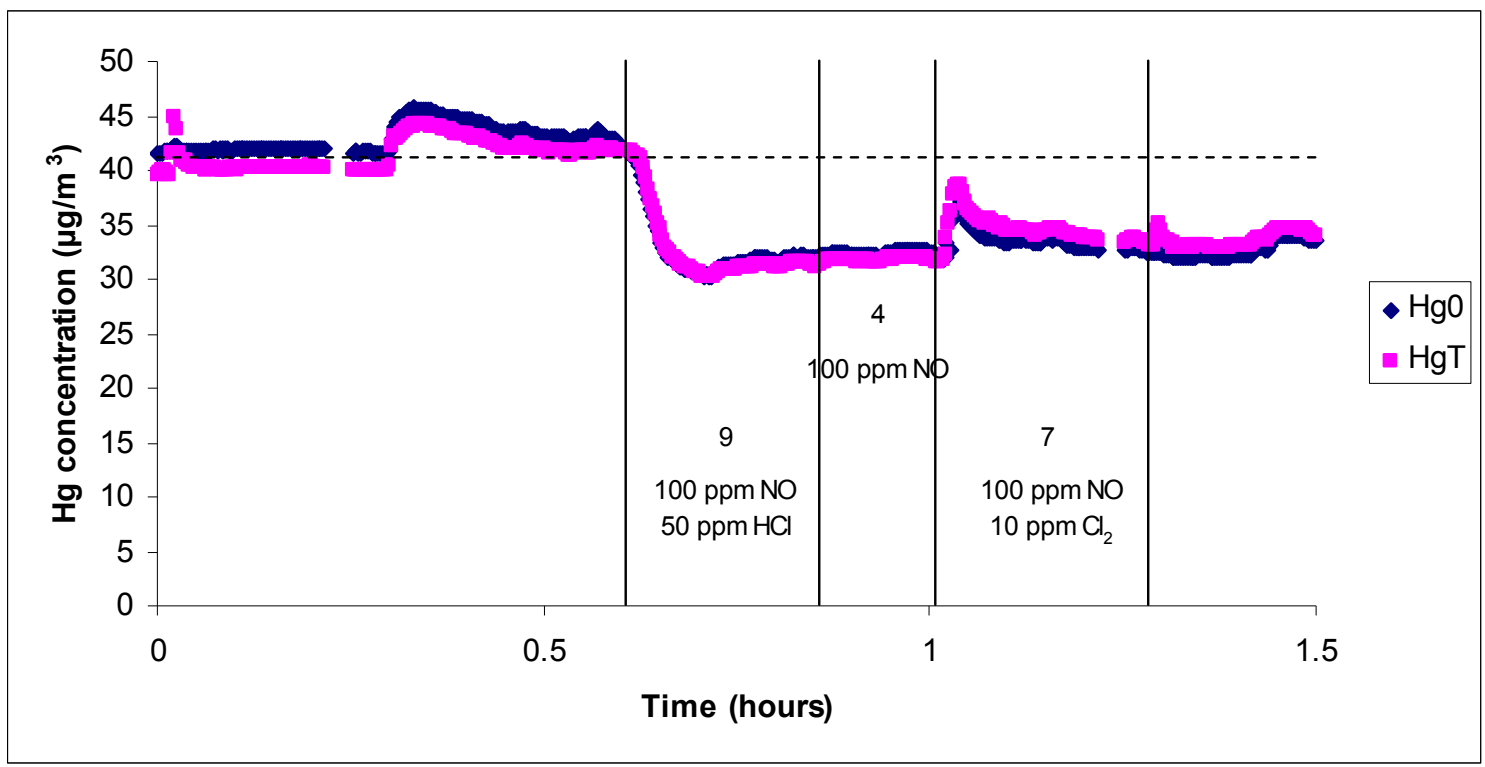

Figure 22: Example of an experiment using $\mathrm{TiO}_{2}$ to demonstrate total mercury shift

mercury spiking system that uses mercuric chloride $\left(\mathrm{HgCl}_{2}\right)$ as a source of oxidized mercury.

Figure 24 shows the data from an experiment using oxidized mercury with no filter in the reactor and for an experiment utilizing a filter loaded with $\mathrm{TiO}_{2}$. The filter with the $\mathrm{TiO}_{2}$ adsorbed about 60 percent of the oxidized mercury. Also, as shown in Figure 22 when no oxidation occurs, the elemental and total mercury concentrations are both at the inlet baseline. Consequently, we conclude that the observed shift in the total mercury concentration was the result from adsorption of oxidized

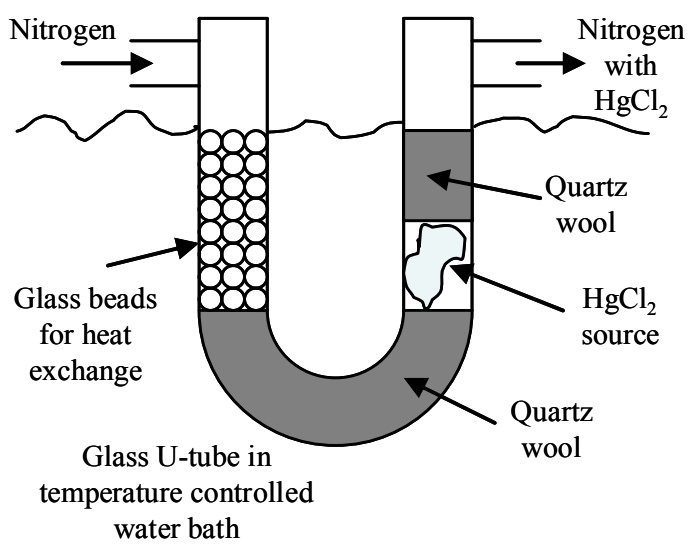

Figure 23: Oxidized mercury spiking system 


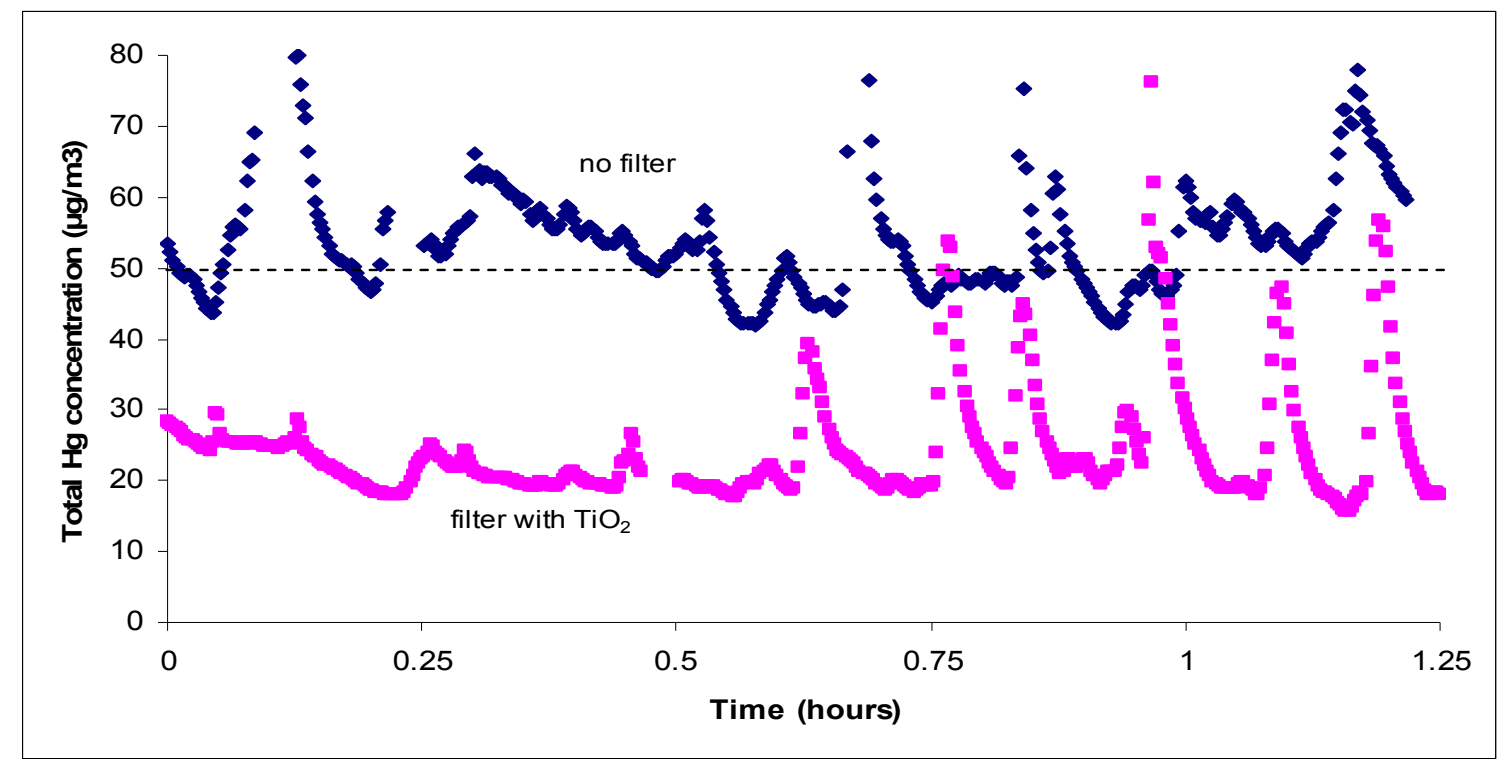

Figure 24: A comparison of mercury outlet concentrations with and without a $\mathrm{TiO}_{2}$ coated filter using an oxidized mercury $\left(\mathrm{HgCl}_{2}\right)$ spiking system

mercury by $\mathrm{TiO}_{2}$.

To determine the extent of mercury oxidation resulting from the bench-scale tests, two types of oxidized mercury were considered. The first type was mercury that makes its way through the reactor with the flue gas and is termed gaseous oxidized mercury. The other type of oxidized mercury was adsorbed by the catalyst substrate and is termed adsorbed oxidized mercury. The gaseous oxidized mercury was found by taking the difference between the total mercury concentration and the elemental mercury concentration. The adsorbed oxidized mercury was found by taking the difference between the total mercury concentration and the baseline addition of mercury, which is represented by the dashed line in each figure. Figure 25 shows an experiment using $\mathrm{Au} / \mathrm{TiO}_{2}$. This figure shows the differences between the two types of oxidized mercury considered in this research. 


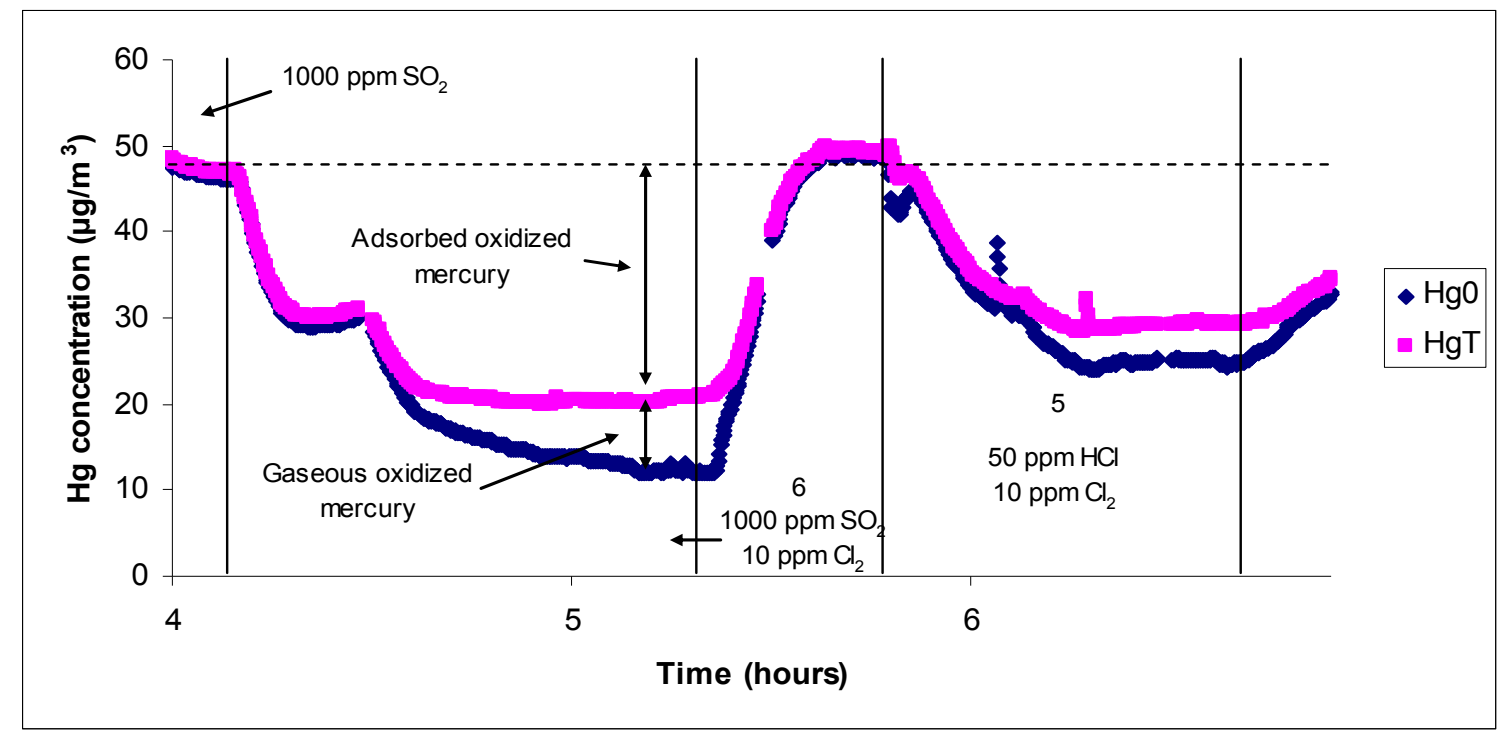

Figure 25: Typical experiment using $\mathrm{Au} / \mathrm{TiO}_{2}$ to demonstrate the different types of oxidized mercury quantified in this study

Bare Filter - RY805

As a baseline control, testing was performed using a fabric sample containing no catalyst. The baseline gas did not oxidize any mercury during any of the bench-scale testing. Figures 26-29 show the effect of each of the acid gases $\mathrm{Cl}_{2}, \mathrm{HCl}, \mathrm{SO}_{2}$, and $\mathrm{NO}$, respectively on mercury oxidation. For the bare filter experiments, nearly all of the oxidized mercury is in the gaseous form. The mercury oxidation that occurs is either homogenous oxidation, or heterogeneous oxidation due to catalysis by the fabric material, or both. As seen in the figures, the amount of oxidation that occurs in most of the tests is around 20 to 35 percent. $\mathrm{SO}_{2}$ appeared to have the greatest effect on mercury oxidation, both when alone and in the presence of the other gases. Table 6 summarizes the bare filter results. 


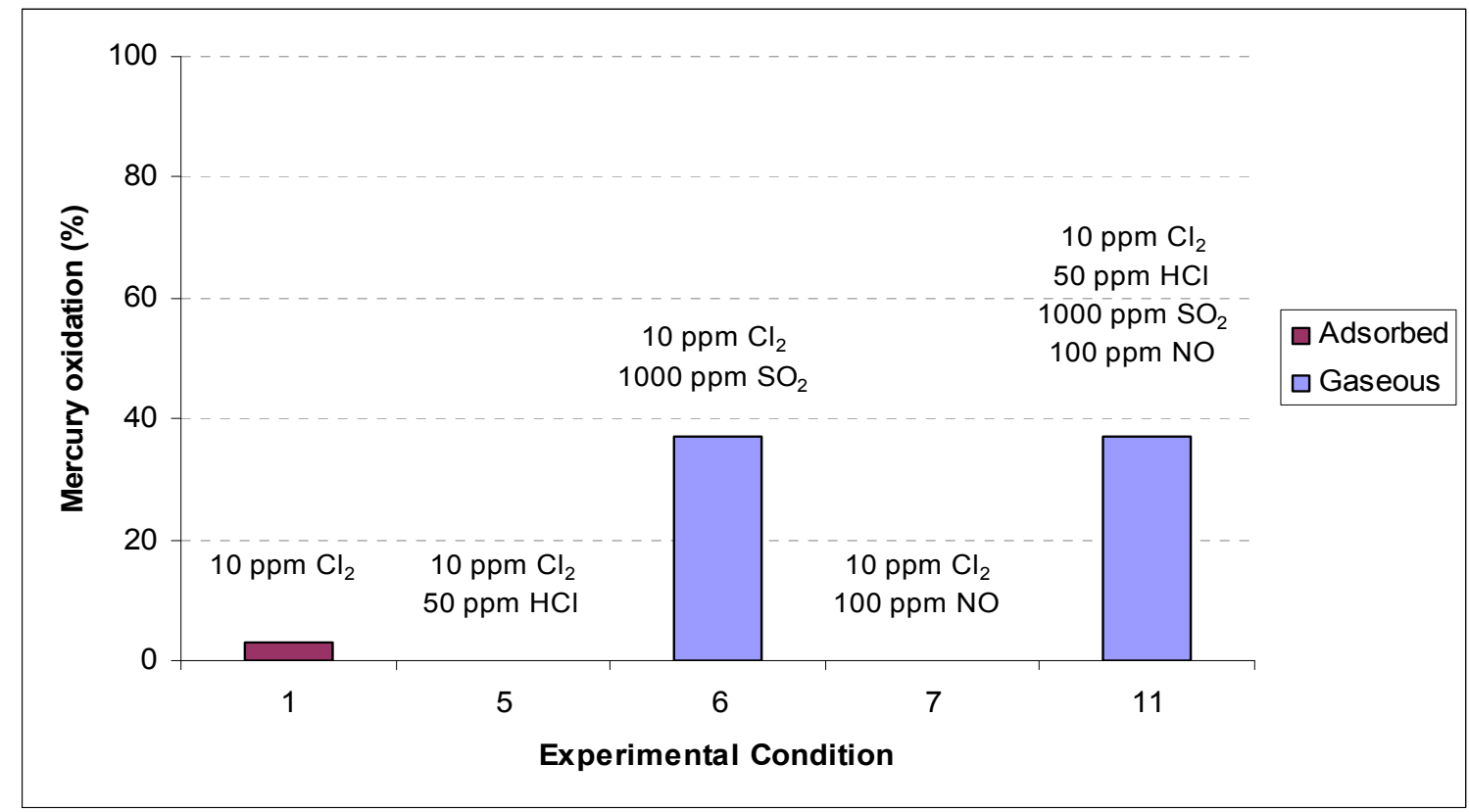

Figure 26: The effect of $\mathrm{Cl}_{2}$ on mercury oxidation for uncoated (bare) filter type $\mathrm{RY} 805$ (baseline gas is $4 \% \mathrm{O}_{2}, 10 \% \mathrm{H}_{2} \mathrm{O}, 20-30 \mu \mathrm{g} / \mathrm{m}^{3} \mathrm{Hg}^{0}$, and balance $\mathrm{N}_{2}$ )

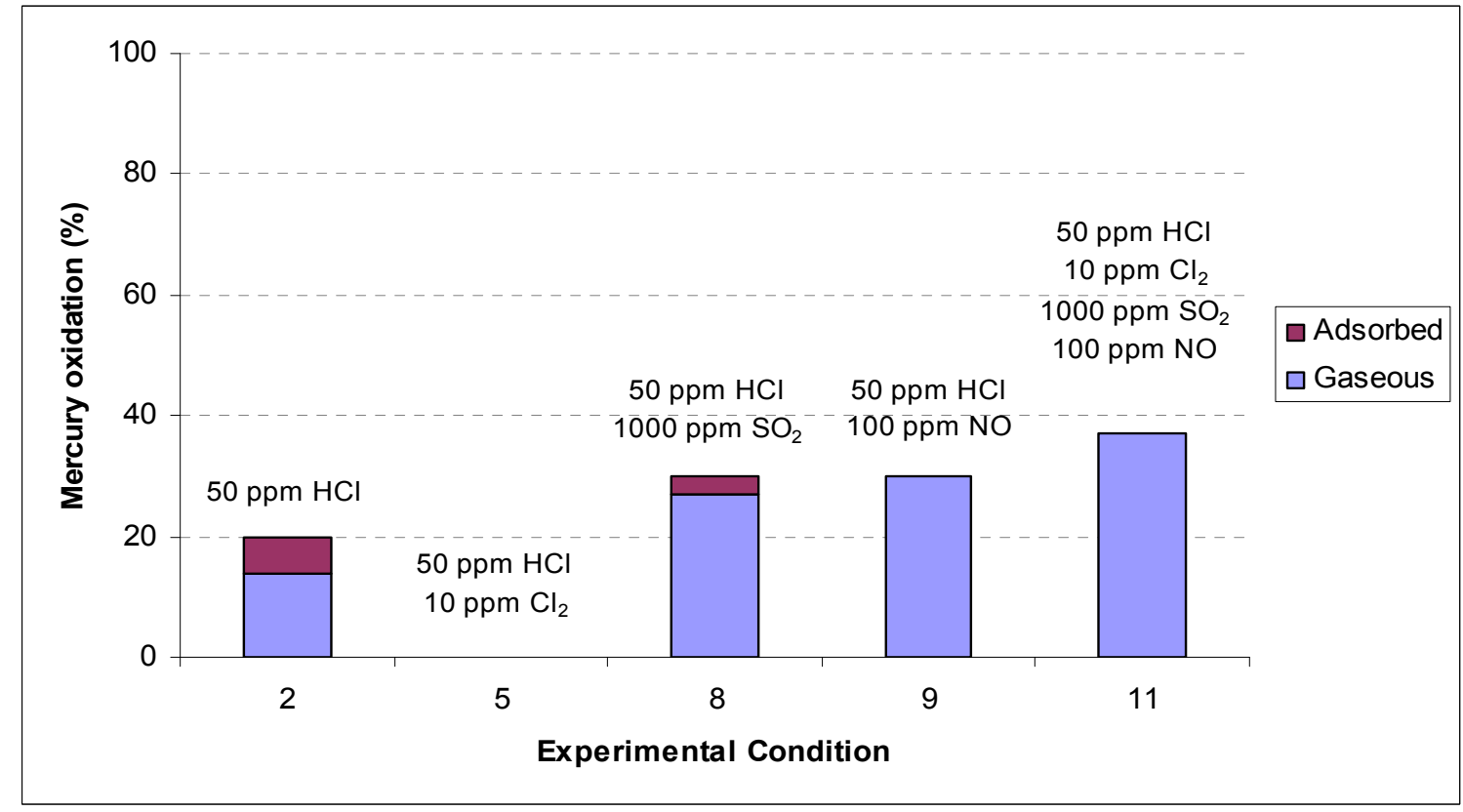

Figure 27: The effect of $\mathrm{HCl}$ on mercury oxidation for uncoated (bare) filter type $\mathrm{RY} 805$ (baseline gas is $4 \% \mathrm{O}_{2}, 10 \% \mathrm{H}_{2} \mathrm{O}, 20-30 \mu \mathrm{g} / \mathrm{m}^{3} \mathrm{Hg}^{0}$, and balance $\mathrm{N}_{2}$ ) 


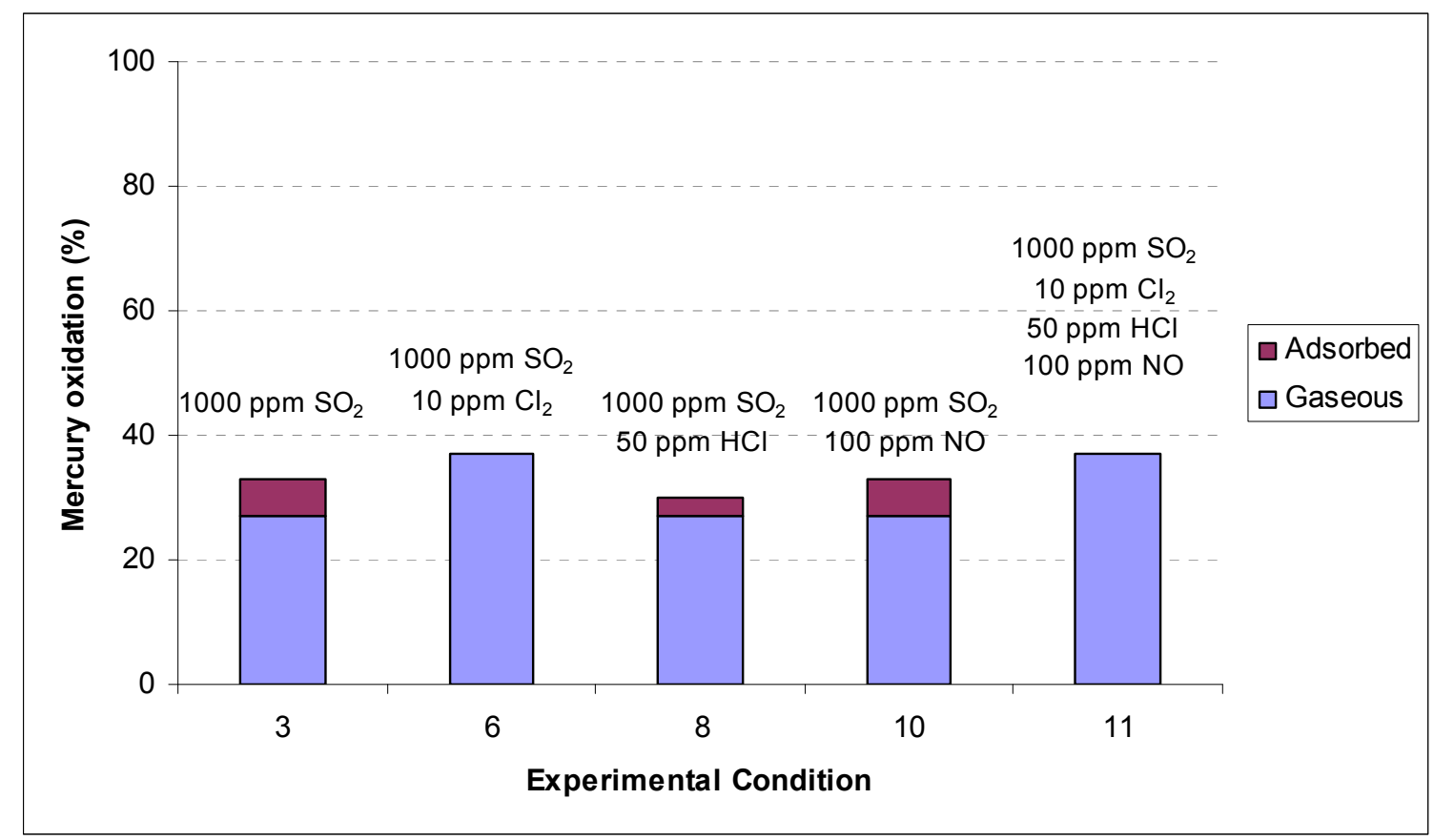

Figure 28: The effect of $\mathrm{SO}_{2}$ on mercury oxidation for uncoated (bare) filter type $\mathrm{RY} 805$ (Baseline gas is $4 \% \mathrm{O}_{2}, 10 \% \mathrm{H}_{2} \mathrm{O}, 20-30 \mu \mathrm{g} / \mathrm{m}^{3} \mathrm{Hg}^{0}$, and balance $\mathrm{N}_{2}$ )

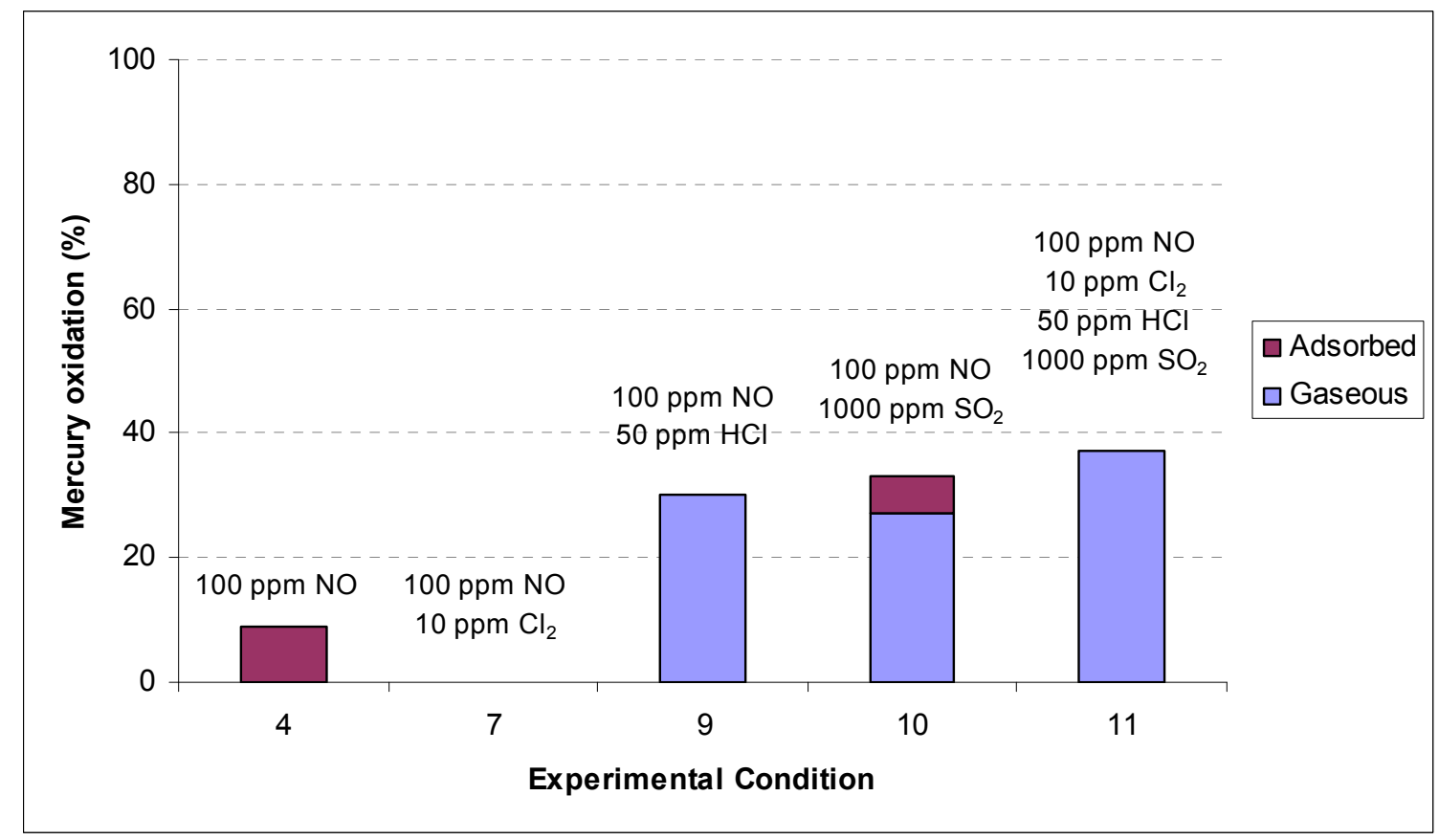

Figure 29: The effect of NO on mercury oxidation for uncoated (bare) filter type RY805 (baseline gas is $4 \% \mathrm{O}_{2}, 10 \% \mathrm{H}_{2} \mathrm{O}, 20-30 \mu \mathrm{g} / \mathrm{m}^{3} \mathrm{Hg}^{0}$, and balance $\mathrm{N}_{2}$ ) 
Table 6: Results for uncoated filter tests using filter type RY805 (baseline gas is $4 \% \mathrm{O}_{2}, 10 \% \mathrm{H}_{2} \mathrm{O}, 20-30 \mu \mathrm{g} / \mathrm{m}^{3} \mathrm{Hg}^{0}$, and balance $\mathrm{N}_{2}$ )

\begin{tabular}{|c|c|c|c|c|c|}
\hline Condition & $\mathrm{Cl}_{2}(\mathrm{ppm})$ & $\mathrm{HCl}(\mathrm{ppm})$ & $\mathrm{SO}_{2}(\mathrm{ppm})$ & $\mathrm{NO}(\mathrm{ppm})$ & $\mathrm{Hg}$ oxidation (\%) \\
\hline 1 & 10 & & & & 3 \\
\hline 2 & & 50 & & & 20 \\
\hline 3 & & & 1000 & & 33 \\
\hline 4 & & & & 100 & 9 \\
\hline 5 & 10 & 50 & & & 37 \\
\hline 6 & 10 & & 1000 & & 0 \\
\hline 7 & 10 & & & 100 & 30 \\
\hline 8 & & 50 & 1000 & & 33 \\
\hline 9 & & 50 & & 100 & 37 \\
\hline 10 & & & 1000 & 100 & 100 \\
\hline 11 & 10 & 50 & 1000 & & \\
\hline
\end{tabular}

$\mathrm{TiO}_{2}$ on $\mathrm{RY} 805$

Experiments using the $\mathrm{TiO}_{2}$ catalyst were performed using $5 \mathrm{~cm}(2 \mathrm{inch})$ diameter samples of RY805 fabric coated with $0.2 \mathrm{~g}$ of catalyst, resulting in a catalyst loading rate of about $10 \mathrm{mg} / \mathrm{cm}^{2}$. The baseline gas did not oxidize any mercury during these tests. Figures 30-33 show the effect of $\mathrm{Cl}_{2}, \mathrm{HCl}, \mathrm{SO}_{2}$, and $\mathrm{NO}$, respectively for filter type RY805 coated with $\mathrm{TiO}_{2}$. None of the spiked gases result in a significant increase in mercury oxidation. In fact, nearly every test with the presence of $\mathrm{TiO}_{2}$ resulted in lower rates of mercury oxidation than a bare filter.

This is likely the result of systematic error since the tests were performed over a large time frame (about 5 months). The surfaces of the bench-scale mercury system can relatively easily adsorb elemental and oxidized mercury even though Teflon and glass are the only materials present in the system. Over time, it is expected that mercury concentrations will vary and create differences significant enough to explain the difference observed between a bare filter and a filter loaded with $\mathrm{TiO}_{2}$. 
Nearly all of the oxidized mercury is adsorbed oxidized mercury. This is an expected observation. Homogenous oxidation most likely occurs in the reactor, as witnessed from the bare filter tests. The oxidized mercury is then adsorbed by the $\mathrm{TiO}_{2}$. A small amount of mercury could also be oxidized by the $\mathrm{TiO}_{2}$ catalyst and then adsorbed by the $\mathrm{TiO}_{2}$ catalyst. However, this is not expected to play a significant role since there is no increase in the amount of mercury oxidation with the $\mathrm{TiO}_{2}$ loaded filter versus the bare filter. Table 7 summarizes the $\mathrm{TiO}_{2}$ results.

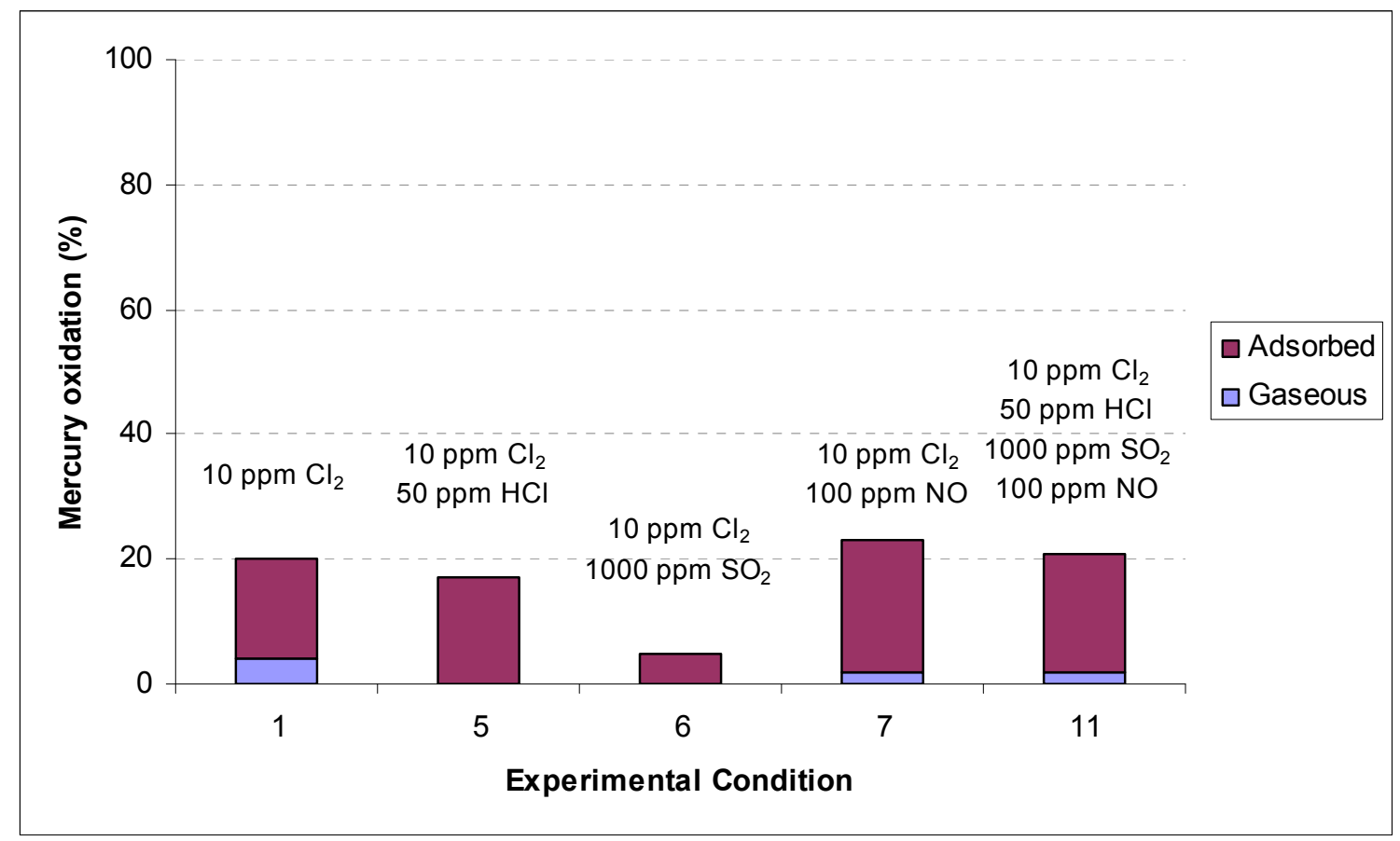

Figure 30: The effect of $\mathrm{Cl}_{2}$ on mercury oxidation for filter type $\mathrm{RY} 805$ coated with $\mathrm{TiO}_{2}$ (baseline gas is $4 \% \mathrm{O}_{2}, 10 \% \mathrm{H}_{2} \mathrm{O}, 20-30 \mu \mathrm{g} / \mathrm{m}^{3} \mathrm{Hg}^{0}$, and balance $\mathrm{N}_{2}$ ) 


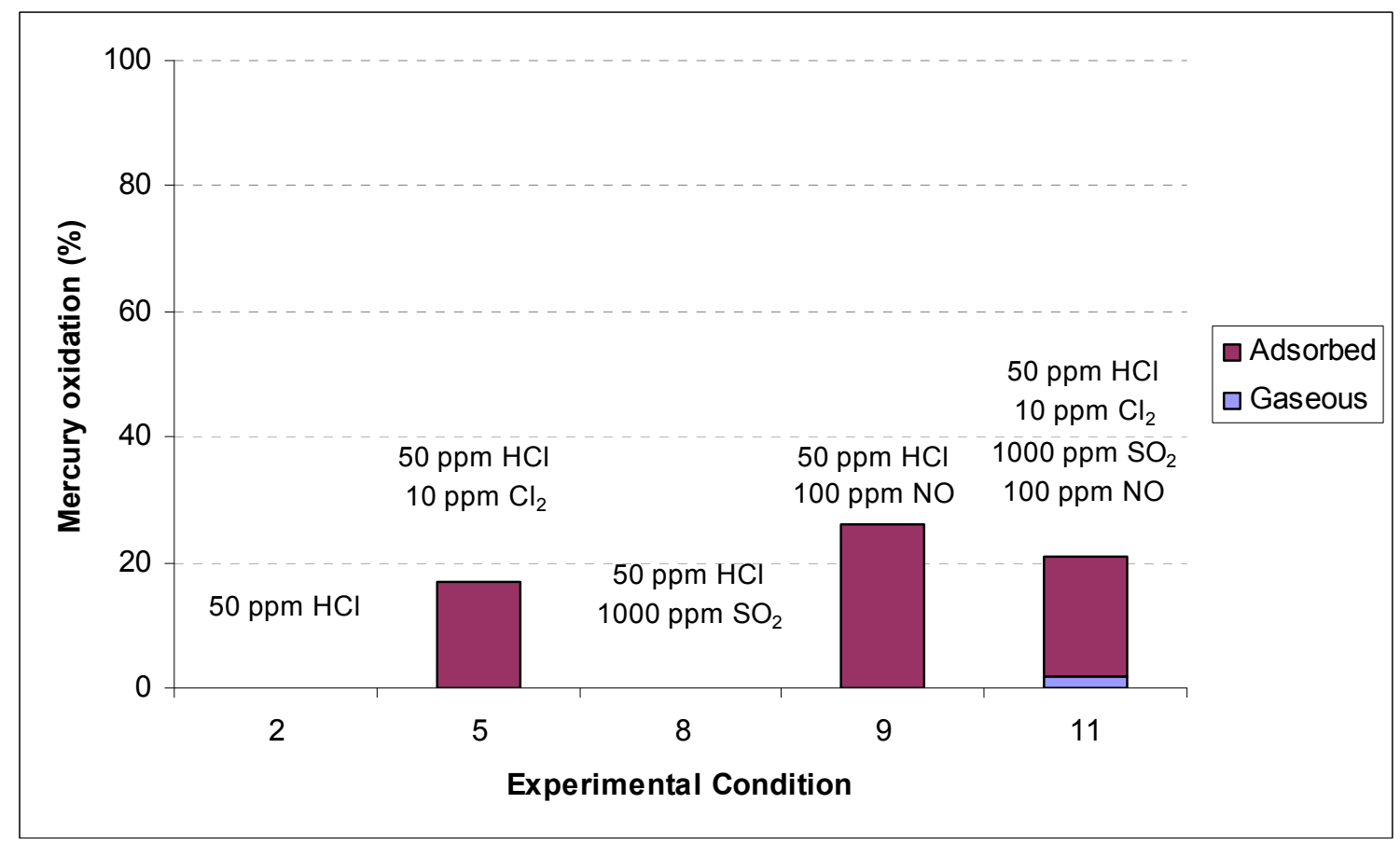

Figure 31: The effect of $\mathrm{HCl}$ on mercury oxidation for filter type $\mathrm{RY} 05$ coated with $\mathrm{TiO}_{2}$ (baseline gas is $4 \% \mathrm{O}_{2}, 10 \% \mathrm{H}_{2} \mathrm{O}, 20-30 \mu \mathrm{g} / \mathrm{m}^{3} \mathrm{Hg}^{0}$, and balance $\mathrm{N}_{2}$ )

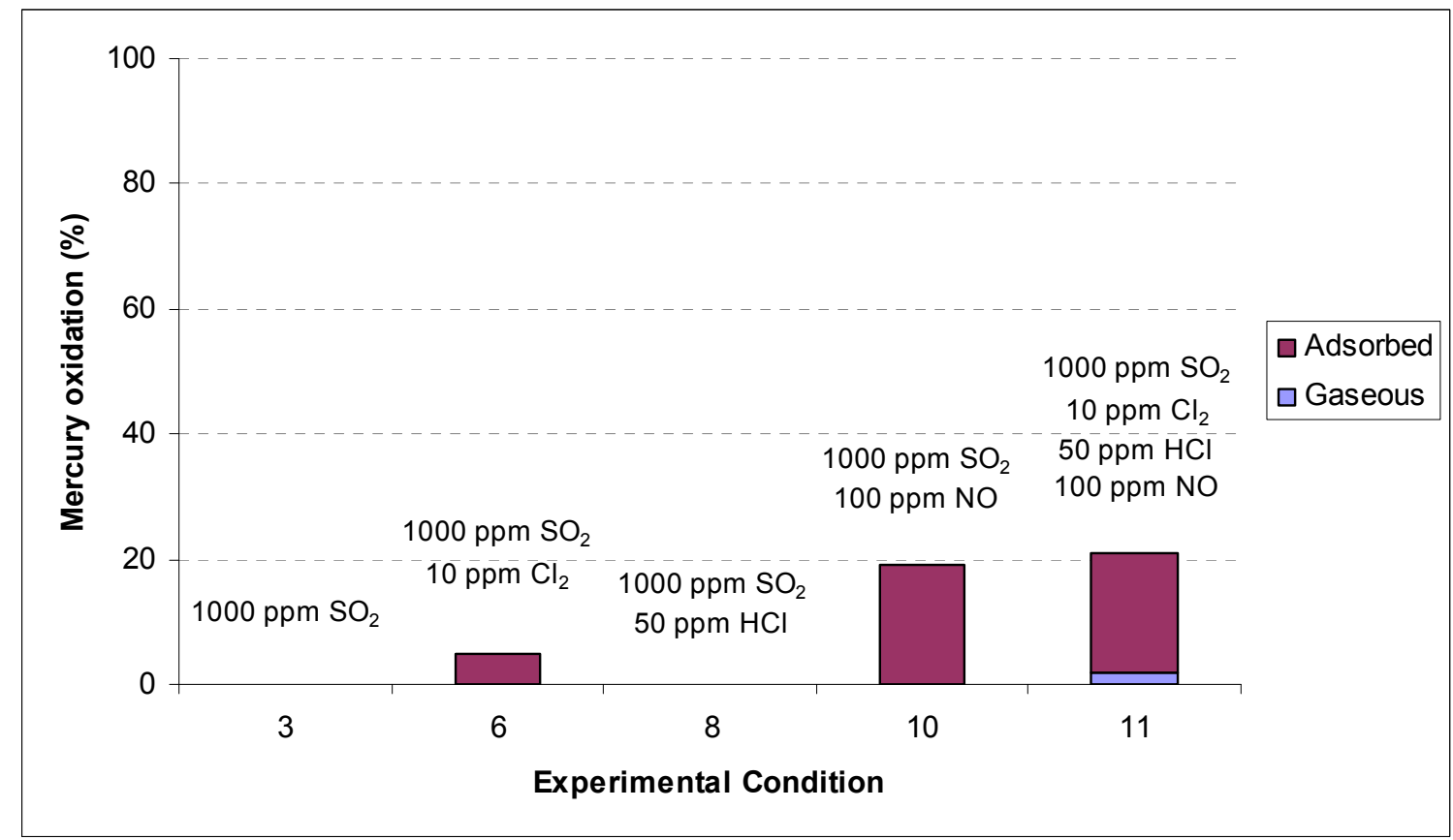

Figure 32: The effect of $\mathrm{SO}_{2}$ on mercury oxidation for filter type $\mathrm{RY} 805$ coated with $\mathrm{TiO}_{2}$ (baseline gas is $4 \% \mathrm{O}_{2}, 10 \% \mathrm{H}_{2} \mathrm{O}, 20-30 \mu \mathrm{g} / \mathrm{m}^{3} \mathrm{Hg}^{0}$, and balance $\mathrm{N}_{2}$ ) 


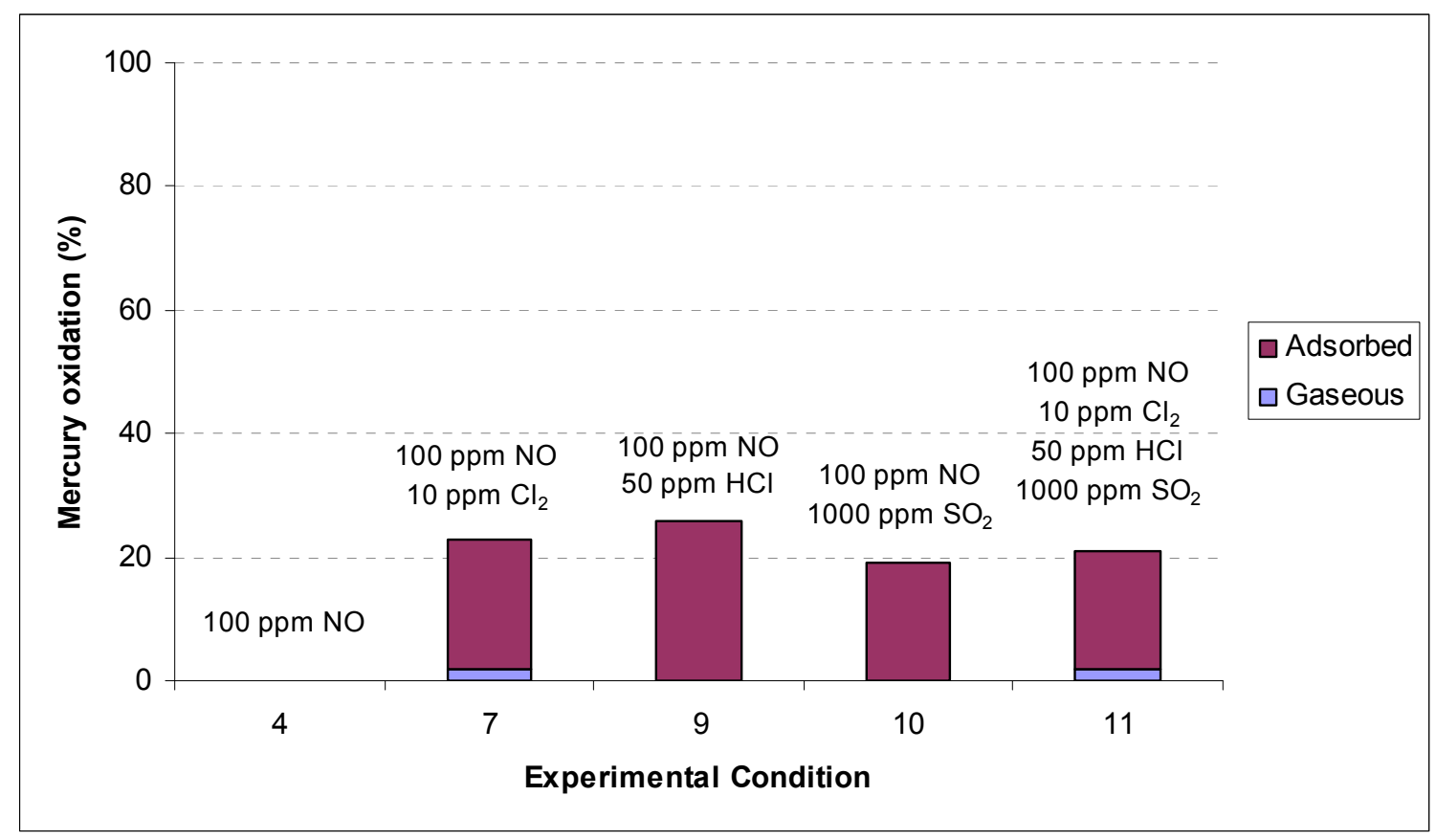

Figure 33: The effect of $\mathrm{NO}$ on mercury oxidation for filter type RY805 coated with $\mathrm{TiO}_{2}$ (baseline gas is $4 \% \mathrm{O}_{2}, 10 \% \mathrm{H}_{2} \mathrm{O}, 20-30 \mu \mathrm{g} / \mathrm{m}^{3} \mathrm{Hg}^{0}$, and balance $\mathrm{N}_{2}$ )

Table 7: Results for filter type RY805 coated with $\mathrm{TiO}_{2}$ (baseline gas is $4 \% \mathrm{O}_{2}, 10 \% \mathrm{H}_{2} \mathrm{O}, 20-30 \mu \mathrm{g} / \mathrm{m}^{3} \mathrm{Hg}^{0}$, and balance $\mathrm{N}_{2}$ )

\begin{tabular}{|c|c|c|c|c|c|}
\hline Condition & $\mathrm{Cl}_{2}(\mathrm{ppm})$ & $\mathrm{HCl}(\mathrm{ppm})$ & $\mathrm{SO}_{2}(\mathrm{ppm})$ & $\mathrm{NO}(\mathrm{ppm})$ & $\mathrm{Hg}$ oxidation (\%) \\
\hline 1 & 10 & & & & 20 \\
\hline 2 & & 50 & & & 0 \\
\hline 3 & & & 1000 & & 0 \\
\hline 4 & & & & 100 & 0 \\
\hline 5 & 10 & 50 & & & 5 \\
\hline 6 & 10 & & 1000 & & 23 \\
\hline 7 & 10 & & & 100 & 0 \\
\hline 8 & & 50 & 1000 & & 26 \\
\hline 9 & & 50 & & 100 & 19 \\
\hline 10 & & & 1000 & 100 & 21 \\
\hline 11 & 10 & 50 & 1000 & 100 & \\
\hline
\end{tabular}

\section{$\mathrm{Au} / \mathrm{TiO}_{2}$ on $\mathrm{RY} 805$}

Experiments were performed using $\mathrm{Au} / \mathrm{TiO}_{2}$ catalyst. $0.2 \mathrm{~g}$ of catalyst was applied to a $6 \mathrm{~cm}$ (2 inch nominal) diameter piece of type RY805 fabric, resulting in a catalyst loading rate of about $10 \mathrm{mg} / \mathrm{cm}^{2}$. Unlike $\mathrm{TiO}_{2}, \mathrm{Au} / \mathrm{TiO}_{2}$ first adsorbed a 
significant amount of total mercury during the baseline testing with $\mathrm{O}_{2}, \mathrm{H}_{2} \mathrm{O}, \mathrm{N}_{2}$, and $\mathrm{Hg}^{0}$. It took about one to two hours to reach the saturation point of the $\mathrm{Au} / \mathrm{TiO}_{2}$ catalyst. Once the reactor outlet concentration reached 90 percent of the inlet concentration, the desired acid gases were spiked accordingly.

Figure 34 shows the effect of $\mathrm{Cl}_{2}$ when mixed with combinations of the other gases. When $\mathrm{Cl}_{2}$ is added in the presence of gold, the rate of mercury oxidation is around 60 percent. When any of the other flue gas constituents were added with $\mathrm{Cl}_{2}$, the rate of oxidation remained around 60 percent. Previous research has shown that $\mathrm{NO}^{[41,46-48]}$ and $\mathrm{SO}_{2}{ }^{[15,21,47,48]}$ can play an inhibitory role in mercury oxidation. However, most previous research only considers homogenous mercury oxidation. The $\mathrm{Cl}_{2}$-gold interaction appears to be strong enough to overcome any inhibitory effects from $\mathrm{NO}$ and $\mathrm{SO}_{2}$. The extent of mercury oxidation with $\mathrm{Cl}_{2}$ and gold is similar to that found in a study by Zhao et al. ${ }^{[3]}$ The study by Zhao et al. also showed oxidation rates of about 60 percent with no significant inhibitory effects from $\mathrm{NO}$ and $\mathrm{SO}_{2}$.

Figures 35-37 show the results of testing with $\mathrm{Au} / \mathrm{TiO}_{2}$ for $\mathrm{HCl}, \mathrm{SO}_{2}$, and $\mathrm{NO}$, respectively. Without $\mathrm{Cl}_{2}$ present, only 10 to 15 percent mercury oxidation is achievable in all of the other conditions with one exception. When $\mathrm{HCl}$ and $\mathrm{NO}$ are present, experimental condition 9, the amount of oxidation increases to 40 percent. There appears to be a synergistic effect between $\mathrm{HCl}$ and $\mathrm{NO}$ in the presence of gold. 


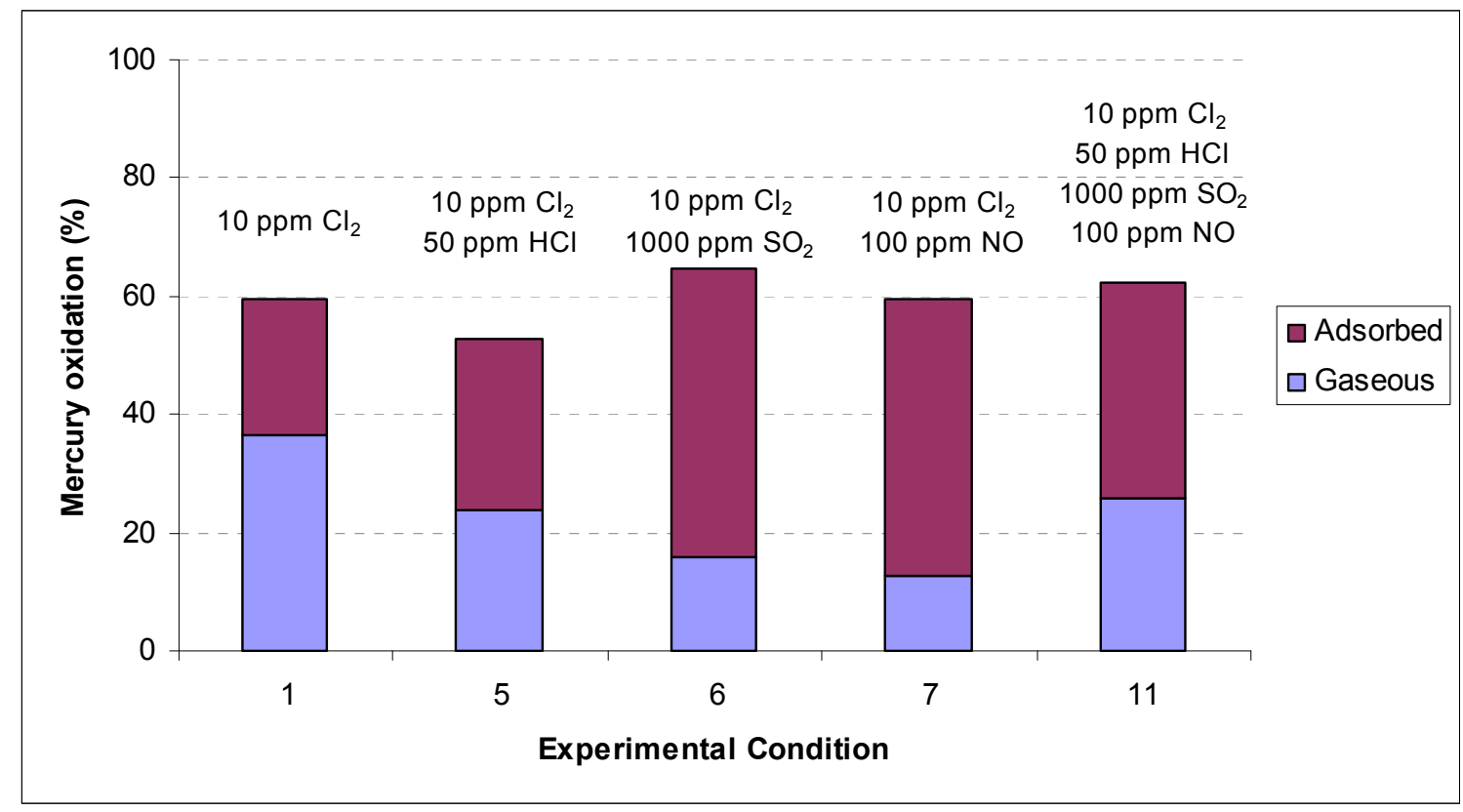

Figure 34: The effect of $\mathrm{Cl}_{2}$ on mercury oxidation for filter type $\mathrm{RY} 805$ coated with $\mathrm{Au} / \mathrm{TiO}_{2}$ (baseline gas is $4 \% \mathrm{O}_{2}, 10 \% \mathrm{H}_{2} \mathrm{O}, 20-30 \mu \mathrm{g} / \mathrm{m}^{3} \mathrm{Hg}^{0}$, and balance $\mathrm{N}_{2}$ )

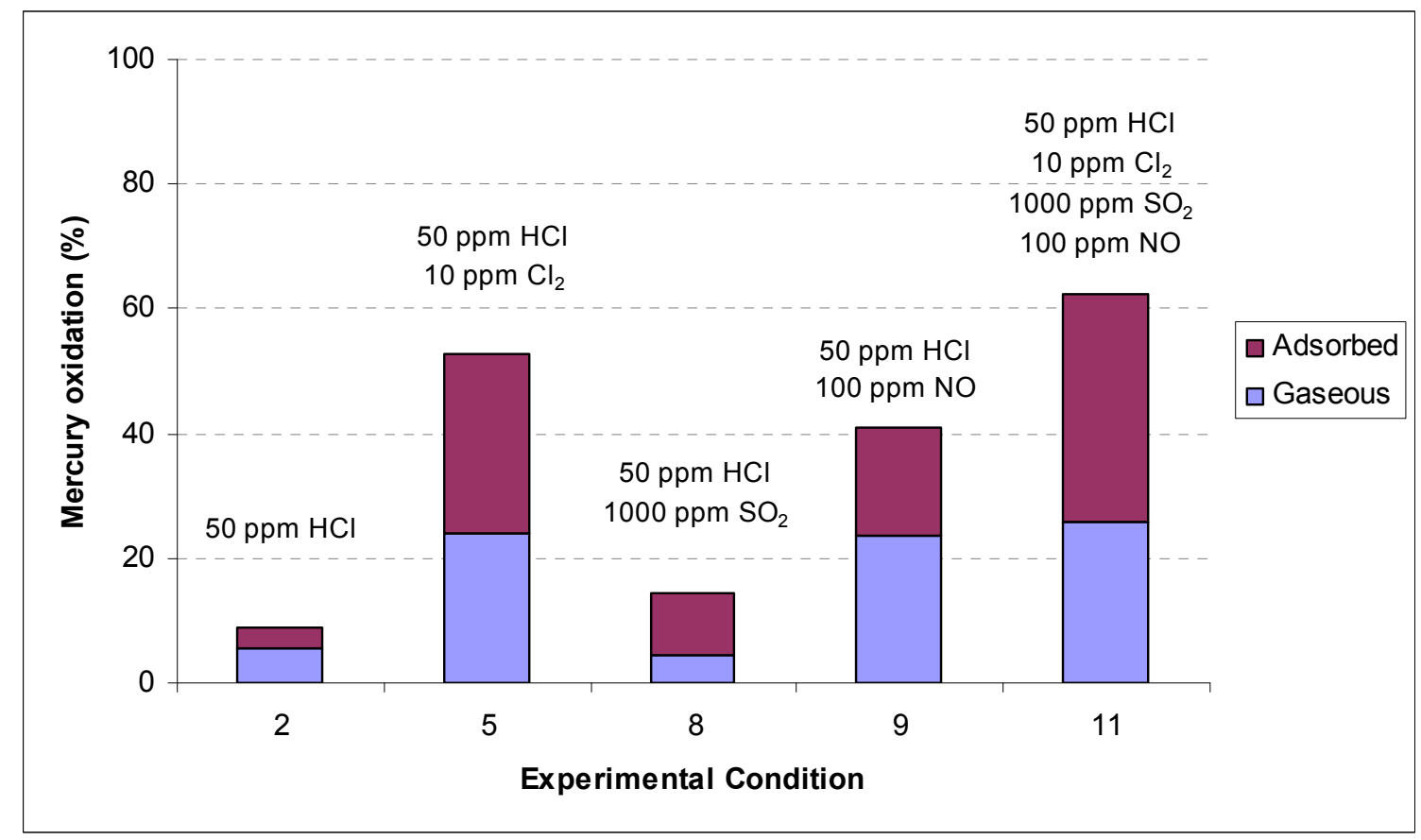

Figure 35: The effect of $\mathrm{HCl}$ on mercury oxidation for filter type $\mathrm{RY} 805$ coated with $\mathrm{Au} / \mathrm{TiO}{ }_{2}$ (baseline gas is $4 \% \mathrm{O}_{2}, 10 \% \mathrm{H}_{2} \mathrm{O}, 20-30 \mu \mathrm{g} / \mathrm{m}^{3} \mathrm{Hg}^{0}$, and balance $\mathrm{N}_{2}$ ) 


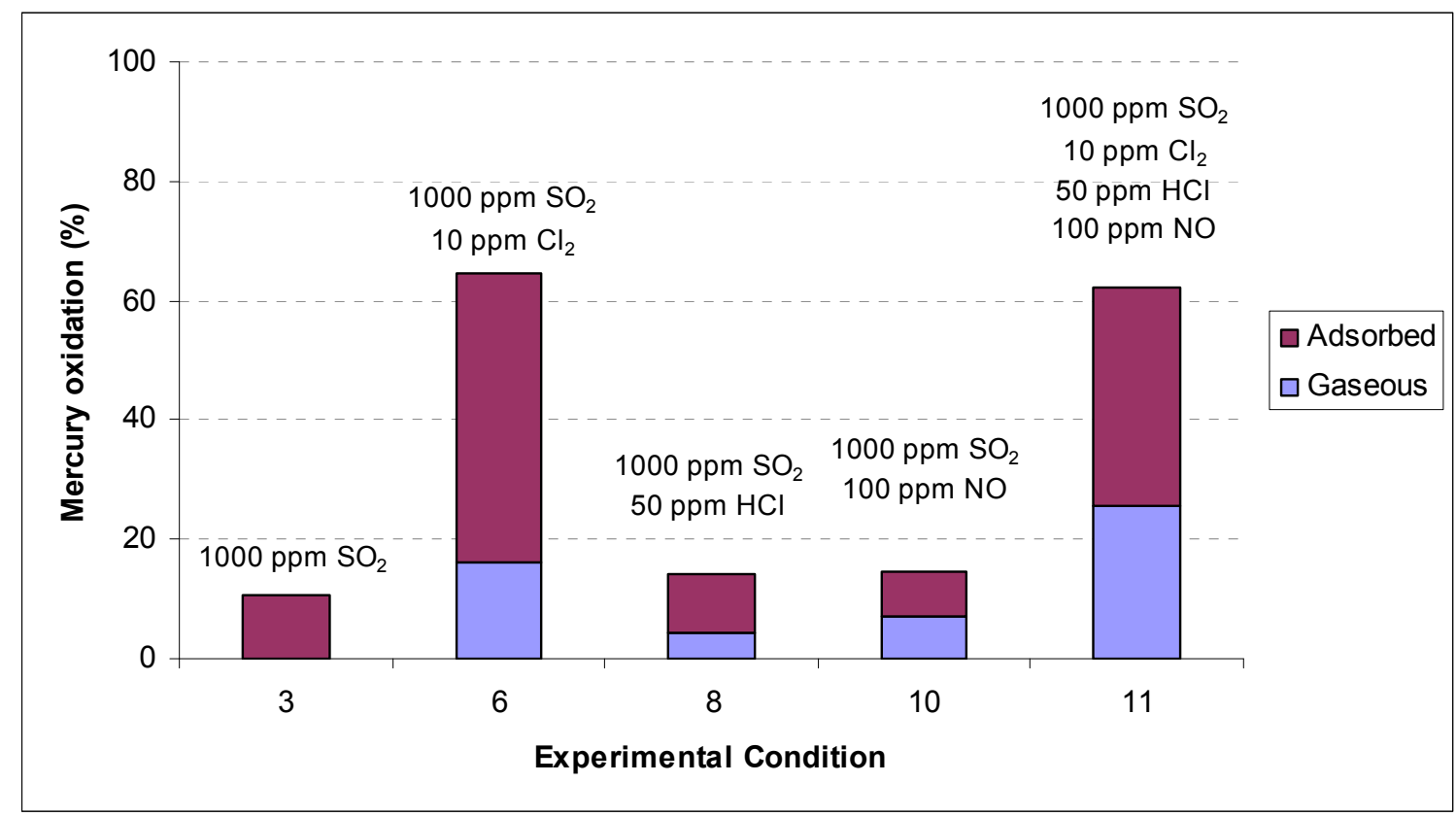

Figure 36: The effect of $\mathrm{SO}_{2}$ on mercury oxidation for filter type $\mathrm{RY} 805$ coated with $\mathrm{Au} / \mathrm{TiO}_{2}$ (baseline gas is $4 \% \mathrm{O}_{2}, 10 \% \mathrm{H}_{2} \mathrm{O}, 20-30 \mu \mathrm{g} / \mathrm{m}^{3} \mathrm{Hg}^{0}$, and balance $\mathrm{N}_{2}$ )

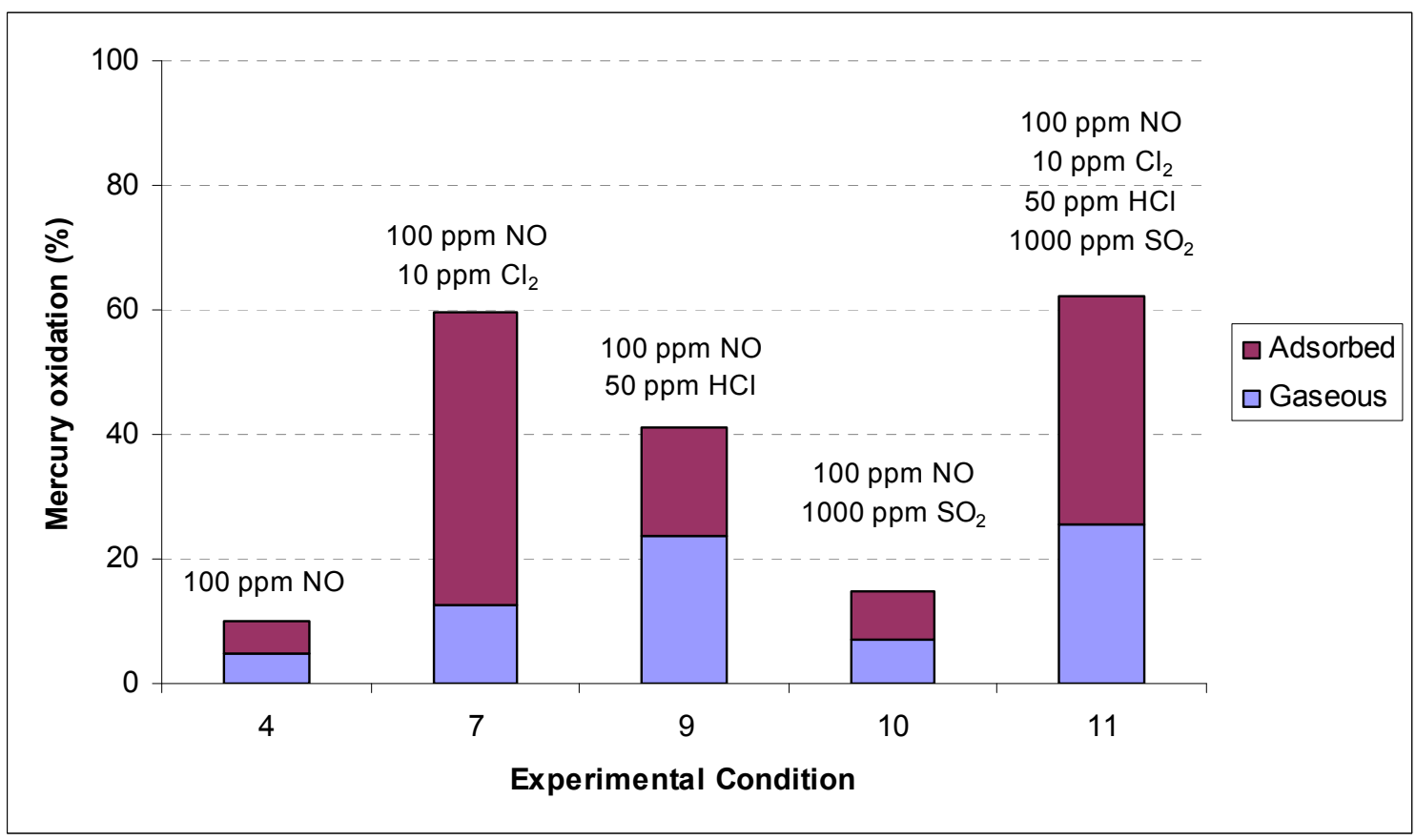

Figure 37: The effect of $\mathrm{NO}$ on mercury oxidation for filter type $\mathrm{RY} 805$ coated with $\mathrm{Au} / \mathrm{TiO}_{2}$ (baseline gas is $4 \% \mathrm{O}_{2}, 10 \% \mathrm{H}_{2} \mathrm{O}, 20-30 \mu \mathrm{g} / \mathrm{m}^{3} \mathrm{Hg}^{0}$, and balance $\mathrm{N}_{2}$ ) 
A similar effect is found in a study done by Norton et al. ${ }^{[46]}$ This study shows an increase in oxidized mercury when both $\mathrm{HCl}$ and $\mathrm{NO}$ are present along with fly ash. The study by Norton et al. found that this interaction was significant. Table 8 summarizes the $\mathrm{Au} / \mathrm{TiO}_{2}$ results.

$\mathrm{Pd} / \mathrm{Al}_{2} \mathrm{O}_{3}$ on $\mathrm{RY} 805$

Experiments were performed using $0.05 \mathrm{~g}$ of $\mathrm{Pd} / \mathrm{Al}_{2} \mathrm{O}_{3}$ catalyst applied to a $6 \mathrm{~cm}$ (2 inch nominal) diameter piece of fabric (type RY805). The resulting catalyst loading rate was about $2.5 \mathrm{mg} / \mathrm{cm}^{2}$. A lower catalyst loading was used for this catalyst because of the large amount of mercury that can be adsorbed by palladium. Using a larger amount of catalyst requires a significant amount of time to reach saturation. Similar to $\mathrm{Au} / \mathrm{TiO}_{2}$, a significant amount of mercury was adsorbed during the baseline testing with $\mathrm{O}_{2}, \mathrm{H}_{2} \mathrm{O}$, $\mathrm{N}_{2}$, and $\mathrm{Hg}^{0}$. It took two to four hours to reach the saturation point of the $\mathrm{Pd} / \mathrm{Al}_{2} \mathrm{O}_{3}$ catalyst. Once the reactor outlet concentration reached 90 percent of the inlet concentration, the desired acid gases were spiked accordingly.

Table 8: Results for filter type RY805 coated with $\mathrm{Au} / \mathrm{TiO}_{2}$ (baseline gas is $4 \% \mathrm{O}_{2}, 10 \% \mathrm{H}_{2} \mathrm{O}, 20-30 \mu \mathrm{g} / \mathrm{m}^{3} \mathrm{Hg}^{0}$, and balance $\mathrm{N}_{2}$ )

\begin{tabular}{|c|c|c|c|c|c|}
\hline Condition & $\mathrm{Cl}_{2}(\mathrm{ppm})$ & $\mathrm{HCl}(\mathrm{ppm})$ & $\mathrm{SO}_{2}(\mathrm{ppm})$ & $\mathrm{NO}(\mathrm{ppm})$ & $\mathrm{Hg}$ oxidation (\%) \\
\hline 1 & 10 & & & & 60 \\
\hline 2 & & 50 & & & 9 \\
\hline 3 & & & 1000 & & 11 \\
\hline 4 & & & & 100 & 10 \\
\hline 5 & 10 & 50 & & & 53 \\
\hline 6 & 10 & & 1000 & & 65 \\
\hline 7 & 10 & & & 100 & 60 \\
\hline 8 & & 50 & 1000 & & 14 \\
\hline 9 & & 50 & & 100 & 41 \\
\hline 10 & & & 1000 & 100 & 15 \\
\hline 11 & 10 & 50 & 1000 & 100 & 62 \\
\hline
\end{tabular}


Figure 38 shows the effect of $\mathrm{Cl}_{2}$ on mercury oxidation using $\mathrm{Pd} / \mathrm{Al}_{2} \mathrm{O}_{3}$. Similar to $\mathrm{Au} / \mathrm{TiO}_{2}, 60$ percent oxidation was obtained when $\mathrm{Cl}_{2}$ was added. However, there is also a significant increase in mercury oxidation when $\mathrm{SO}_{2}$ is added in the presence of $\mathrm{Cl}_{2}$ (oxidation increases to above 80 percent). Thus there is a probable synergistic effect between $\mathrm{Cl}_{2}$ and $\mathrm{SO}_{2}$ in the presence of palladium, although the activity of palladium might also be increased by the addition of $\mathrm{SO}_{2}$. Figure 39 shows the increased mercury oxidation that occurs when $\mathrm{SO}_{2}$ and $\mathrm{Cl}_{2}$ are added in the presence of $\mathrm{Pd} / \mathrm{Al}_{2} \mathrm{O}_{3}$.

Figure 39 also shows mercury concentrations above the spiked level. This is observed at various conditions for all of the catalysts. This increase is due to the desorption of mercury previously adsorbed by the catalyst during that particular experiment.

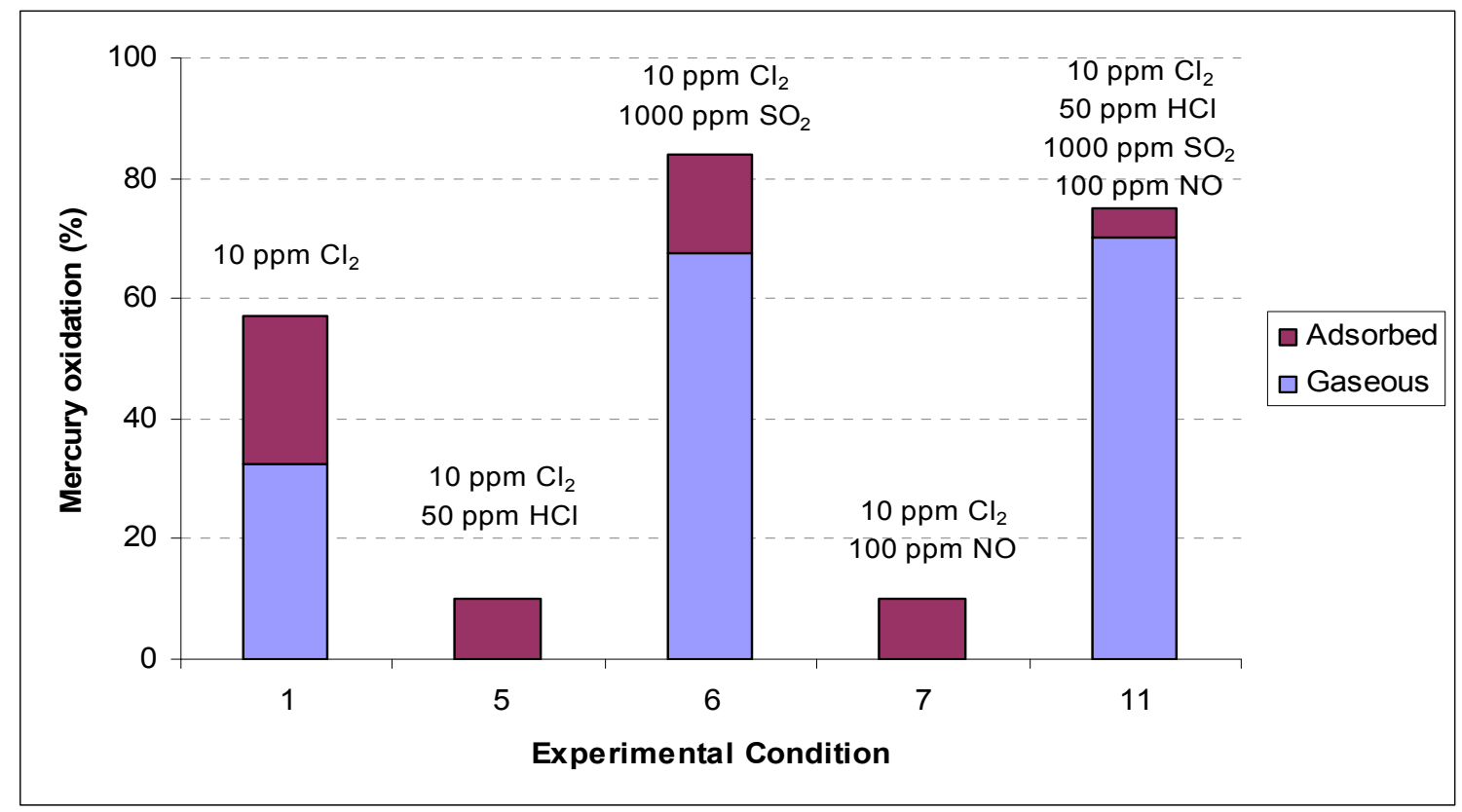

Figure 38: The effect of $\mathrm{Cl}_{2}$ on mercury oxidation using filter type $\mathrm{RY} 805$ coated with $\mathrm{Pd} / \mathrm{Al}_{2} \mathrm{O}_{3}$ (baseline gas is $4 \% \mathrm{O}_{2}, 10 \% \mathrm{H}_{2} \mathrm{O}, 20-30 \mu \mathrm{g} / \mathrm{m}^{3} \mathrm{Hg}^{0}$, and balance $\mathrm{N}_{2}$ ) 


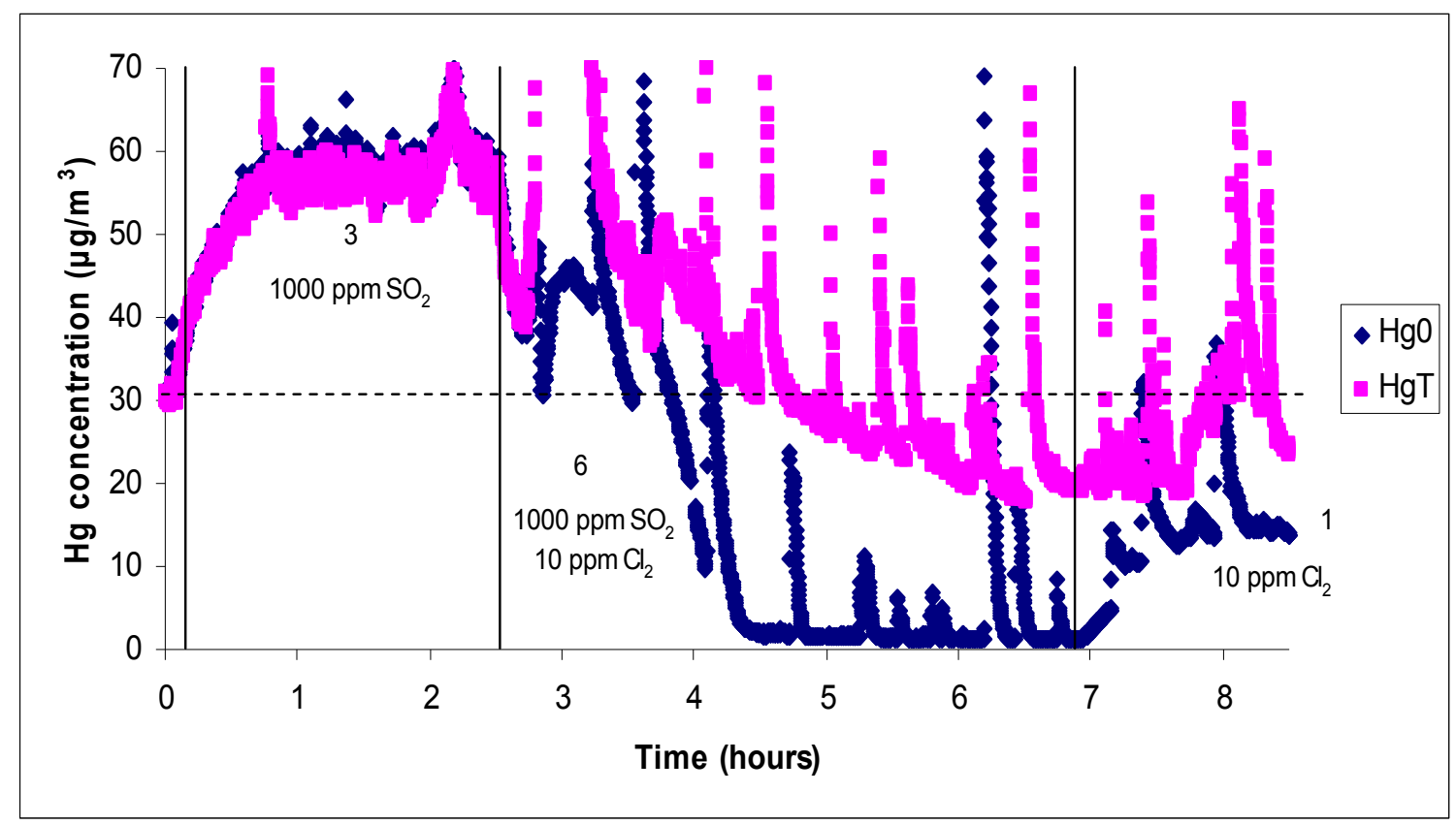

Figure 39: Oxidation promotion by $\mathrm{SO}_{2}$ in the presence of $\mathrm{Cl}_{2}$ and $\mathrm{Pd} / \mathrm{Al}_{2} \mathrm{O}_{3}$ (filter type $\mathrm{RY} 805$ )

Experimental conditions 5 and 7 (Figure 38) gave unusual results. The observed amounts of oxidation are much lower than expected because the elemental mercury concentration is higher than the total mercury concentration. Figures 40 and 41 show the unusual trends for $\mathrm{Cl}_{2}$ and $\mathrm{HCl}$, and $\mathrm{Cl}_{2}$ and $\mathrm{NO}$, respectively. It was first thought that these results were due to experimental artifacts. However, these conditions were duplicated in random succession and the same unusual trend was observed. One possible reason for the high levels of elemental mercury is due to the reduction of oxidized mercury in the elemental mercury conditioning solution. Fry ${ }^{[58]}$ et al. found that $\mathrm{SO}_{2}$ and $\mathrm{NO}$ can significantly reduce oxidized mercury in the $\mathrm{KCl}$ solution of the conditioning system. The newly formed elemental mercury is then released from solution resulting in high levels of elemental mercury. 


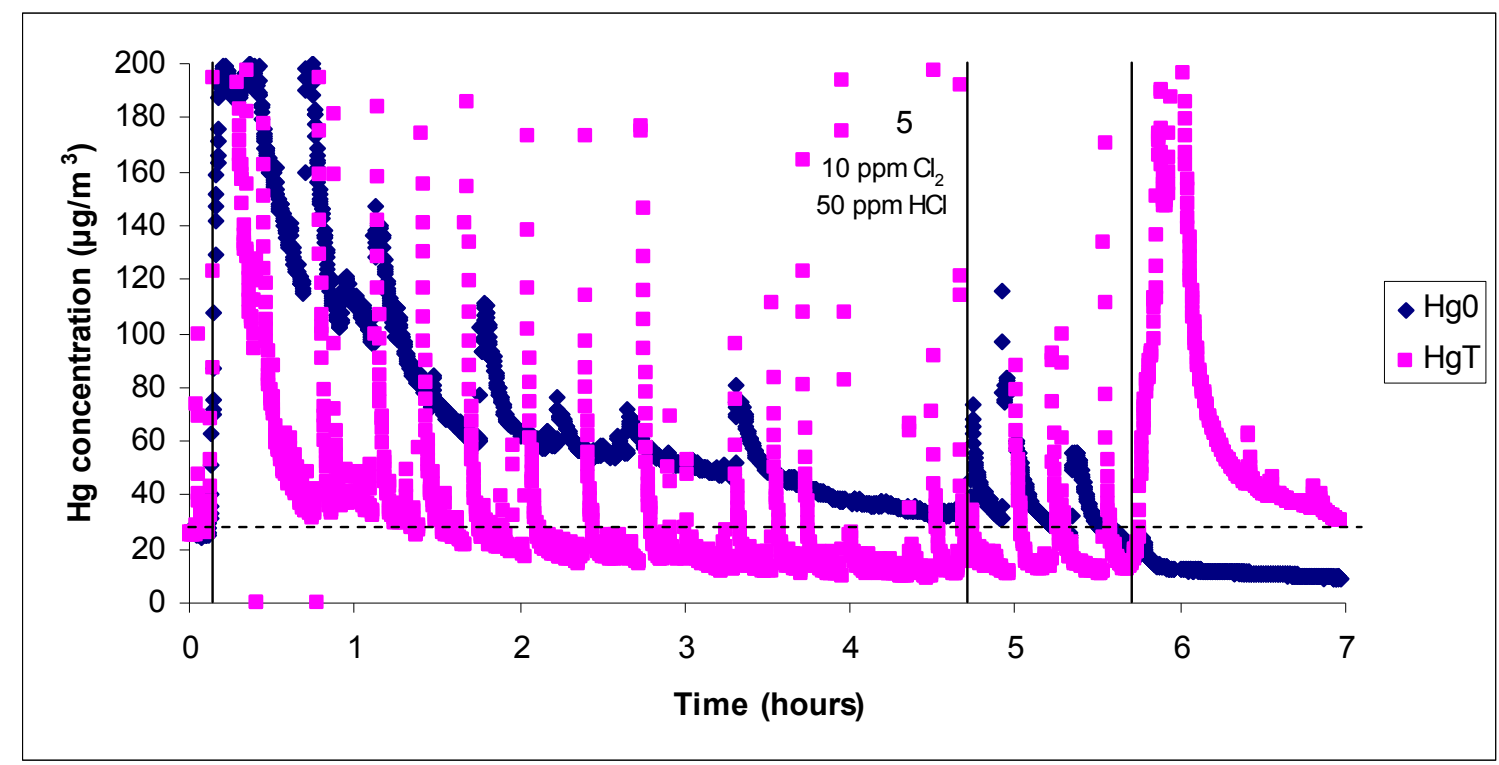

Figure 40: Spike in elemental mercury concentration with $\mathrm{Cl}_{2}$ and $\mathrm{HCl}$ addition using filter type $\mathrm{RY} 805$ coated with $\mathrm{Pd} / \mathrm{Al}_{2} \mathrm{O}_{3}$

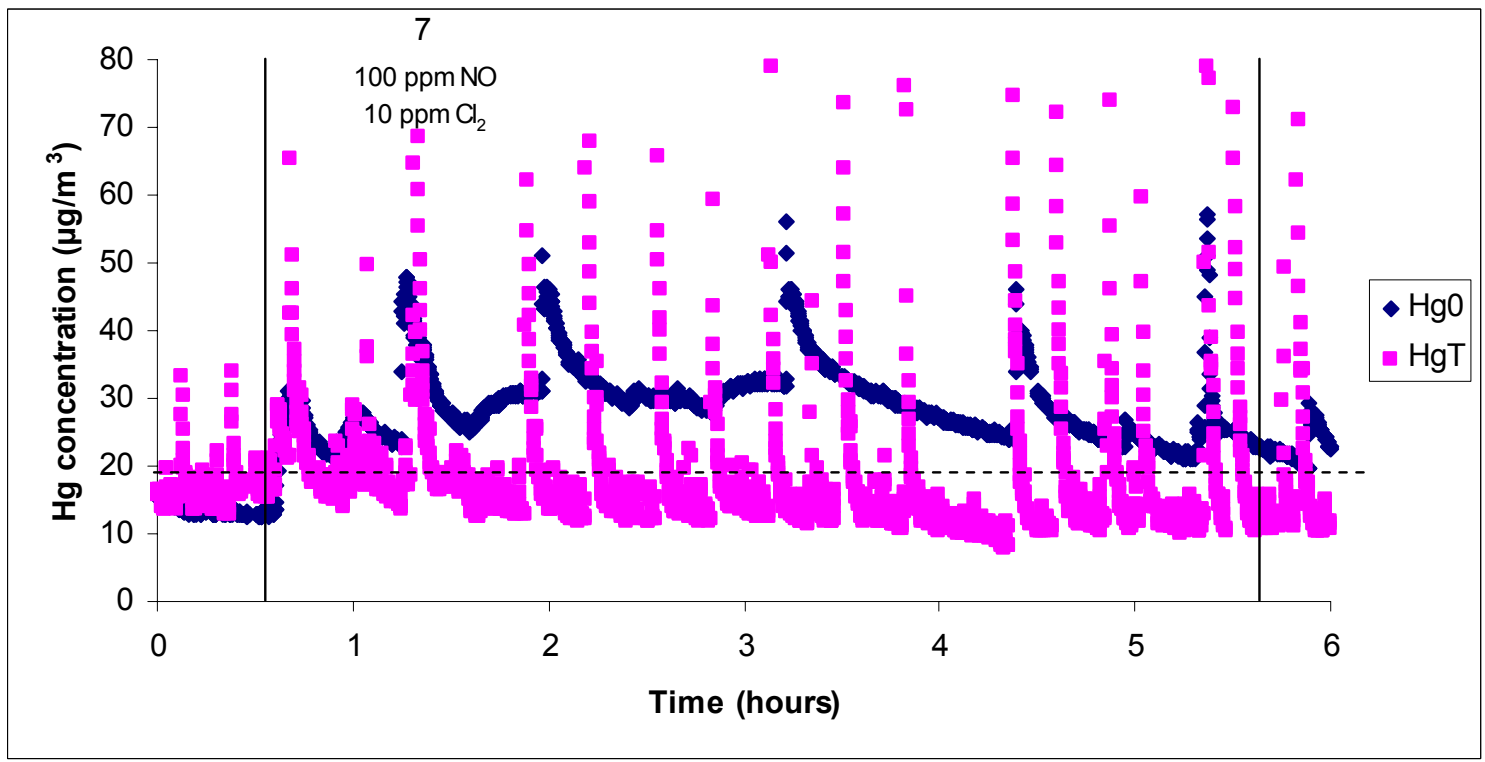

Figure 41: Spike in elemental mercury concentration with $\mathrm{Cl}_{2}$ and $\mathrm{NO}$ addition using filter type $\mathrm{RY} 805$ coated with $\mathrm{Pd} / \mathrm{Al}_{2} \mathrm{O}_{3}$

There may be a similar phenomenon occurring in this research when $\mathrm{Cl}_{2}$ and $\mathrm{HCl}$ or $\mathrm{Cl}_{2}$ and $\mathrm{NO}$ are added to the $\mathrm{KCl}$ solution. This observation, however, is specific to $\mathrm{Pd} / \mathrm{Al}_{2} \mathrm{O}_{3}$ as it was not witnessed when using $\mathrm{TiO}_{2}$ or $\mathrm{Au} / \mathrm{TiO}_{2}$. There may be a specific 
mercury or chlorine containing species formed on the $\mathrm{Pd} / \mathrm{Al}_{2} \mathrm{O}_{3}$ surface that is causing this phenomenon to occur. However, at least 50 percent mercury oxidation is expected for these two conditions due to adsorbed oxidized mercury. This is determined from the difference of total mercury concentration and the baseline mercury concentration.

The effects of $\mathrm{HCl}, \mathrm{SO}_{2}$, and $\mathrm{NO}$ are shown in Figures 42-44, respectively. The synergistic effect between $\mathrm{HCl}$ and $\mathrm{NO}$ (experimental condition 9, Figure 42) is also seen with $\mathrm{Pd} / \mathrm{Al}_{2} \mathrm{O}_{3}$ as it was with $\mathrm{Au} / \mathrm{TiO}_{2}$. Figure 43 shows the increased mercury oxidation rates due to the promotion of oxidation by $\mathrm{SO}_{2}$, which is likely due to increased catalytic activity. Table 9 summarizes the $\mathrm{Pd} / \mathrm{Al}_{2} \mathrm{O}_{3}$ results.

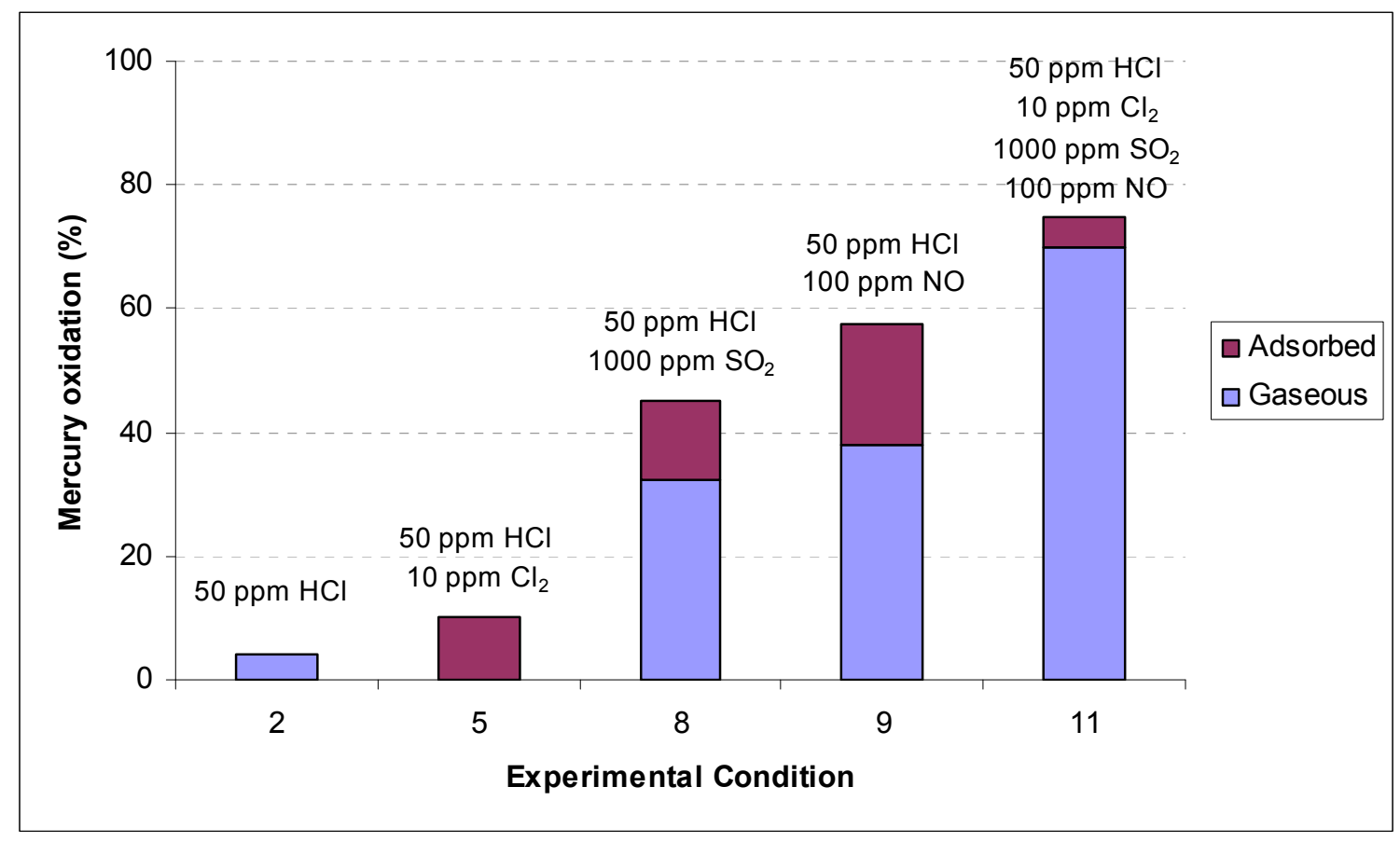

Figure 42: The effect of $\mathrm{HCl}$ on mercury oxidation using filter type $\mathrm{RY} 805$ coated with $\mathrm{Pd} / \mathrm{Al}_{2} \mathrm{O}_{3}$ (baseline gas is $4 \% \mathrm{O}_{2}, 10 \% \mathrm{H}_{2} \mathrm{O}, 20-30 \mu \mathrm{g} / \mathrm{m}^{3} \mathrm{Hg}^{0}$, and balance $\mathrm{N}_{2}$ ) 


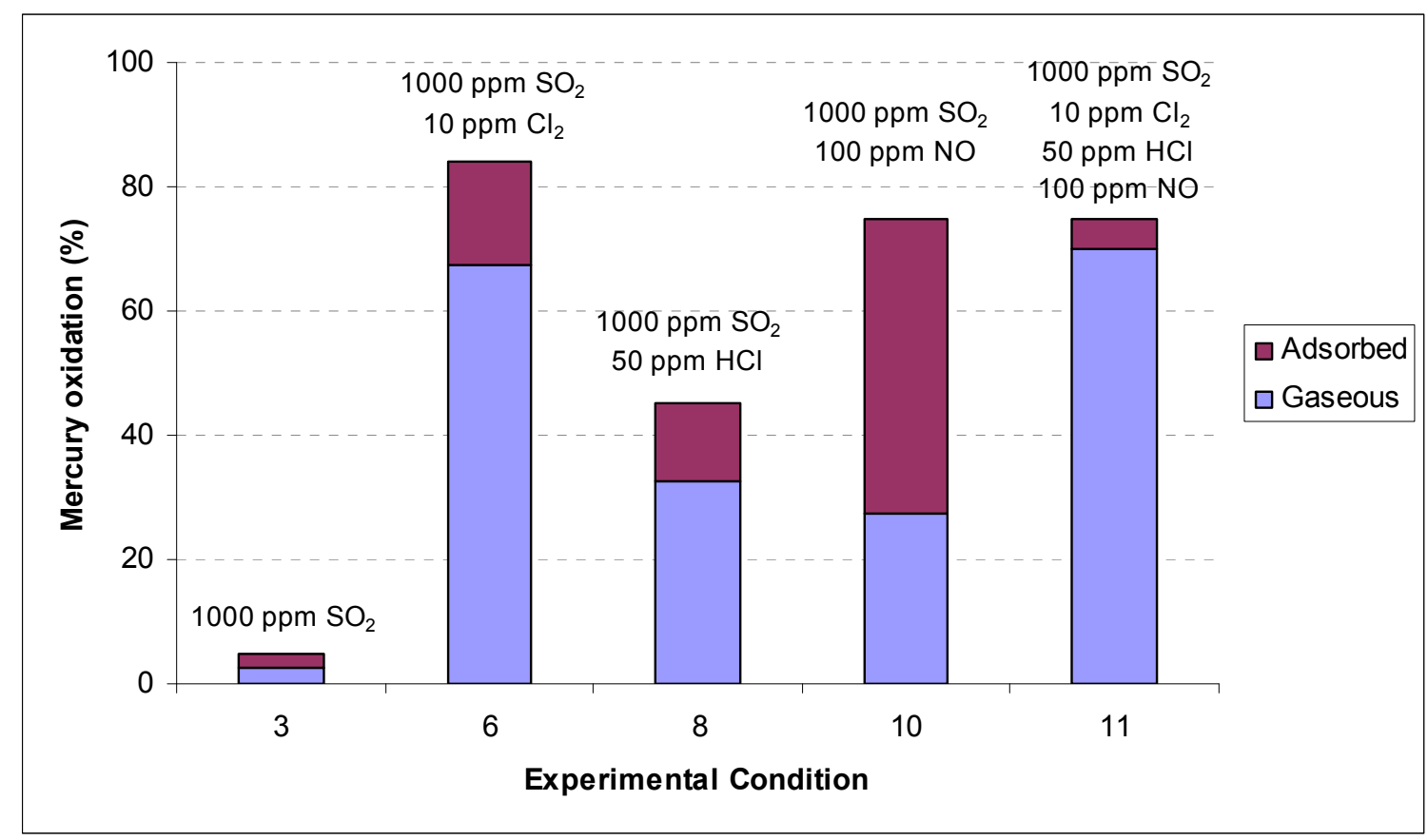

Figure 43: The effect of $\mathrm{SO}_{2}$ on mercury oxidation using filter type $\mathrm{RY} 805$ coated with $\mathrm{Pd} / \mathrm{Al}_{2} \mathrm{O}_{3}$ (baseline gas is $4 \% \mathrm{O}_{2}, 10 \% \mathrm{H}_{2} \mathrm{O}, 20-30 \mu \mathrm{g} / \mathrm{m}^{3} \mathrm{Hg}^{0}$, and balance $\mathrm{N}_{2}$ )

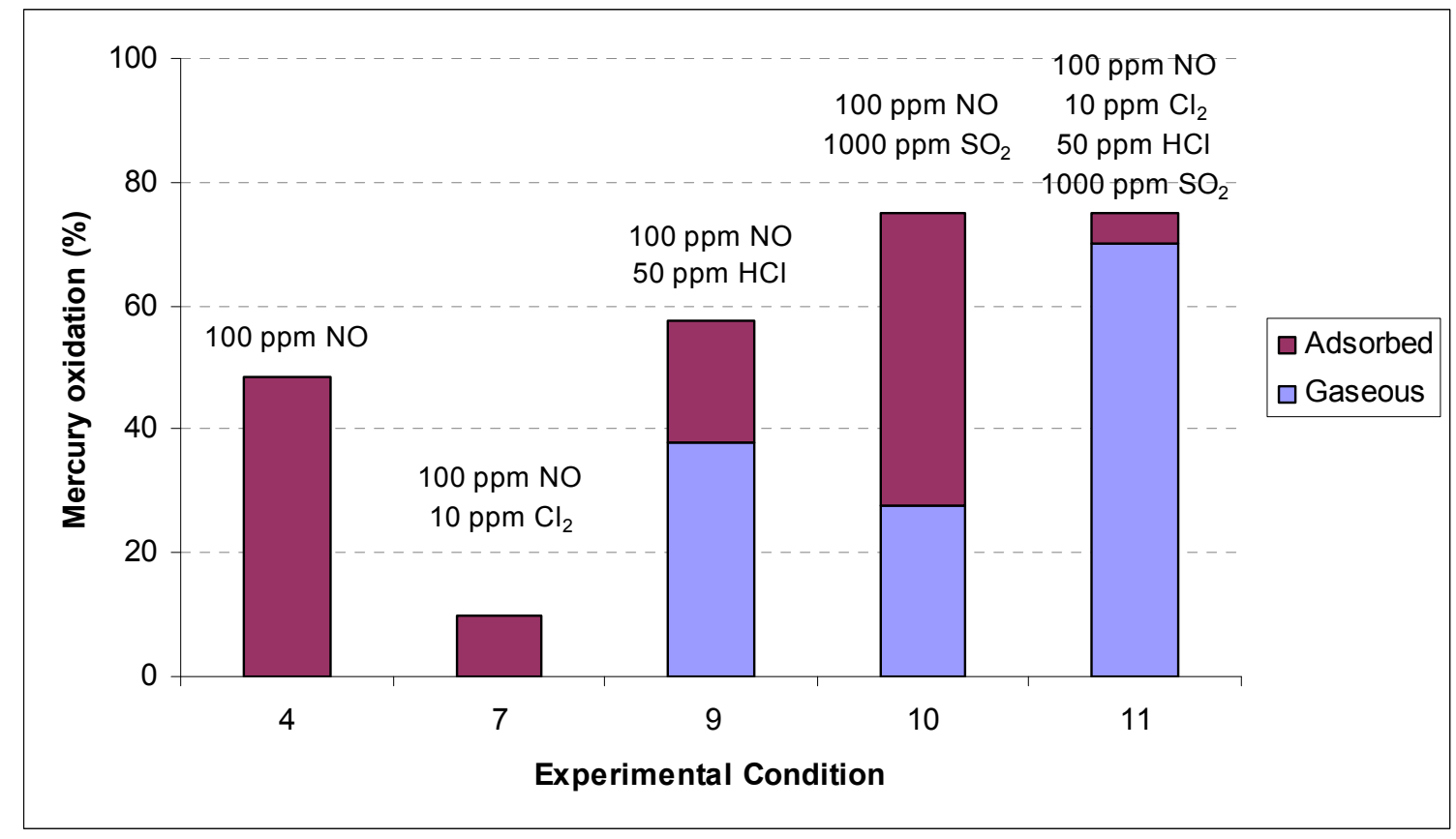

Figure 44: The effect of $\mathrm{NO}$ on mercury oxidation using filter type $\mathrm{RY} 805$ coated with $\mathrm{Pd} / \mathrm{Al}_{2} \mathrm{O}_{3}$ (baseline gas is $4 \% \mathrm{O}_{2}, 10 \% \mathrm{H}_{2} \mathrm{O}, 20-30 \mu \mathrm{g} / \mathrm{m}^{3} \mathrm{Hg}^{0}$, and balance $\mathrm{N}_{2}$ ) 
Table 9: Results for filter type $\mathrm{RY} 805$ coated with $\mathrm{Pd} / \mathrm{Al}_{2} \mathrm{O}_{3}$

(Baseline gas is $4 \% \mathrm{O}_{2}, 10 \% \mathrm{H}_{2} \mathrm{O}, 20-30 \mu \mathrm{g} / \mathrm{m}^{3} \mathrm{Hg}^{0}$, and balance $\mathrm{N}_{2}$ )

\begin{tabular}{|c|c|c|c|c|c|}
\hline Condition & $\mathrm{Cl}_{2}(\mathrm{ppm})$ & $\mathrm{HCl}(\mathrm{ppm})$ & $\mathrm{SO}_{2}(\mathrm{ppm})$ & $\mathrm{NO}(\mathrm{ppm})$ & $\mathrm{Hg}$ oxidation (\%) \\
\hline 1 & 10 & & & & 57 \\
\hline 2 & & 50 & & & 4 \\
\hline 3 & & & 1000 & & 5 \\
\hline 4 & & & & 100 & 49 \\
\hline 5 & 10 & 50 & & & 84 \\
\hline 6 & 10 & & 1000 & & 10 \\
\hline 7 & 10 & & & 100 & 45 \\
\hline 8 & & 50 & 1000 & & 58 \\
\hline 9 & & 50 & & 100 & 75 \\
\hline 10 & & & 1000 & 100 & 75 \\
\hline 11 & 10 & 50 & 1000 & 100 & \\
\hline
\end{tabular}

\section{Comparison of Catalysts}

Three catalysts were considered for mercury oxidation in this bench-scale testing.

Figures 45 and 46 show the levels of mercury oxidation achieved for each of the catalysts at each experimental condition. $\mathrm{Pd} / \mathrm{Al}_{2} \mathrm{O}_{3}$ performed the best at each of the conditions with the exception of conditions 5 and 7. These conditions produced unusual trends as discussed above.

None of the catalysts performed particularly well in the presence of $\mathrm{HCl}$ or $\mathrm{SO}_{2}$, experimental conditions 2 and 3, respectively. $\mathrm{Au} / \mathrm{TiO}_{2}$ is a promising catalyst in the presence of $\mathrm{Cl}_{2}$, otherwise it does not oxidize a significant amount of mercury, with the exception of experimental condition 9 in the presence of $\mathrm{HCl}$ and $\mathrm{NO}$. $\mathrm{TiO}_{2}$ itself does not oxidize an appreciable amount of mercury at any condition. 


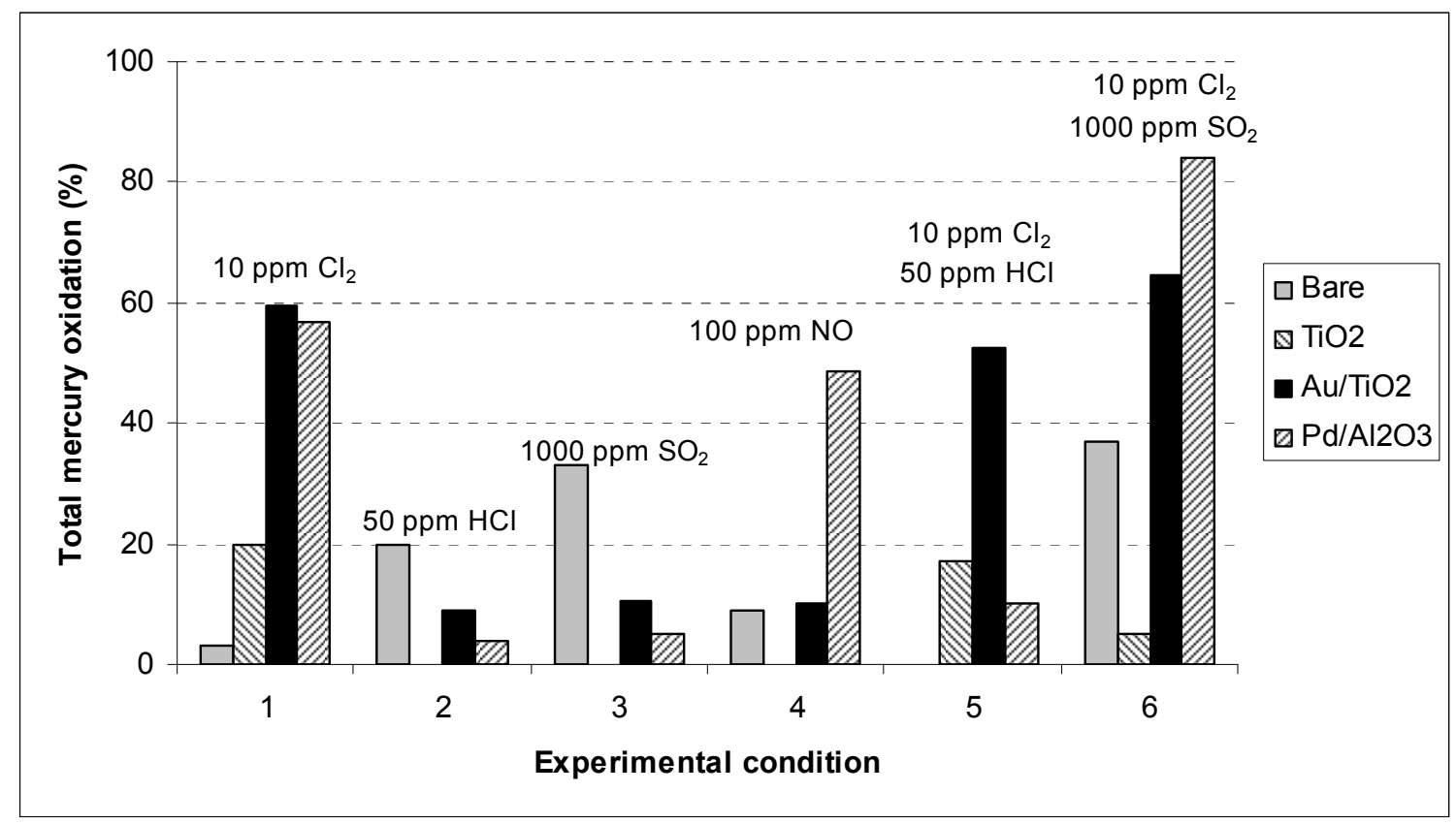

Figure 45: A comparison of mercury oxidation achieved for the three study catalysts under experimental conditions 1-6

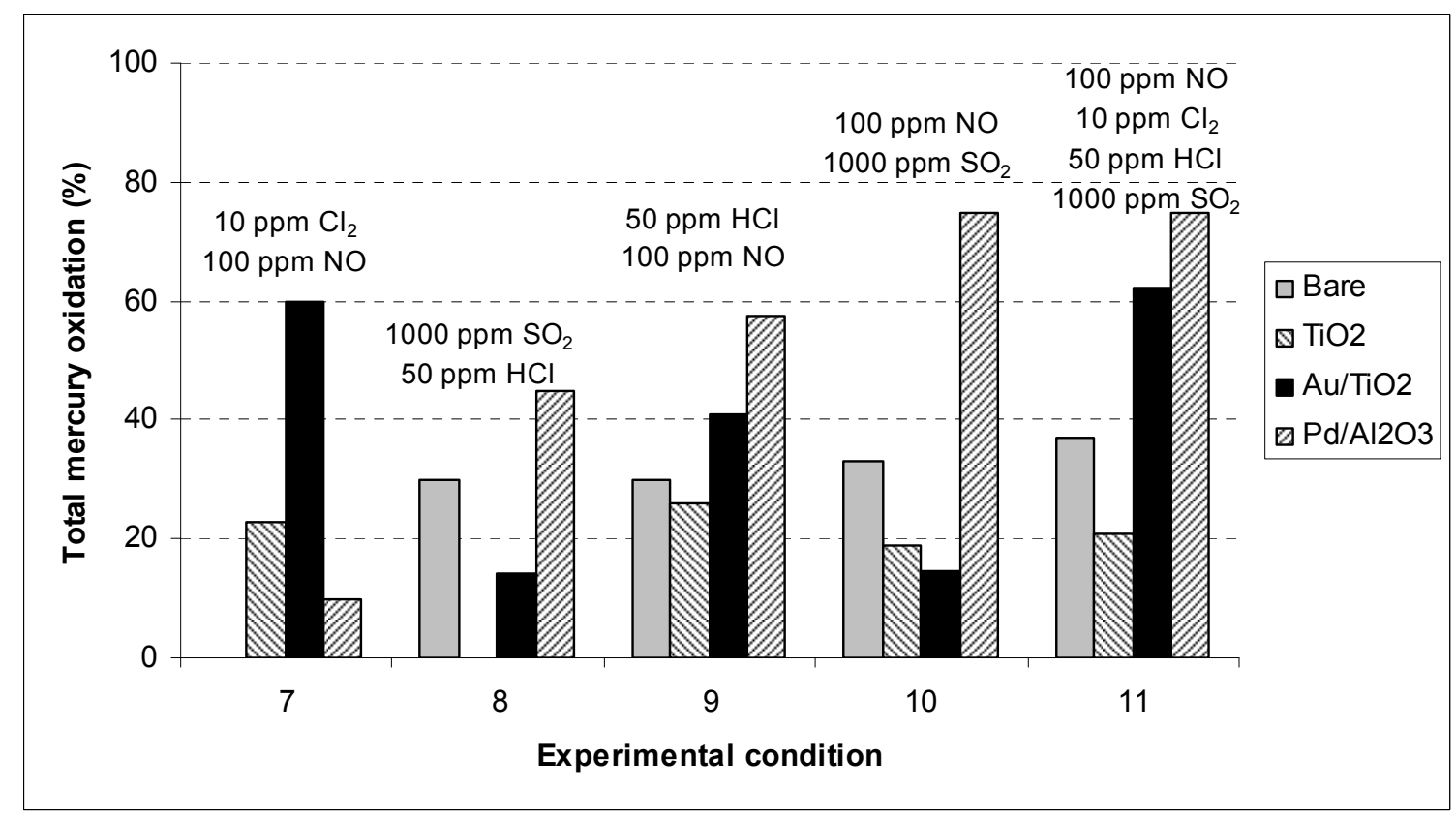

Figure 46: A comparison of mercury oxidation achieved for the three study catalysts under experimental conditions 7-11 


\section{Comparison of Filter Types}

Two types of filters were recommended by the manufacturer for use in this project. Filter type RY805 was used exclusively throughout the bench-scale study. Filter type PC012 is the type that the manufacturer prepared for use in the small pilot-scale study for this project. To test for any difference in bag type, a small set of random tests were performed using the $\mathrm{Au} / \mathrm{TiO}_{2}$ catalyst at the bench-scale using PC012. Figure 47 shows a comparison of the two filter types.

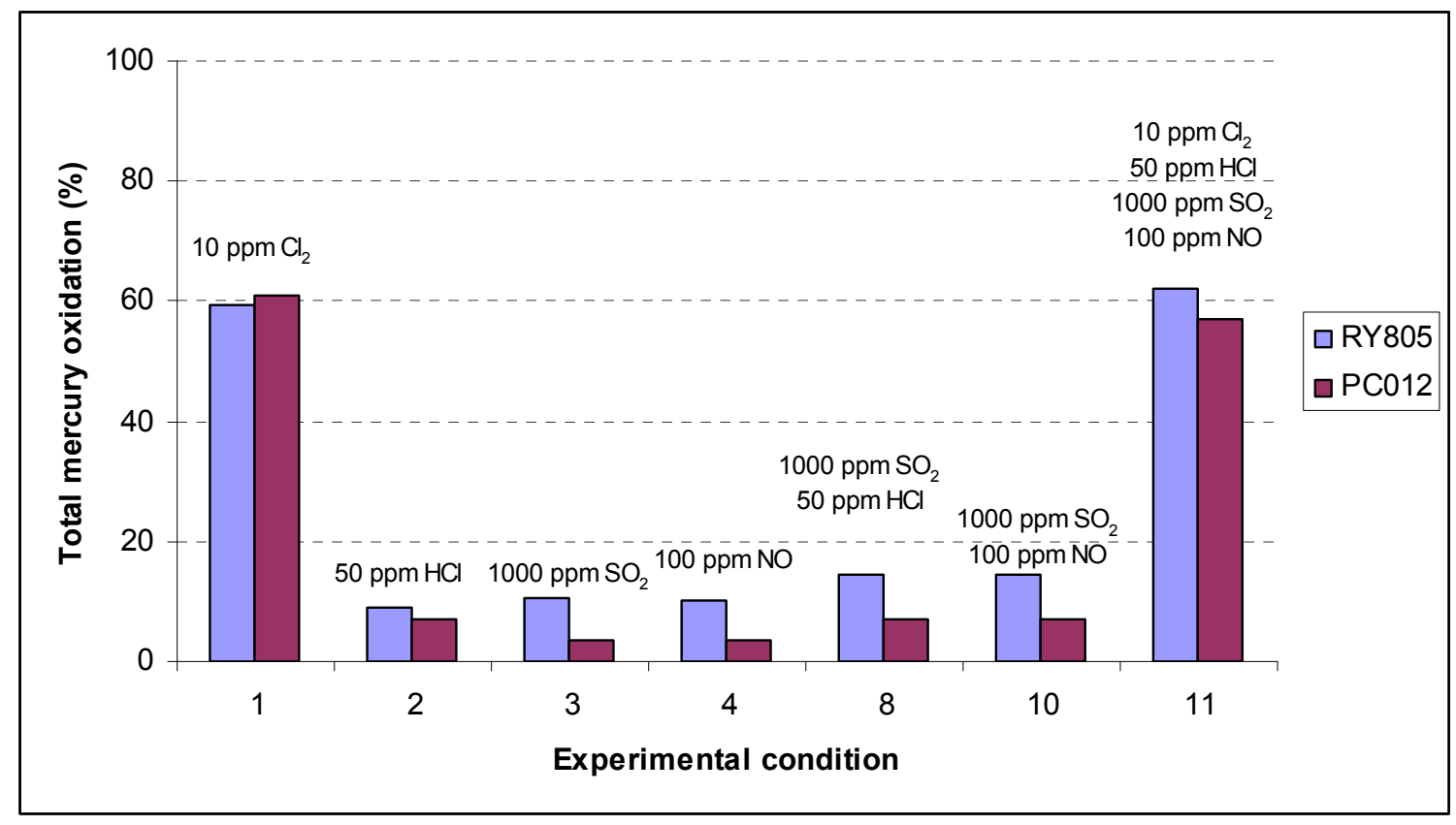

Figure 47: A comparison of mercury oxidation achieved with the two study filter fabric types under various experimental conditions

As shown in Figure 47, mercury oxidation with the PC012 filter is only slightly lower than with the RY805 filter. However, there does appear to be a difference in the noise of the measurements between bag types. Figures 48 and 49 show the random spiking that can occur in the mercury measurements using filter type RY805. Figure 50 
shows the relative smoothness of the measurements that is obtained using filter type PC012.

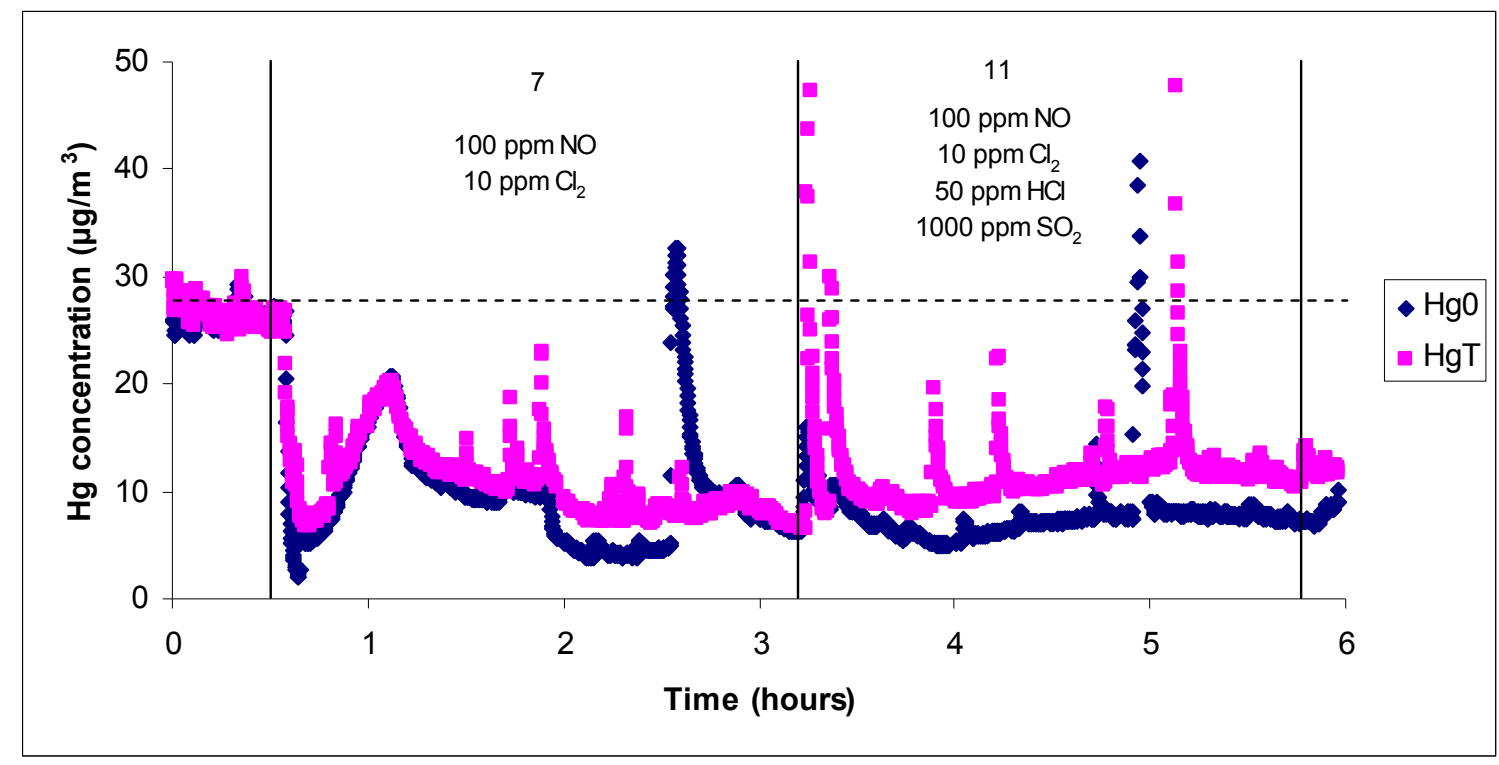

Figure 48: Typical measurement spiking profile for experiments with fabric type RY805 coated with $\mathrm{Au} / \mathrm{TiO}_{2}$

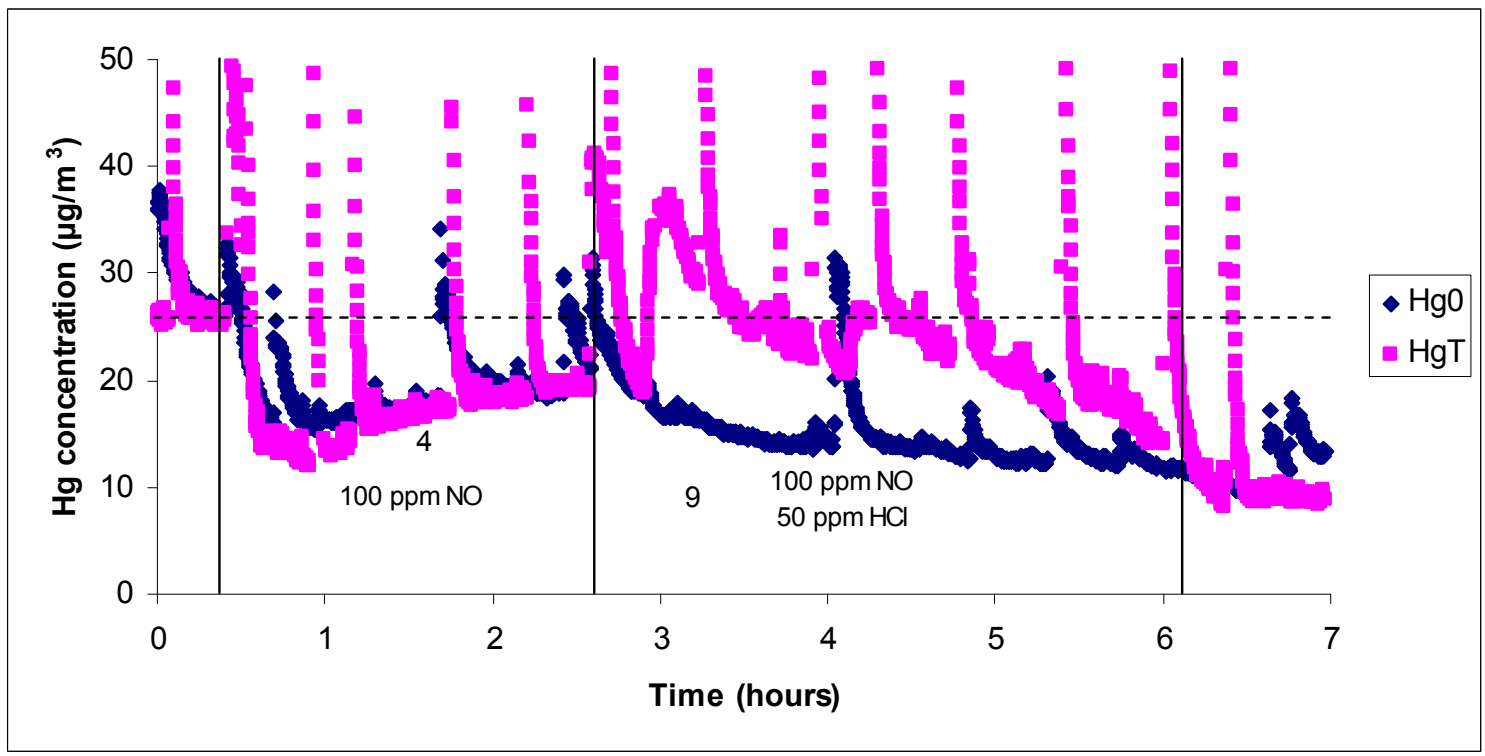

Figure 49: Typical measurement spiking profile for experiments with fabric type RY805 coated with $\mathrm{Pd} / \mathrm{Al}_{2} \mathrm{O}_{3}$ 


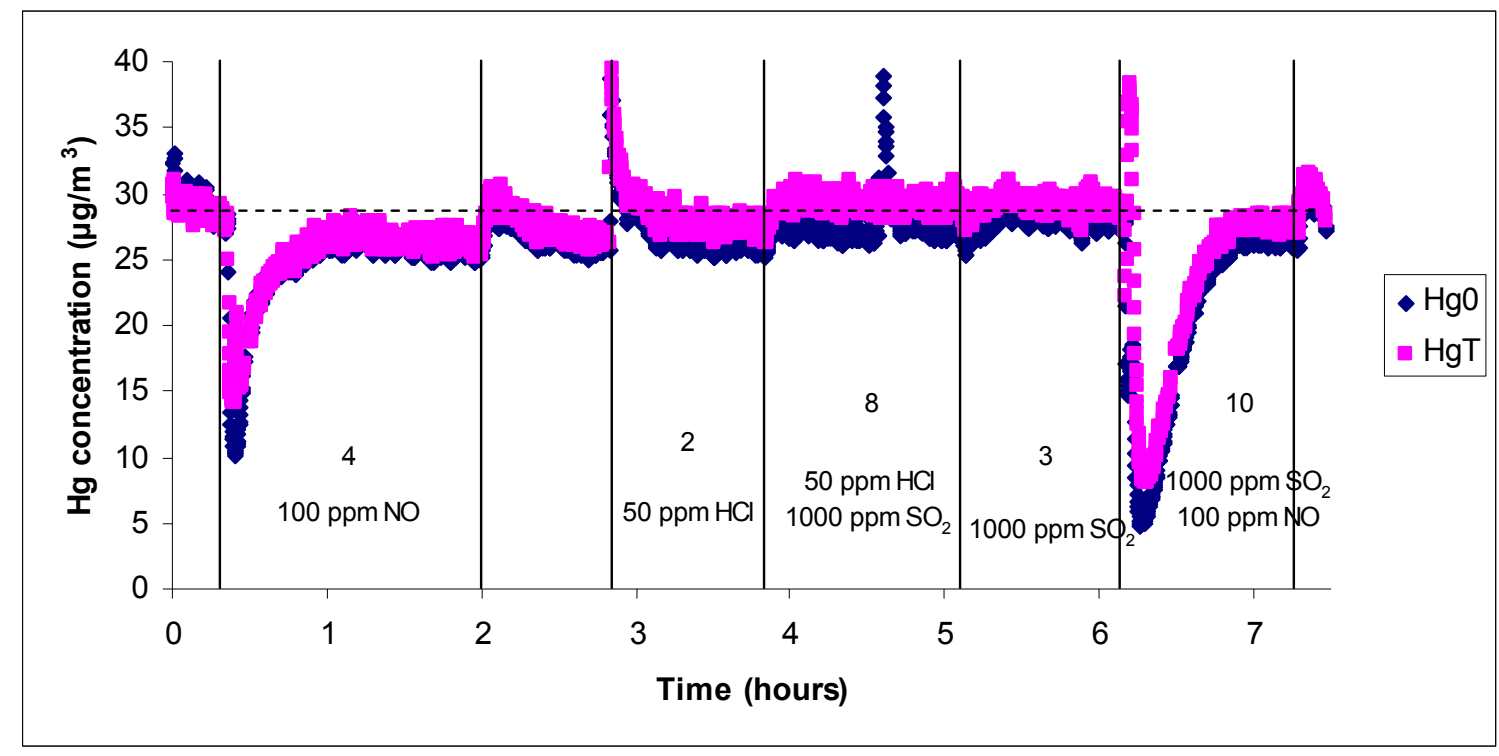

Figure 50: Typical measurement spiking profile for experiments with fabric type PC012 coated with $\mathrm{Au} / \mathrm{TiO}_{2}$. Note the relateive smoothness of the measurements compared to figures 48 and 49.

The sharp spiking that occurs is expected to be due to pressure and flow fluctuations that occur from the catalyst-loaded filter. A plugged filter would create flow restrictions causing these sharp spikes in mercury concentration, whereas an unplugged filter would allow the gas to flow freely. The floats in the flow meters would sharply bounce at regular intervals that correspond directly with the spikes in mercury concentration. In addition, the pressure in the analyzer would sharply bounce at the same regular interval. Thus, the observed measurement profiles suggest that catalyst plugging of the pores in the RY805 filter was experienced.

The filter plugging is attributed to the texture of the filter used. Type RY805 has a rigid cardboard-like texture whereas type PC012 has a soft blanket-like texture. The fabric integrity of type RY805 could be decreased relatively easily by bending the fabric or applying a high loading of catalyst to it. Type PC012 is expected to overcome these limitations due to its larger thickness and slightly greater porosity, as indicated in the manufacturer's specifications. 


\section{Objective 3- Small Pilot-Scale Testing}

Three test coals (analyses in Table 3) were fired during the small pilot-scale testing in the UND Chemical Engineering $19 \mathrm{~kW}$ research combustor: Illinois \#6 (eastern bituminous), Falkirk (North Dakota lignite), and Eagle Butte (Powder River Basin subbituminous). Each coal was fired at a feed rate of $1.8 \mathrm{~kg} / \mathrm{hr}(4.0 \mathrm{lb} / \mathrm{hr})$ and 20 percent excess air resulting in a flue gas oxygen concentration of about $3.2 \mathrm{vol} \%$.

The fabric type used in these tests was type PC012. All of the experiments performed in this testing were performed using the wet solution conditioning system on the mercury analyzer, as described in the experimental section, above. Detailed combustor information is described elsewhere. ${ }^{[56]}$

Mercury emissions were monitored at the outlet of the baghouse that services the research combustor. Each of the parallel baghouses contains one $15 \mathrm{~cm}$ (6 in) diameter filter that is $76 \mathrm{~cm}$ (30 in) in length. For each coal, baseline mercury concentrations were obtained using a bare filter. Mercury concentrations were then measured using a catalyst loaded filter. The temperature of the baghouse was maintained at $413 \mathrm{~K}\left(284^{\circ} \mathrm{F}\right)$ using electric heaters.

Pulse-jet cleaning cycles were performed after the pressure drop across the baghouse reached $1.5 \mathrm{kPa}\left(6\right.$ inches of $\left.\mathrm{H}_{2} \mathrm{O}\right)$, or approximately every 30 minutes. The cleaning cycle had no effect on mercury concentration. Fly ash samples were analyzed for unburned carbon using a Shimadzu total carbon analyzer at the UND Environmental and Analytical Research Laboratory (EARL). 
The $\mathrm{Pd} / \mathrm{Al}_{2} \mathrm{O}_{3}$ catalyst was chosen for use in the small pilot-scale study for the following reasons which are based on the bench-scale study:

- Overall increase in mercury oxidation rates,

- Apparent increase in catalytic activity in the presence of $\mathrm{SO}_{2}$,

- Lower mass loading rate required,

- Higher observed adsorption capacity, and

- Commercial availability of palladium catalysts versus gold catalysts.

The catalyst mass loading used was $2.5 \mathrm{mg} / \mathrm{cm}^{2}$, the same as in the bench-scale tests. Catalysts were loaded on the bags using the spray coating method.

Initial tests were conducted with uncatalyzed filter bags in order to define a baseline to assess the oxidation efficiency of the catalyzed filters.

\section{Illinois \#6}

Figure 51 shows the elemental and total mercury concentrations measured at the outlet of the baghouse for Illinois $\# 6$ for an uncoated (no catalyst) filter bag. The lefthand side of the figure shows the elemental mercury concentration was less than 1 $\mu \mathrm{g} / \mathrm{m}^{3}$ for the duration of the test. With this low elemental concentration, it would be impossible to assess the effectiveness of the catalyst for mercury oxidation.

An attempt was made to obtain an appreciable amount of elemental mercury by using the PSA Hg generator to dope $\mathrm{Hg}^{0}$ directly into the baghouse. As seen in the right 


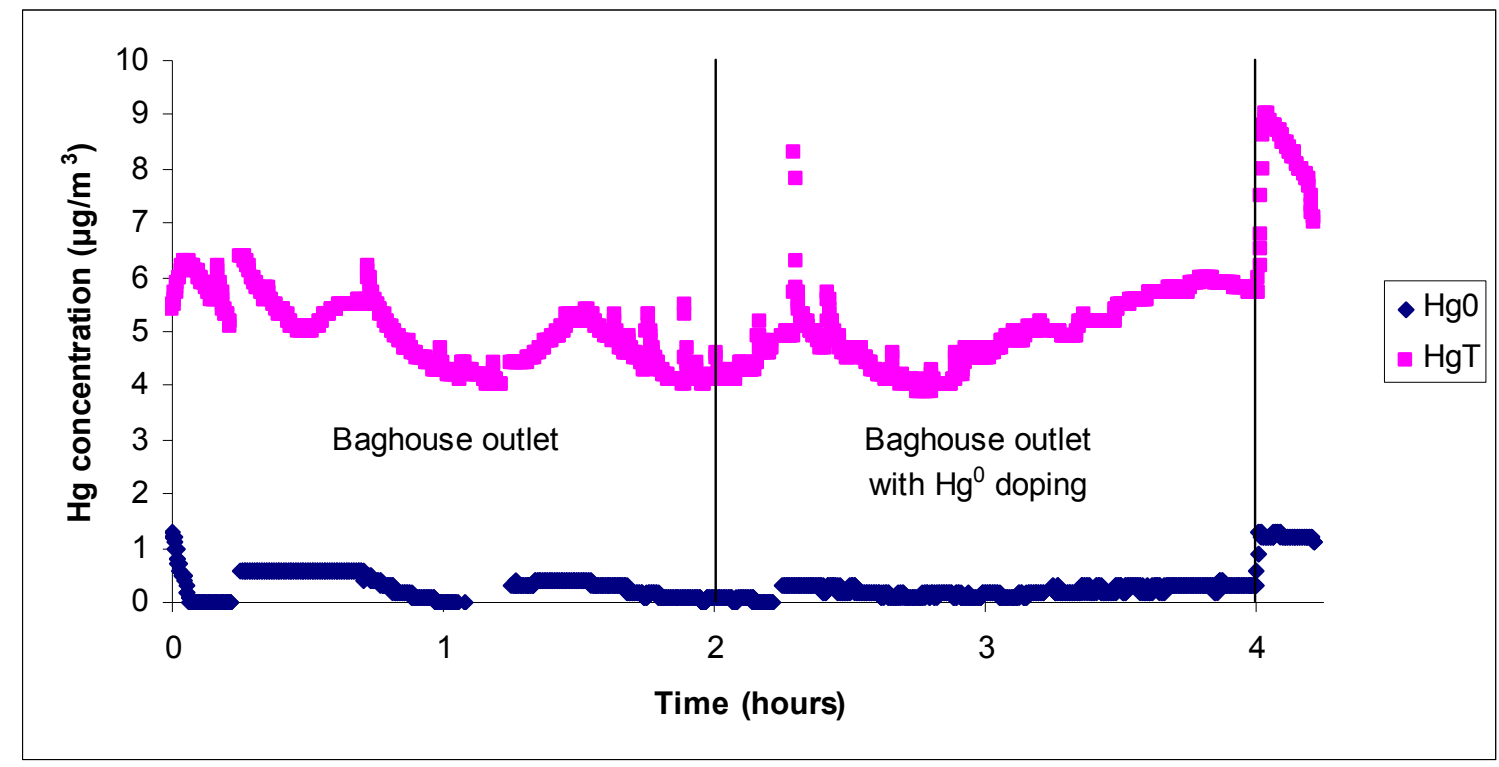

Figure 51: Elemental and total mercury concentrations at the outlet of a baghouse fitted with uncoated (no catalyst) filters attached to a $19 \mathrm{~kW}$ combustor firing Illinois \#6 coal (doping results are based on injecting $\mathrm{Hg}^{0}$ directly into the baghouse at a concentration of $6 \mu \mathrm{g} / \mathrm{m}^{3}$ )

hand portion of Figure $51, \mathrm{Hg}^{0}$ doping at a concentration of $6 \mu \mathrm{g} / \mathrm{m}^{3}$ did not increase the amount of mercury in the baghouse outlet.

This is most likely due to the oxidation of elemental mercury by chlorine and sulfur containing species, which is then catalyzed and adsorbed by the fly ash filter cake. The oxidized mercury adsorbs to the fly ash since there was no increase in the total mercury concentration. Illinois \#6 has a relatively high chlorine and sulfur content, as shown in Table 3. The fly ash had an unburned carbon content of 10.2 percent, as determined at UND EARL.

Fly ash is expected to play a large role in mercury oxidation and adsorption, particularly due to the amount of unburned carbon in the fly ash. A study by Hassett and Eylands $^{[59]}$ demonstrated a direct correlation between carbon content and mercury partitioning. Kellie et al. ${ }^{[60]}$ found that chlorine promotes the chemisorption of mercury 
onto fly ash and that sulfur can promote the oxidation of elemental mercury. Kellie et al. ${ }^{[61]}$ suggest that the removal of vapor phase mercury by fly ash is mostly due to the removal of oxidized mercury. Kolker et al. ${ }^{[62]}$ postulates carbon sites to be Lewis bases. Oxidized mercury can bind to these sites. Acid gases $\left(\mathrm{HCl}, \mathrm{SO}_{2}, \mathrm{NO}_{2}, \mathrm{NO}\right)$ can also bind to the sites and adsorb and subsequently oxidize elemental mercury.

For most bituminous coals like Illinois \#6, the vast majority of the mercury emitted from a commercial combustion system is in the oxidized form. However, the higher surface area to gas volume within the $19 \mathrm{~kW}$ combustion system, and specifically within the baghouse, provides additional sites that contribute to higher levels of mercury oxidation compared to a commercial system. As a consequence, Illinois \#6 was not used to assess the oxidation efficiency of catalyzed filter bags in this study.

\section{Falkirk}

Figure 52 shows the mercury concentrations at the outlet of the baghouse fitted with uncoated filters when firing a North Dakota lignite coal (Falkirk). As shown in the lefthand portion of the figure, the elemental mercury concentration is less than $1 \mu \mathrm{g} / \mathrm{m}^{3}$. To obtain an appreciable amount of elemental mercury, the PSA Hg generator was used to dope $10 \mu \mathrm{g} / \mathrm{m}^{3} \mathrm{Hg}^{0}$ directly into the baghouse. As seen in the righthand side of Figure 52 , the $\mathrm{Hg}^{0}$ doping resulted in a baghouse outlet elemental mercury concentration of about $5 \mu \mathrm{g} / \mathrm{m}^{3}$. The Falkirk coal was then fired using a $\mathrm{Pd} / \mathrm{Al}_{2} \mathrm{O}_{3}$ catalyst-coated fabric filter in the baghouse. Figure 53 shows the results from this six hour experiment with a $\mathrm{Hg}^{0}$ doping concentration of $10 \mu \mathrm{g} / \mathrm{m}^{3}$ throughout the testing.

As shown in Figure 53, the catalyst oxidized virtually all of the elemental mercury. There was also an increase in the adsorption of mercury onto the fabric filter, 
as shown by the decrease in total mercury concentration. By using the $\mathrm{Pd} / \mathrm{Al}_{2} \mathrm{O}_{3}$ catalyst, the amount of elemental mercury emitted decreased by 90 percent and the amount of oxidized mercury emitted decreased by 60 percent.

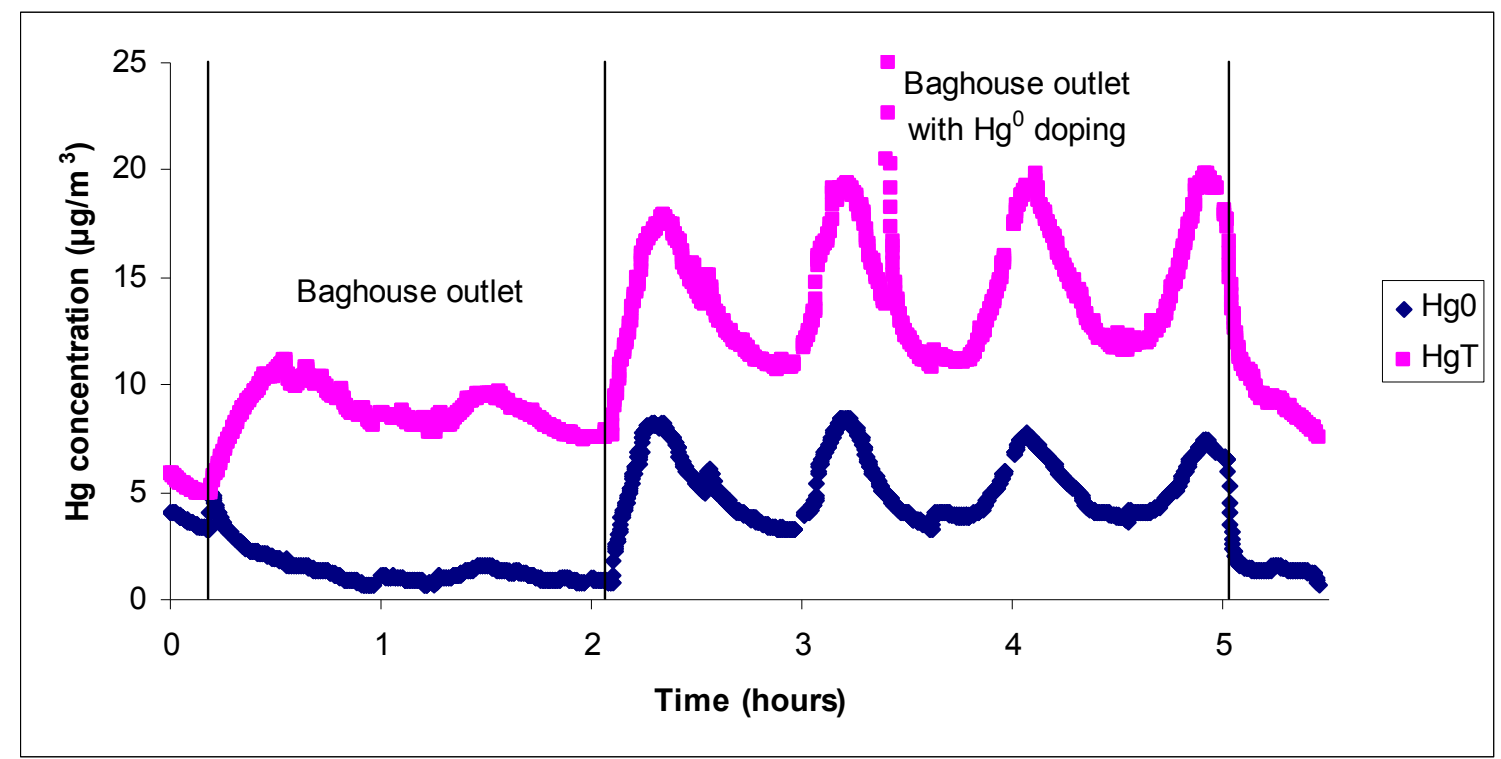

Figure 52: Elemental and total mercury concentrations at the outlet of a baghouse fitted with uncoated (no catalyst) filters attached to a $19 \mathrm{~kW}$ combustor firing Falkirk lignite (doping results are based on injecting $\mathrm{Hg}^{0}$ directly into the baghouse at a concentration of $10 \mu \mathrm{g} / \mathrm{m}^{3}$ )

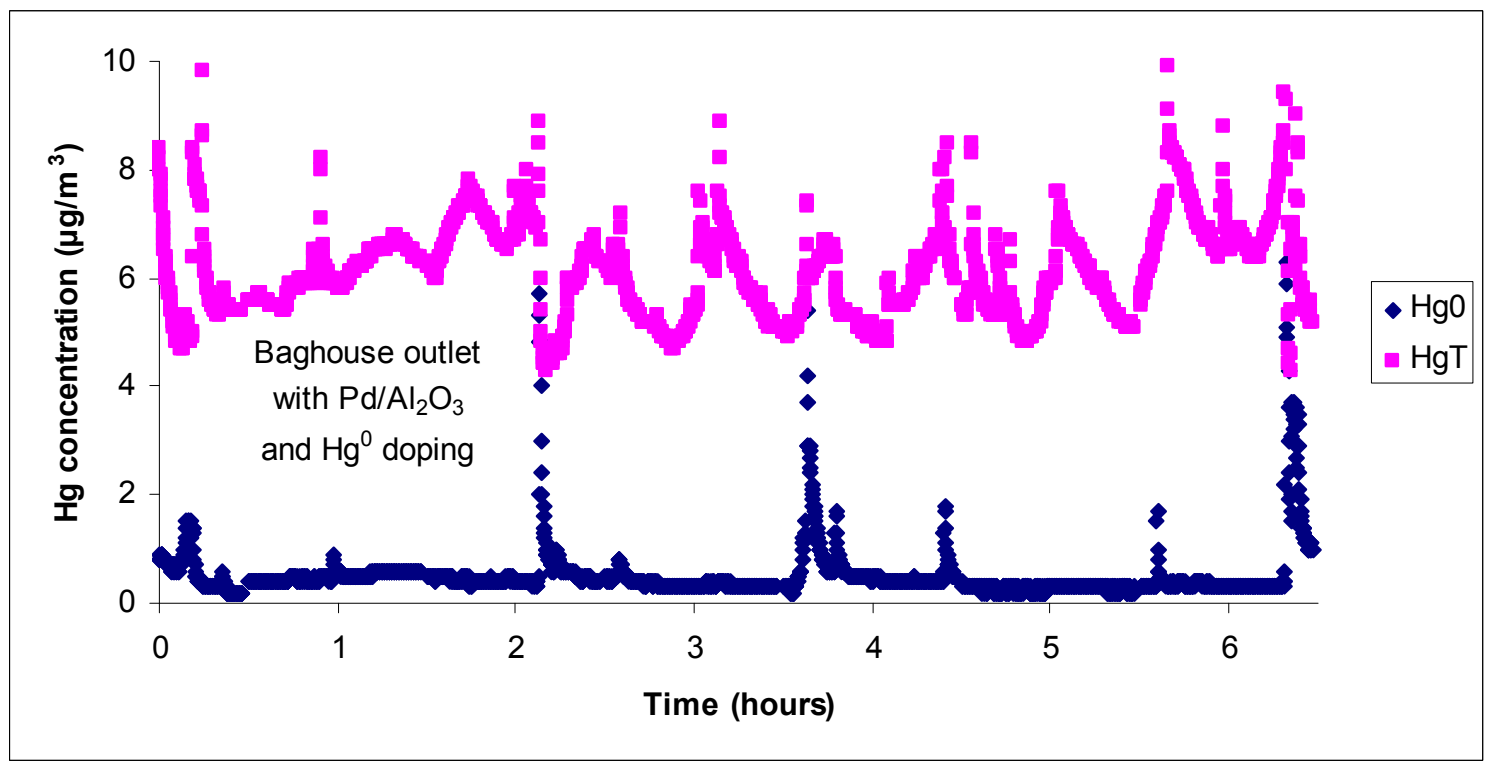

Figure 53: Elemental and total mercury concentrations at the outlet of a baghouse fitted with $\mathrm{Pd} / \mathrm{Al}_{2} \mathrm{O}_{3}$ catalyst coated filters attached to a $19 \mathrm{~kW}$ combustor firing Falkirk lignite (doping results are based on injecting $\mathrm{Hg}^{0}$ directly into the baghouse at a concentration of $10 \mu \mathrm{g} / \mathrm{m}^{3}$ ) 
The fly ash carbon and coal chlorine and sulfur content do not play as large of a role with the Falkirk coal as for the Illinois \#6 coal. The chlorine content in the Falkirk is nearly an order of magnitude less than Illinois \#6, the sulfur is 75 percent less, and the unburned carbon content is 4.8 percent, compared to 10.2 percent for Illinois \#6 fly ash. The lower unburned carbon content and low coal chlorine and sulfur content most likely resulted in very low oxidization of the additional $\mathrm{Hg}^{0}$ doped into the Falkirk flue gas without the assistance of the catalyst. These tests demonstrate that, for combustion systems where appreciable elemental mercury is present in the flue gas, catalyzed filter bags can provide substantial mercury oxidation.

Ontario-Hydro (OH) method sampling and off-line mercury analysis were performed to verify some of the measurements given by the DM-6B mercury analyzer. The $\mathrm{OH}$ method is very similar to the online analyzer method. Both methods use potassium chloride $(\mathrm{KCl})$ to capture oxidized mercury. The $\mathrm{OH}$ method uses potassium permanganate $\left(\mathrm{KMnO}_{4}\right)$ to capture elemental mercury. Both of the methods then use cold vapor atomic absorption spectrometry (CVAAS) to analyze for mercury. Figure 54 shows the comparison between the two methods of measurement for the Falkirk tests with and without the $\mathrm{Pd} / \mathrm{Al}_{2} \mathrm{O}_{3}$ catalyst in the baghouse. The results are statistically similar as expected due to the similarities in measurement methods. 


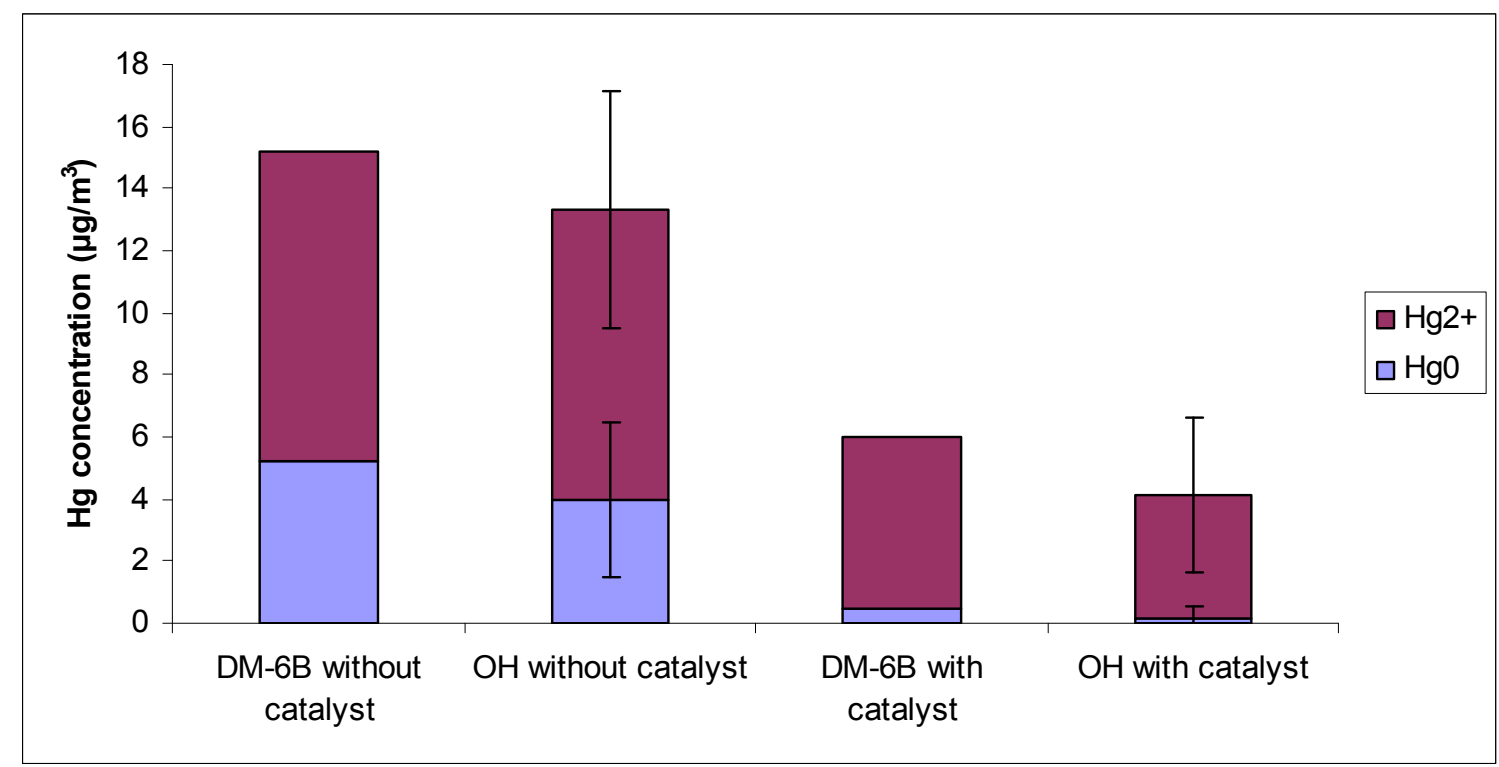

Figure 54: A comparison of mercury measurements for the DM-6B mercury analyzer method and the Ontario-Hydro $(\mathrm{OH})$ method for Falkirk tests with and without the $\mathrm{Pd} / \mathrm{Al}_{2} \mathrm{O}_{3}$ catalyst

\section{Eagle Butte}

Figure 55 shows mercury concentrations at the outlet of the baghouse fitted with uncoated filters when firing an Eagle Butte subbituminous coal in the $19 \mathrm{kw}$ combustor. The lefthand side of the figure shows that the elemental mercury concentration is less than $1 \mu \mathrm{g} / \mathrm{m}^{3}$. In order to try and obtain an appreciable amount of elemental mercury, the PSA $\mathrm{Hg}$ generator was used to dope $\mathrm{Hg}^{0}$ directly into the baghouse. As seen in the right hand portion of Figure $55, \mathrm{Hg}^{0}$ doping resulted in a baghouse outlet elemental mercury concentration of about $6 \mu \mathrm{g} / \mathrm{m}^{3}$. Similar to Falkirk, the Eagle Butte flue gas without the catalyst did not oxidize all of the doped elemental mercury.

The Eagle Butte coal was then fired using a $\mathrm{Pd} / \mathrm{Al}_{2} \mathrm{O}_{3}$ catalyst-coated fabric filter in the baghouse. Figure 56 shows the results from this six hour experiment employing a $\mathrm{Hg}^{0}$ doping concentration of $10 \mu \mathrm{g} / \mathrm{m}^{3}$ for the entire test. 


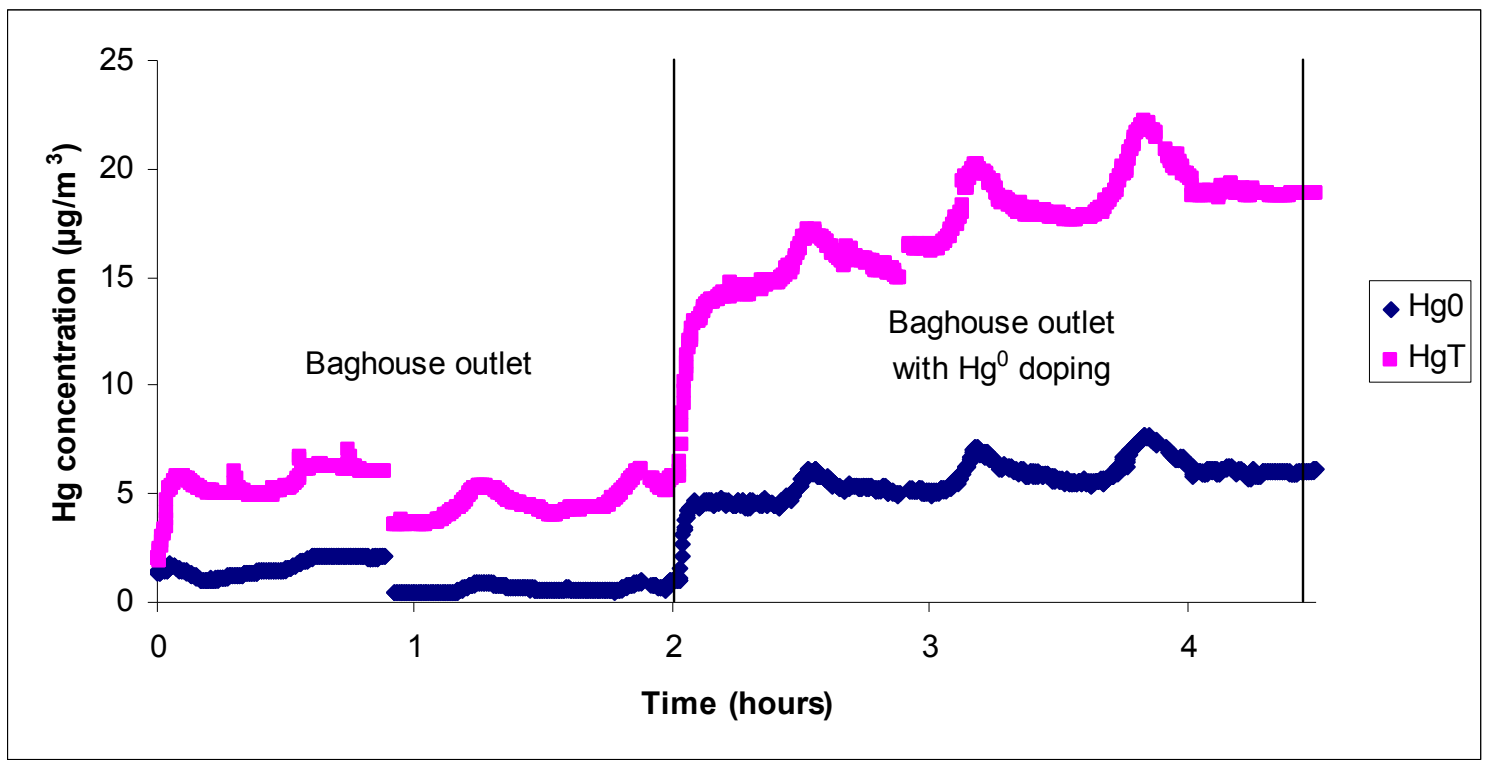

Figure 55: Elemental and total mercury concentrations at the outlet of a baghouse fitted with uncoated (no catalyst) filters attached to a $19 \mathrm{~kW}$ combustor firing Eagle Butte coal (doping results are based on injecting $\mathrm{Hg}^{0}$ directly into the baghouse at a concentration of $10 \mu \mathrm{g} / \mathrm{m}^{3}$ )

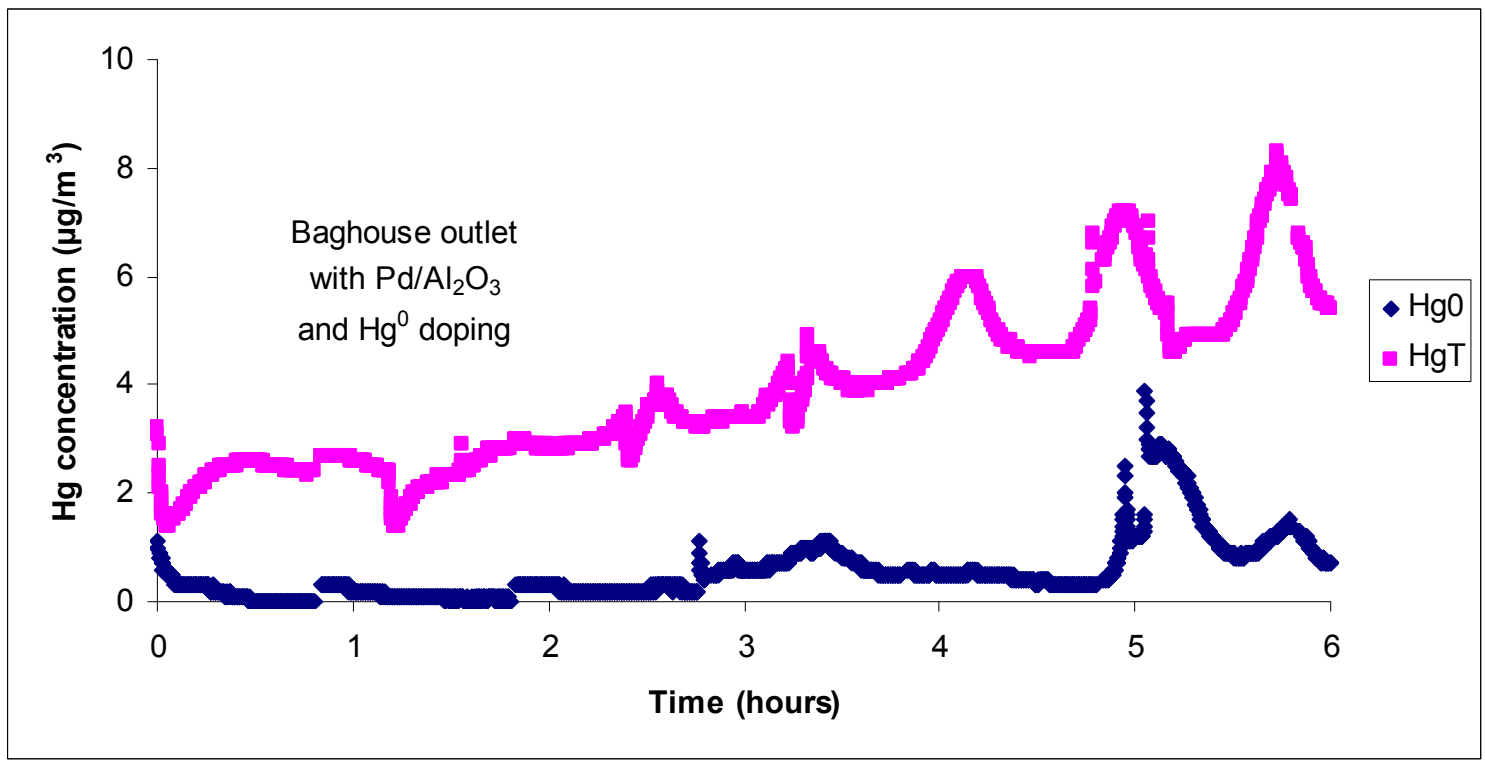

Figure 56: Elemental and total mercury concentrations at the outlet of a baghouse fitted with $\mathrm{Pd} / \mathrm{Al}_{2} \mathrm{O}_{3}$ catalyst coated filters attached to a $19 \mathrm{~kW}$ combustor firing Eagle Butte coal (doping results are based on injecting $\mathrm{Hg}^{0}$ directly into the baghouse at a concentration of $10 \mu \mathrm{g} / \mathrm{m}^{3}$ )

The unburned carbon content of the Eagle Butte fly ash is high, 17.5 percent. However unlike Illinois \#6, the Eagle Butte coal has a much lower chlorine and sulfur 
content, resulting in less mercury oxidation. However, in the presence of the $\mathrm{Pd} / \mathrm{Al}_{2} \mathrm{O}_{3}$ catalyst, the elemental mercury appears to be oxidized. The amount of elemental mercury emitted decreased by 90 percent and the amount of oxidized mercury emitted decreased by 50 percent.

A comparison of mercury measurement methods (on-line vs. Ontario Hydro) was performed during the Eagle Butte tests. The results for the Eagle Butte comparison were similar to the results obtained from the Falkirk comparison. The two methods of measurement produce statistically similar results due to the similarities in sample conditioning and analysis. Figure 57 shows the comparison between the two methods of measurement for the Eagle Butte tests with and without the $\mathrm{Pd} / \mathrm{Al}_{2} \mathrm{O}_{3}$ catalyst in the baghouse.

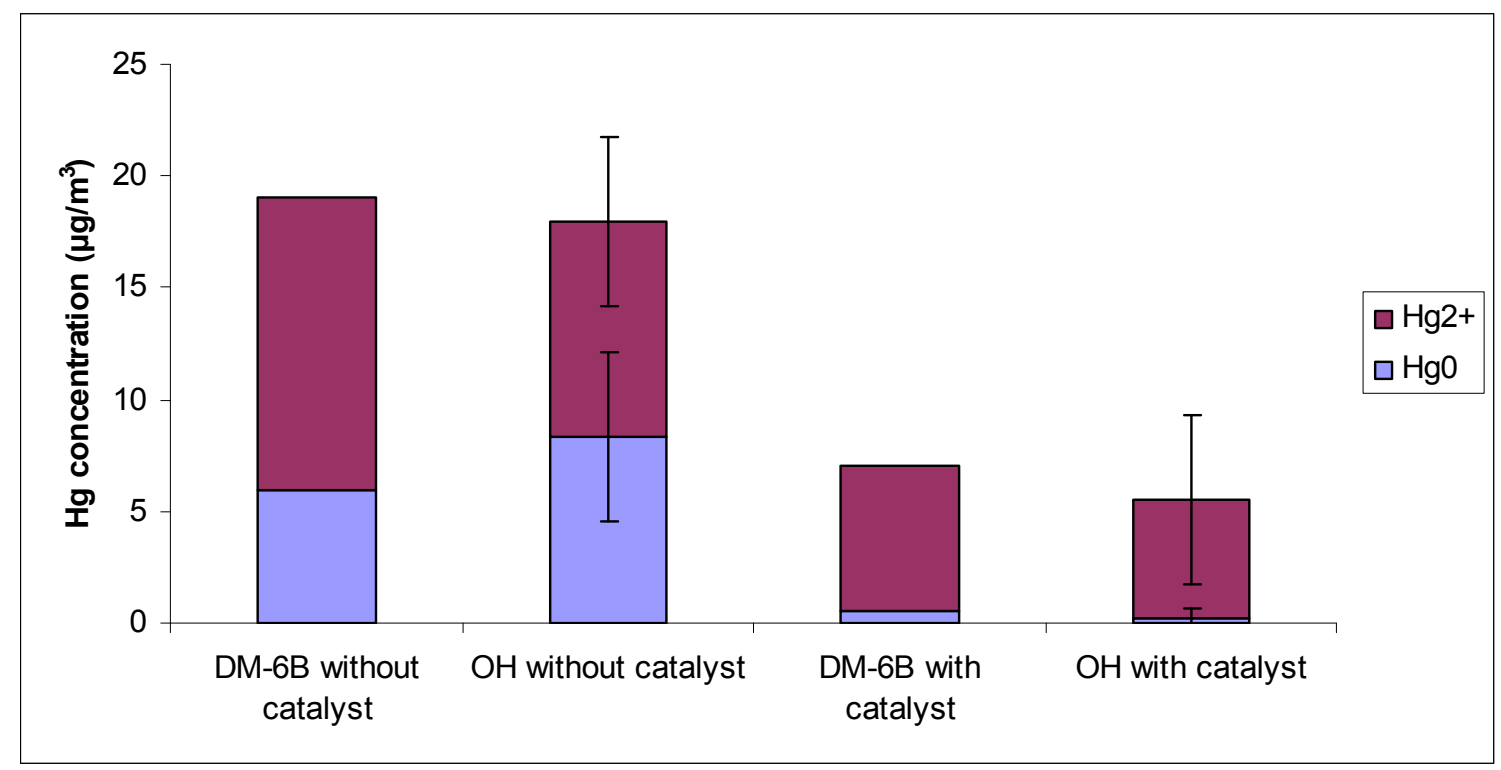

Figure 57: A comparison of mercury measurements for the DM-6B mercury analyzer method and the Ontario-Hydro $(\mathrm{OH})$ method for Eagle Butte tests with and without the $\mathrm{Pd} / \mathrm{Al}_{2} \mathrm{O}_{3}$ catalyst 
The Eagle Butte coal was chosen for use in a longer verification test to determine the catalyst performance over a longer period of time. Figure 58 shows the result of this test which also uses $\mathrm{Pd} / \mathrm{Al}_{2} \mathrm{O}_{3}$ with $\mathrm{Hg}^{0}$ doping of $10 \mu \mathrm{g} / \mathrm{m}^{3}$.

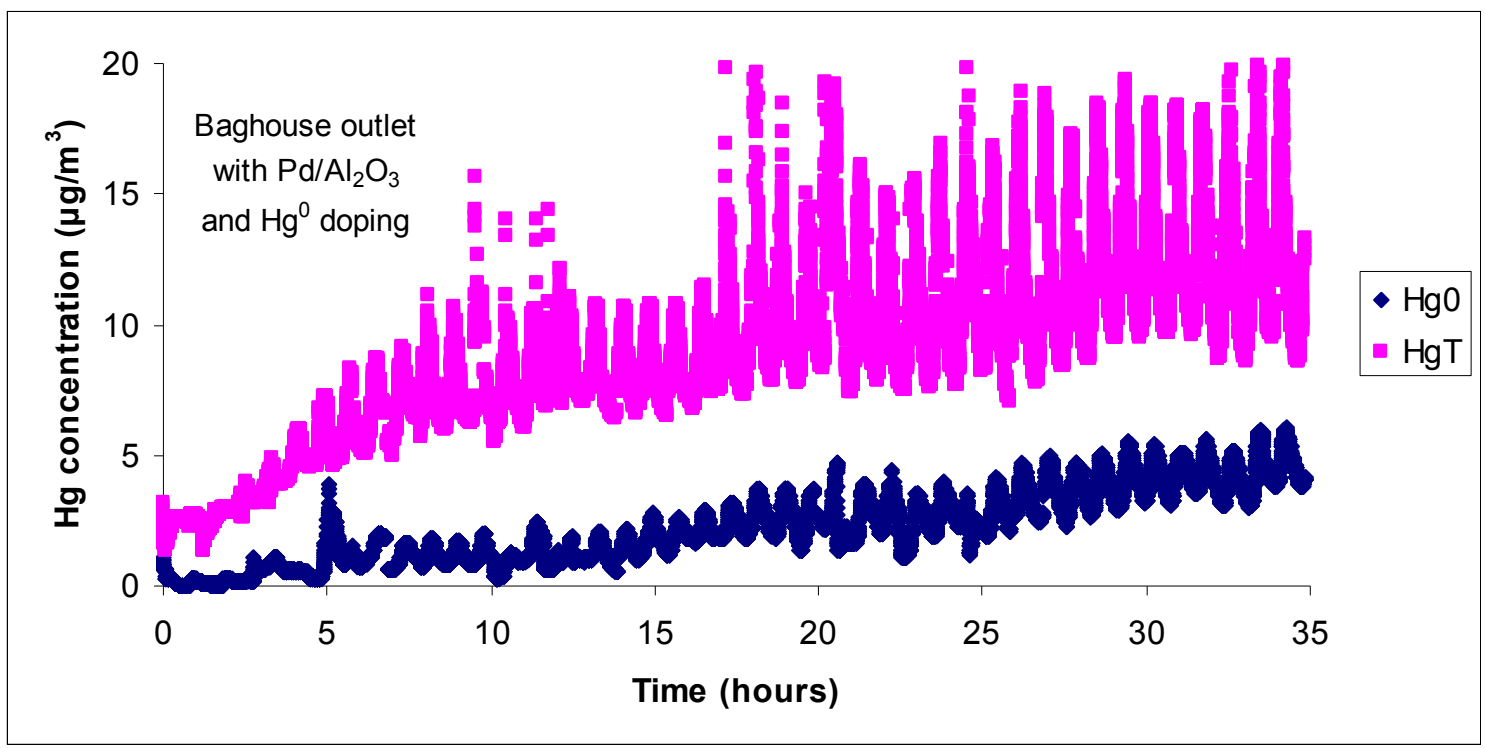

Figure 58: Verification test for Eagle Butte using $\mathrm{Pd} / \mathrm{Al}_{2} \mathrm{O}_{3}$ catalyst during small pilot-scale testing $\left(\mathrm{Hg}^{0}\right.$ is injected directly into the baghouse at a concentration of $\left.10 \mu \mathrm{g} / \mathrm{m}^{3}\right)$

Figure 58 shows a decrease in catalyst performance after 35 hours. The initial observed mercury oxidation was around 90 percent, comparable to the short-term results shown in Figure 55. However, after 35 hours, the elemental mercury concentration rose to above 80 percent of the concentration measured when using a bare filter, shown in Figure 55. One or more of three hypothesized events is likely occurring: 1) the catalyst is mostly adsorbing mercury and reaches saturation over time, 2) the catalyst is being deactivated by some component of the flue gas, and//or 3) the catalyst is not properly adhering to the fabric filter and is being lost to the flue gas over time, possibly due to the 
pulse-jet cleaning cycles. Note, the bench-scale tests predict that the latter two events likely would not occur.

The bench-scale tests showed that the $\mathrm{Pd} / \mathrm{Al}_{2} \mathrm{O}_{3}$ adsorbed a significant amount of mercury before reaching a saturation point. The bench-scale testing also showed that $\mathrm{Cl}_{2}$ was necessary to oxidize an appreciable amount of elemental mercury. The Eagle Butte coal contains a relatively low amount of chlorine. In order to test for the significance of the presence of $\mathrm{Cl}_{2}$ in the flue gas, $\mathrm{Cl}_{2}$ doping tests were performed.

First, $\mathrm{Cl}_{2}$ injection was performed using a bare filter. Figure 59 shows the result of doping $10 \mathrm{ppm} \mathrm{Cl}_{2}$ using a bare filter and $\mathrm{Hg}^{0}$ doping at $10 \mu \mathrm{g} / \mathrm{m}^{3}$. As expected, the fly ash appears to act as a catalyst in the presence of $\mathrm{Cl}_{2}$. The addition of $\mathrm{Cl}_{2}$ results in elemental mercury oxidation of around 80 percent.

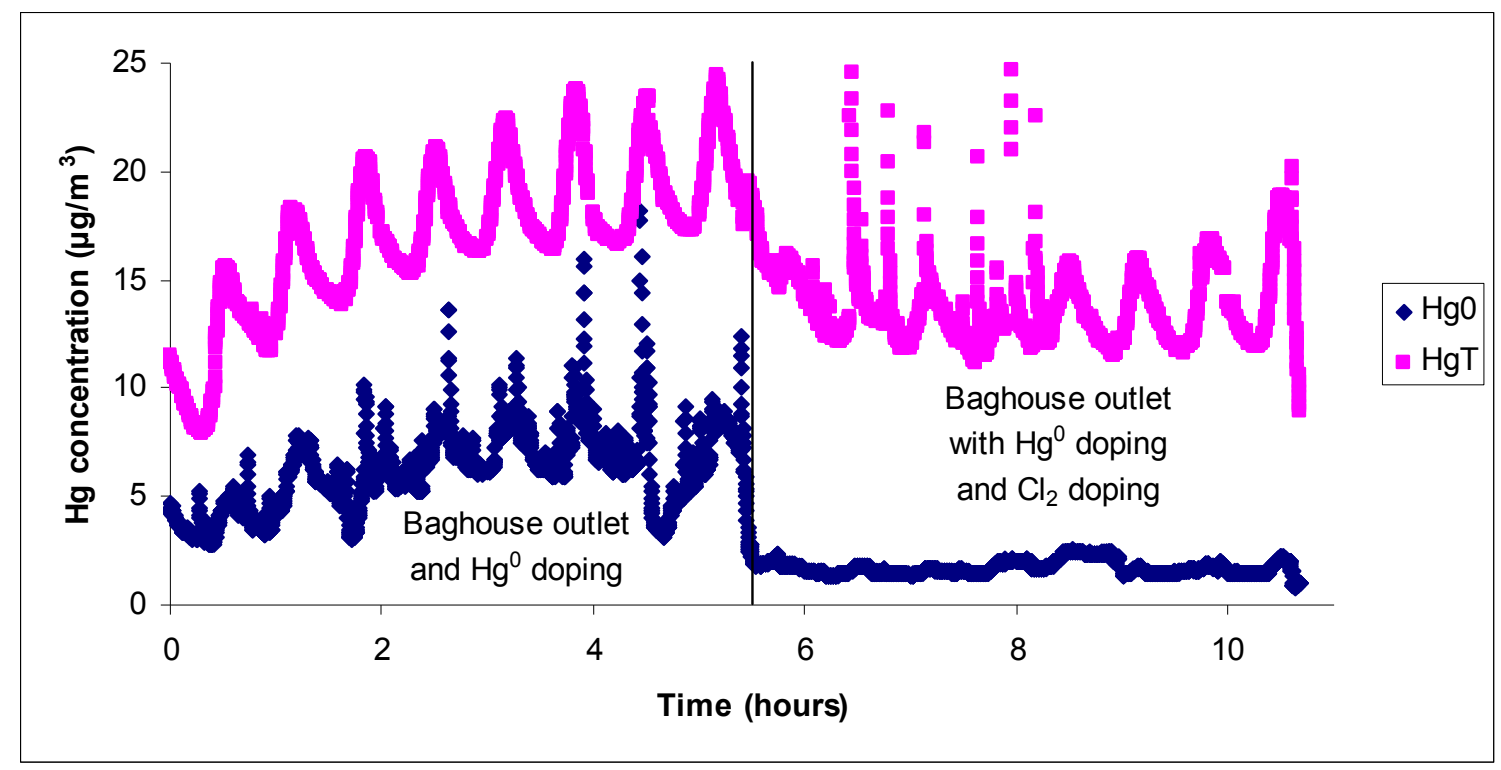

Figure 59: Mercury measurement at baghouse outlet for Eagle Butte during small pilot-scale testing with $\mathrm{Cl}_{2}$ doping $\left(\mathrm{Hg}^{0}\right.$ is injected directly into the baghouse at a concentration of $10 \mu \mathrm{g} / \mathrm{m}^{3}$ and $\mathrm{Cl}_{2}$ is injected at a concentration of $10 \mathrm{ppm}$ ) 
Figure 60 shows the result of doping $10 \mathrm{ppm} \mathrm{Cl}_{2}$ using a filter loaded with $\mathrm{Pd} / \mathrm{Al}_{2} \mathrm{O}_{3}$ and $\mathrm{Hg}^{0}$ doping of $10 \mu \mathrm{g} / \mathrm{m}^{3}$. The same filter from the verification test was used to determine if there was any catalyst activity remaining. The $\mathrm{Pd} / \mathrm{Al}_{2} \mathrm{O}_{3}$, in the presence of $\mathrm{Cl}_{2}$, slightly enhances the elemental mercury oxidation to about 90 percent. In order for there to be an additional amount of mercury oxidation there appears to be unpoisoned catalyst on the fabric filter. Therefore, the most likely explanation is that the filter became saturated with mercury during the long-term tests and that the lower performance in the long-term tests was due to a lack of oxidation source.

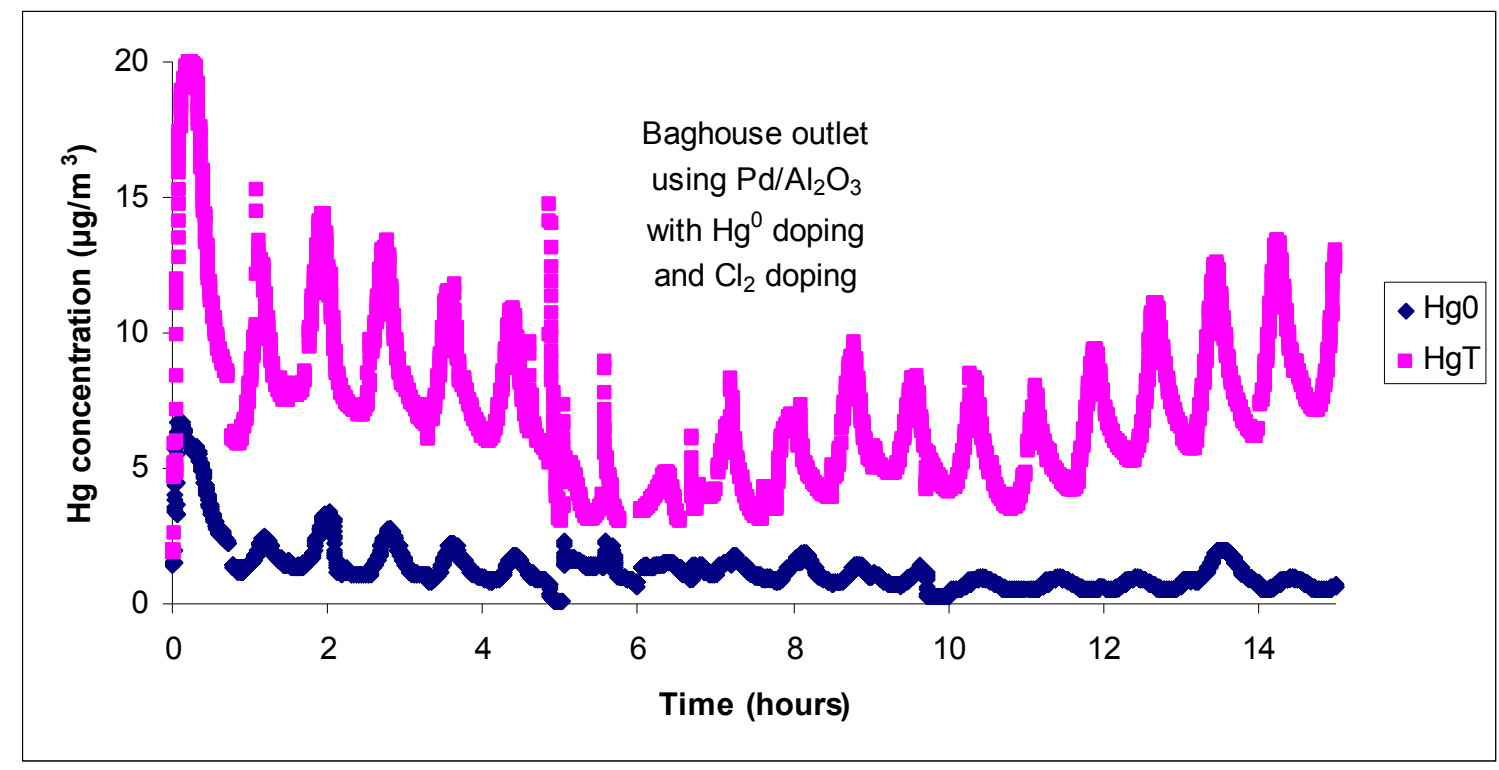

Figure 60: Mercury measurement at baghouse outlet for Eagle Butte using $\mathrm{Pd} / \mathrm{Al}_{2} \mathrm{O}_{3}$ catalyst during small pilot-scale testing with $\mathrm{Cl}_{2}$ doping $\left(\mathrm{Hg}^{0}\right.$ is injected directly into the baghouse at a concentration of $10 \mu \mathrm{g} / \mathrm{m}^{3}$ and $\mathrm{Cl}_{2}$ is injected at a concentration of $10 \mathrm{ppm}$ )

Thus, even when using a catalyst, there is a minimum level of oxidant required in the gas stream for effective mercury oxidation. However, the level of oxidant addition required is likely to be much smaller than would be required without the coated filter bags and this level may prove low enough to mitigate corrosion and deposition concerns 
in downstream

systems. These

issues must be

explored further

prior to final

commercialization

of the technology.
Table 10: Summary of results from Falkirk and Eagle Butte coals, short test is 6 hours and long test is 35 hours (All tests have $\mathrm{Hg}^{0}$ doping of $10 \mu \mathrm{g} / \mathrm{m}^{3}$ and $\mathrm{Cl}_{2}$ doping is $10 \mathrm{ppm}$ for Eagle Butte)

\begin{tabular}{|l|c|c|}
\hline & $\begin{array}{c}\text { Falkirk } \\
\mathrm{Hg} \text { Oxid \% }\end{array}$ & $\begin{array}{c}\text { Eagle Butte } \\
\mathrm{Hg} \text { Oxid \% }\end{array}$ \\
\hline Bare filter (short test) & 40 & 33 \\
\hline $\mathrm{Pd} / \mathrm{Al}_{2} \mathrm{O}_{3}$ (short test) & 90 & 90 \\
\hline Bare filter w/ $\mathrm{Cl}_{2}$ doping (long test) & -- & 80 \\
\hline $\mathrm{Pd} / \mathrm{Al}_{2} \mathrm{O}_{3} \mathrm{w} / \mathrm{Cl}_{2}$ doping (long test) & -- & 90 \\
\hline
\end{tabular}

Table 10 summarizes the results from the Falkirk and Eagle Butte coals. 


\section{SUMMARY OF PHASE II}

Spray coating the fabrics with a $25 \mathrm{wt} \%$ slurry under approximately $138 \mathrm{kPa}$ pressure and a cone shaped spray gave the highest catalyst loadings. The spray method is easier to control to a constant slurry concentration because of free mixing in the slurry. The fabric is not in the slurry to interfere with mixing. As long as the spray pressure and flow rate to the spray nozzle remains constant the coating process is simple. This also applies to the commercial scale of the project. If a proper nozzle is chosen for the desired spray pattern and design pressure, the spray coat method will provide the highest catalyst loading and have the simplest operation. The best scenario for a coating method is to spray the catalyst on at a low pressure (under $345 \mathrm{kPa}$ ) and use a felted fabric.

Dip coat application can achieve relatively high dosage levels approaching doses of $20 \mathrm{wt} \%$. The dip coat method has more variables that can give inconsistent dosing from sample to sample. The highest coating levels approaching $20 \mathrm{wt} \%$ were achieved with two successive dip coats with each dip followed by rolling the sample under a weighted rolling pin. If two coats were required in production this would require two successive dip tanks with each dip followed by pressing in a low pressure roll press to assure distribution of the slurry into the fabric.

The parametric testing in this project investigated the effects of three catalysts on mercury oxidation. The catalysts were $\mathrm{TiO}_{2}, \mathrm{Au} / \mathrm{TiO}_{2}(1 \% \mathrm{Au})$, and $\mathrm{Pd} / \mathrm{Al}_{2} \mathrm{O}_{3}(1 \% \mathrm{Pd})$. The bench-scale testing was performed with a small test reactor and used a simulated flue gas. The baseline gas included $\mathrm{O}_{2}, \mathrm{H}_{2} \mathrm{O}, \mathrm{N}_{2}$, and $\mathrm{Hg}^{0}$. Parametric testing was performed and included $\mathrm{Cl}_{2}, \mathrm{HCl}, \mathrm{SO}_{2}$, and $\mathrm{NO}$. Two types of fabric were considered: $\mathrm{RY} 805$ and 
PC012. The majority of the work used type RY805 and a set of verification tests used type PC012 to determine differences between filter types.

$\mathrm{TiO}_{2}$ was found to be ineffective at oxidizing elemental mercury. However, $\mathrm{TiO}_{2}$ adsorbs oxidized mercury. This was seen in the oxidized mercury spiking tests and was observed when a bare filter produced nearly all gaseous oxidized mercury and a $\mathrm{TiO}_{2}$ filter produced nearly all adsorbed oxidized mercury.

$\mathrm{Au} / \mathrm{TiO}_{2}$ is an effective catalyst in the presence of $\mathrm{Cl}_{2}$. The gold- $\mathrm{Cl}_{2}$ interaction appears to be strong enough to overcome any inhibitory effects from $\mathrm{SO}_{2}$ and $\mathrm{NO}$ often seen in other research. Without $\mathrm{Cl}_{2}$, little elemental mercury is oxidized with one exception. There is a synergistic effect between $\mathrm{HCl}$ and $\mathrm{NO}$ that produces increased levels of mercury oxidation, but not as much as $\mathrm{Cl}_{2} . \quad \mathrm{SO}_{2}$ slightly increased mercury oxidation in the presence of $\mathrm{Cl}_{2}$.

$\mathrm{Pd} / \mathrm{Al}_{2} \mathrm{O}_{3}$ is as effective as $\mathrm{Au} / \mathrm{TiO}_{2}$ in the presence of $\mathrm{Cl}_{2}$. However, in the presence of $\mathrm{Cl}_{2}$ and $\mathrm{SO}_{2}$, mercury oxidation increased to higher levels likely due to increased catalytic activity. The synergistic effect between $\mathrm{HCl}$ and $\mathrm{NO}$ was also observed with $\mathrm{Pd} / \mathrm{Al}_{2} \mathrm{O}_{3}$. $\mathrm{Pd} / \mathrm{Al}_{2} \mathrm{O}_{3}$ is considered to be the best catalyst for the following reasons: overall increase in mercury oxidation rates, apparent increase in catalytic activity in the presence of $\mathrm{SO}_{2}$, lower mass loading rate required, higher observed adsorption capacity, and commercial availability of palladium catalysts versus gold catalysts.

No difference was observed for mercury oxidation between the two fabric types. However, PC012 was found to be better because of the higher air permeability of the fabric. The higher permeability inhibited the plugging from the catalyst that was observed by type RY805. 
Recommendations for future work include investigating the phenomenon that occurred with the wet conditioning system during the testing with $\mathrm{Pd} / \mathrm{Al}_{2} \mathrm{O}_{3}$. When $\mathrm{Cl}_{2}$ and $\mathrm{HCl}$ or $\mathrm{Cl}_{2}$ and $\mathrm{NO}$ were added in the presence of $\mathrm{Pd} / \mathrm{Al}_{2} \mathrm{O}_{3}$, mercury was released from the elemental mercury conditioning solution. This created a significant bias in the mercury measurement.

Sulfated alumina or titanium dioxide could be looked at to determine the effect that sulfur has on mercury oxidation. This would give a better idea as to how sulfur promotes mercury oxidation on the catalyst surface.

Small pilot-scale testing was performed using three coals: Illinois \#6, Falkirk, and Eagle Butte. For all of the coals, $\mathrm{Hg}^{0}$ had to be doped into the baghouse to generate an appreciable amount of $\mathrm{Hg}^{0}$. For Illinois \#6, none of the $\mathrm{Hg}^{0}$ was recovered, most likely due to the high chlorine and sulfur contents in the coal. Chlorine and sulfur oxidize the mercury and it is then most likely adsorbed by the fly ash.

The Falkirk coal has low chlorine and sulfur content and produced $\mathrm{Hg}^{0}$ in the flue gas. When using $\mathrm{Pd} / \mathrm{Al}_{2} \mathrm{O}_{3}$, initial mercury oxidation of 90 percent was observed. The Eagle Butte coal also has low chlorine and sulfur content and also produced $\mathrm{Hg}^{0}$ in the flue gas. The Eagle Butte flue gas also produced mercury oxidation of 90 percent in the presence of $\mathrm{Pd} / \mathrm{Al}_{2} \mathrm{O}_{3}$.

Eagle Butte was chosen for a longer verification test. After 35 hours, the 90 percent mercury oxidation dropped to less than 20 percent mercury oxidation. $\mathrm{Cl}_{2}$ was then doped into the baghouse both with and without $\mathrm{Pd} / \mathrm{Al}_{2} \mathrm{O}_{3}$. Fly ash alone, in the presence of doped $\mathrm{Cl}_{2}$, oxidized about 80 percent of the elemental mercury while 
$\mathrm{Pd} / \mathrm{Al}_{2} \mathrm{O}_{3}$ oxidized near 90 percent of the elemental mercury. From this, at least a portion of the catalyst appears to be having an effect on mercury oxidation.

The online analyzer mercury measurements were verified using the OntarioHydro method. The two methods produced statistically similar results due to the similarities in the methods.

This method of mercury control is expected to overcome limitations seen in previous research. Other studies using palladium catalysts ${ }^{[4,63]}$ have shown mercury oxidation rates around 90 percent. However, a large amount of catalyst is required in previous studies. Results from this research show that a much smaller amount of metal catalyst can achieve 80 percent mercury oxidation. The method used in this project allows the mercury to come into close contact with the catalyst, whereas other methods use catalyst screens with a much smaller surface area.

Recommendations for future work include performing additional testing to determine the catalyst loading in an actual combustion environment. During the benchscale testing, it was observed that $\mathrm{TiO}_{2}$ was very soluble in water, while $\mathrm{Au} / \mathrm{TiO}_{2}$ and $\mathrm{Pd} / \mathrm{Al}_{2} \mathrm{O}_{3}$ were slightly hydrophobic. Additional tests could be performed to determine the catalyst loading over a longer period of time with several cleaning cycles in an actual combustion environment.

Additional testing could also be performed to determine whether or not the catalyst is being poisoned over a long period of time (more than 48 hours) for all of the coals. Analytical methods could be explored to find out how to examine a piece of fabric to determine the integrity of the catalyst before and after use in a combustion system. 
Parametric testing could be examined in the actual flue gas in order to determine the effects of various flue gas components in an actual combustion environment. This would give a better idea as to how certain components affect the catalyst's performance in an actual combustion flue gas.

Bench-scale tests could be performed with fly ash to determine the effect of fly ash from a number of different coals. Using comprehensive fly ash analyses, it would be helpful to know the effect of various fly ash components on mercury oxidation and adsorption.

This method of mercury control shows promise for meeting abatement compliance in the future. Much of the work in this project showed mercury oxidation of 80-90 percent, exceeding the current expected regulation of 70 percent. 


\section{REFERENCES}

1. Brown, T. D., Smith, D. N., Hargis Jr., R. A., and O'Dowd, W. J., Mercury measurement and its control: What we know, have learned, and need to further investigate. Journal of the Air and Waste Management Association. 1999, 49(6), p. 628-640.

2. $\quad$ Cooper, C. D. and Alley, F. C., Air Pollution Control: A Design Approach. 3 ed. 2002, Prospect Heights, IL: Waveland Press, Inc.

3. Zhao, Y., Mann, M. D., Pavlish, J. H., Mibeck, B. A. F., Dunham, G. E., and Olson, E. S., Application of gold catalyst for mercury oxidation by chlorine. Environmental Science and Technology. 2006, 40(5), p. 1603-1608.

4. Blythe, G. M., Richardson, C. F., Lani, B. W., Rhudy, R. G., Strohfus, M., Riveland, G., and Loritz, L. Pilot testing of oxidation catalysts for enhanced mercury control by wet FGD. in Combined Power Plant Air Pollutant Control Mega Symposium. 2004. Washington, DC, United States.

5. Keating, M. H., Mahaffey, K. R., Schoeny, R., Rice, G. E., Bullock, O. R., Ambrose, J., R.B., Swartout, J., and Nichols, J. W., Mercury Study Report to Congress. 1997. United States Environmental Protection Agency, EPA-452/R-97003 through 010

6. French, C. L., Maxwell, W. H., Peters, W. D., Rice, G. E., Bullock, O. R., Vasu, A. B., Hetes, R., Colli, A., Nelson, C., and Lyons, B. F., Study of Hazardous Air Pollutant Emissions from Electric Utility Steam Generating Units -- Final Report to Congress. 1998. United States Envionmental Protection Agency, EPA-453/R98-004a through 004b

7. Galbreath, K. C. and Zygarlicke, C. J., Mercury speciation in coal combustion and gasification flue gases. Environmental Science and Technology. 1996, 30(8), p. 2421-2426.

8. Sondreal, E. A., Benson, S. A., Pavlish, J. H., and Ralston, N. V. C., An overview of air quality III: Mercury, trace elements, and particulate matter. Fuel Processing Technology. 2004, 85(6-7), p. 425-440.

9. Controlling Power Plant Emissions: Decision Process and Chronology. United States Environmental Protection Agency. http://www.epa.gov/mercury/control_emissions/decision.htm. accessed on June 27, 2006

10. McCarthy, J. E., Mercury emissions from electric power plants: States are setting stricter limits. 2006. CRS Report for Congress, Order Code RL33535

11. Pavlish, J. H., Sondreal, E. A., Mann, M. D., Olson, E. S., Galbreath, K. C., Laudal, D. L., and Benson, S. A., Status review of mercury control options for coal-fired power plants. Fuel Processing Technology. 2003, 82(2-3), p. 89-165.

12. Hylander, L. D. and Goodsite, M. E., Environmental costs of mercury pollution. Science of the Total Environment. 2006, 368(1), p. 352-370.

13. Presto, A. A. and Granite, E. J., Survey of catalysts for oxidation of mercury in flue gas. Environmental Science and Technology. 2006, 40(18), p. 5601-5609.

14. Ebner, T., Fisher, K., Ley, T., Slye, R., Chang, R., Richardson, C., Aljoe, W., Strohfus, M., and Sjostrom, S. Large-scale demonstration of the Mercap 
technology for mercury control. in Air Quality V Conference. 2005. Arlington, VA, United States.

15. Cao, Y., Duan, Y., Kellie, S., Li, L., Xu, W., Riley, J. T., Pan, W.-P., Chu, P., Mehta, A. K., and Carty, R., Impact of coal chlorine on mercury speciation and emission from a 100-MW utility boiler with cold-side electrostatic precipitators and low-NO $\mathrm{N}_{\mathrm{x}}$ burners. Energy and Fuels. 2005, 19(3), p. 842-854.

16. Dunham, G. E., DeWall, R. A., and Senior, C. L., Fixed-bed studies of the interactions between mercury and coal combustion fly ash. Fuel Processing Technology. 2003, 82(2-3), p. 197-213.

17. Tan, Y., Mortazavi, R., Dureau, B., and Douglas, M. A., An investigation of mercury distribution and speciation during coal combustion. Fuel. 2004, 83(16), p. 2229-2236.

18. Zhuang, Y., Thompson, J. S., Zygarlicke, C. J., and Pavlish, J. H., Development of a mercury transformation model in coal combustion flue gas. Environmental Science and Technology. 2004, 38(21), p. 5803-5808.

19. Galbreath, K. C., Zygarlicke, C. J., Tibbetts, J. E., Schulz, R. L., and Dunham, G. E., Effects of $\mathrm{NO}_{x}, ?-\mathrm{Fe} 2 \mathrm{O} 3$, ?-Fe2O3, and $\mathrm{HCl}$ on mercury transformations in a 7-kW coal combustion system. Fuel Processing Technology. 2004, 86(4), p. 429448.

20. Yamaguchi, A., Tochihara, Y., and Ito, S. Mercury oxidation with catalytic materials in combustion flue gases. in Combined Power Plant Air Pollutant Control Mega Symposium. 2004. Washington, DC, United States: Air and Waste Management Association, Pittsburgh, PA 15222, United States.

21. Galbreath, K. C. and Zygarlicke, C. J., Mercury transformations in coal combustion flue gas. Fuel Processing Technology. 2000, 65-66, p. 289-310.

22. Galbreath, K. C., Zygarlicke, C. J., Olson, E. S., Pavlish, J. H., and Toman, D. L., Evaluating mercury transformation mechanisms in a laboratory-scale combustion system. Science of the Total Environment. 2000, 261(1-3), p. 149-155.

23. Presto, A. A., Granite, E. J., Karash, A., Hargis, R. A., O'Dowd, W. J., and Pennline, H. W., A kinetic approach to the catalytic oxidation of mercury in flue gas. Energy and Fuels. 2006, 20(5), p. 1941-1945.

24. Lee, T. G., Hedrick, E., and Biswas, P., Hg reactions in the presence of chlorine species: Homogeneous gas phase and heterogeneous gas-solid phase. Journal of the Air and Waste Management Association. 2002, 52(11), p. 1316-1323.

25. Shi, L. and Bayless, D. J. Removal of mercury from flue gas by coated fabric filters. in Proceedings of the Air and Waste Management Association Annual Conference. 2004. Indianapolis, IN, United States: Air and Waste Management Association, Pittsburgh, PA 15222, United States.

26. Granite, E. J. and Pennline, H. W., Photochemical removal of mercury from flue gas. Industrial and Engineering Chemistry Research. 2002, 41(22), p. 5470-5476.

27. McLarnon, C. R., Granite, E. J., and Pennline, H. W., The PCO process for photochemical removal of mercury from flue gas. Fuel Processing Technology. 2005, 87(1), p. 85-89.

28. Eswaran, S. and Stenger, H. G., Understanding mercury conversion in selective catalytic reduction (SCR) catalysts. Energy and Fuels. 2005, 19(6), p. 2328-2334. 
29. Benson, S. A., Laumb, J. D., Crocker, C. R., and Pavlish, J. H., SCR catalyst performance in flue gases derived from subbituminous and lignite coals. Fuel Processing Technology. 2005, 86(5), p. 577-613.

30. Richardson, C., Machalek, T., Miller, S., Dene, C., and Chang, R., Effect of $\mathrm{NO}_{\mathrm{x}}$ control processes on mercury speciation in utility flue gas. Journal of the Air and Waste Management Association. 2002, 52(8), p. 941-947.

31. Lee, C. W., Srivastava, R. K., Behrooz Ghorishi, S., Karwowski, J., Hastings, T. W., and Hirschi, J. C., Pilot-scale study of the effect of selective catalytic reduction catalyst on mercury speciation in Illinois and Powder River Basin coal combustion flue gases. Journal of the Air and Waste Management Association. 2006, 56(5), p. 643-649.

32. Nolan, P. S., Redinger, K. E., Amrhein, G. T., and Kudlac, G. A., Demonstration of additive use for enhanced mercury emissions control in wet FGD systems. Fuel Processing Technology. 2004, 85(6-7), p. 587-600.

33. Chang, J. C. S. and Ghorishi, S. B., Simulation and evaluation of elemental mercury concentration increase in flue gas across a wet scrubber. Environmental Science and Technology. 2003, 37(24), p. 5763-5766.

34. Renninger, S. A., Farthing, G. A., Ghorishi, S. B., Teets, C., and Neureuter, J. A. Effects of SCR catalyst, ammonia injection and sodium hydrosulfide on the speciation and removal of mercury within a forced-oxidized limestone scrubber. in Combined Power Plant Air Pollutant Control Mega Symposium. 2004. Washington, DC, United States: Air and Waste Management Association, Pittsburgh, PA 15222, United States.

35. Toole-O'Neil, B., Tewalt, S. J., Finkelman, R. B., and Akers, D. J., Mercury concentration in coal - Unraveling the puzzle. Fuel. 1999, 78(1), p. 47-54.

36. Senior, C. L., Helble, J. J., and Sarofim, A. F., Emissions of mercury, trace elements, and fine particles from stationary combustion sources. Fuel Processing Technology. 2000, 65-66, p. 263-288.

37. Senior, C. L., Sarofim, A. F., Zeng, T., Helble, J. J., and Mamani-Paco, R., Gasphase transformations of mercury in coal-fired power plants. Fuel Processing Technology. 2000, 63(2), p. 197-213.

38. Laudal, D. L., Brown, T. D., and Nott, B. R., Effects of flue gas constituents on mercury speciation. Fuel Processing Technology. 2000, 65-66, p. 157-165.

39. Sliger, R. N., Kramlich, J. C., and Marinov, N. M., Towards the development of a chemical kinetic model for the homogeneous oxidation of mercury by chlorine species. Fuel Processing Technology. 2000, 65-66, p. 423-438.

40. Widmer, N. C., West, J., and Cole, J. A. Thermochemical study of mercury oxidation in utility boiler flue gases. in Proceedings of the Air \& Waste Management Association Annual Conference. 2000. Salt Lake City, UT, United States.

41. Niksa, S., Helble, J. J., and Fujiwara, N., Kinetic modeling of homogeneous mercury oxidation: The importance of $\mathrm{NO}$ and $\mathrm{H}_{2} \mathrm{O}$ in predicting oxidation in coal-derived systems. Environmental Science and Technology. 2001, 35(18), p. 3701-3706. 
42. Edwards, J. R., Srivastava, R. K., and Kilgroe, J. D., A study of gas-phase mercury speciation using detailed chemical kinetics. Journal of the Air and Waste Management Association. 2001, 51(6), p. 869-877.

43. Frandsen, F., Dam-Johansen, K., and Rasmussen, P., Trace elements from combustion and gasification of coal--An equilibrium approach. Progress in Energy and Combustion Science. 1994, 20(2), p. 115-138.

44. Xu, M., Qiao, Y., Zheng, C., Li, L., and Liu, J., Modeling of homogeneous mercury speciation using detailed chemical kinetics. Combustion and Flame. 2003, 132(1-2), p. 208-218.

45. Qiao, Y. and Xu, M. H., The oxidation kinetics of mercury in $\mathrm{Hg} / \mathrm{O} / \mathrm{H} / \mathrm{Cl}$ system. Developments in Chemical Engineering and Mineral Processing. 2005, 13(3-4), p. 483-494.

46. Norton, G. A., Yang, H., Brown, R. C., Laudal, D. L., Dunham, G. E., and Erjavec, J., Heterogeneous oxidation of mercury in simulated post combustion conditions. Fuel. 2003, 82(2), p. 107-116.

47. Zhao, Y., Mann, M. D., Olson, E. S., Pavlish, J. H., and Dunham, G. E., Effects of sulfur dioxide and nitric oxide on mercury oxidation and reduction under homogeneous conditions. Journal of the Air and Waste Management Association. 2006, 56(5), p. 628-635.

48. Agarwal, H., Stenger, H. G., Wu, S., and Fan, Z., Effects of $\mathrm{H}_{2} \mathrm{O}, \mathrm{SO}_{2}$, and $\mathrm{NO}$ on homogeneous $\mathrm{Hg}$ oxidation by $\mathrm{Cl}_{2}$. Energy and Fuels. 2006, 20(3), p. 1068-1075.

49. Hall, B., Schager, P., and Lindqvist, O., Chemical reactions of mercury in combustion flue gases. Water, Air, and Soil Pollution. 1991, 56(SPEC. VOL.), p. $3-14$.

50. Niksa, S. and Fujiwara, N., A predictive mechanism for mercury oxidation on selective catalytic reduction catalysts under coal-derived flue gas. Journal of the Air and Waste Management Association. 2005, 55(12), p. 1866-1875.

51. Bartholomew, C. H. and Farrauto, R. J., Fundamentals of Industrial Catalytic Processes. 2 ed. 2006, Hoboken, NJ: John Wiley \& Sons.

52. Cohen, E. D. and Gutoff, E. B., Modern Coating and Drying Technology. 1992, Hoboken, NJ: John Wiley \& Sons, Inc.

53. Horiba Instruments Incorporated, Horiba DM-6B HG CEMS Instruction Manual. 2005, Irvine, CA, United States.

54. PS Analytical, PSA 10.534 Mercury Calibration System User Manual. 2004, Kent, England.

55. Mallick, K., Witcomb, M. J., and Scurrell, M. S., Simplified single-step synthetic route for the preparation of a highly active gold-based catalyst for $\mathrm{CO}$ oxidation. Journal of Molecular Catalysis A: Chemical. 2004, 215(1-2), p. 103-106.

56. Seames, W., Gadgil, M., Wang, C., and Fetsch, J. Impacts on trace metal leaching from fly ash due to the co-combustion of switchgrass with coal. in 23rd International Pittsburgh Coal Conference. 2006. Pittsburgh, PA, United States.

57. GE Energy Fabric characteristics. GE Energy. http://www.gepower.com/prod_serv/products/particulate_matter/en/fbc/fc.htm. accessed on October 7, 2007

58. Fry, A., Cauch, B., Wendt, J. O. L., Silcox, G. D., Lighty, J. S., and Senior, C. L. Impact of $\mathrm{NO}$ and $\mathrm{SO}_{2}$ on measurement of mercury speciation in a wet chemical 
conditioning system. in 23rd International Pittsburgh Coal Conference. 2006. Pittsburgh, PA, United States.

59. Hassett, D. J. and Eylands, K. E., Mercury capture on coal combustion fly ash. Fuel. 1999, 78(2), p. 243-248.

60. Kellie, S., Cao, Y., Duan, Y., Li, L., Chu, P., Mehta, A., Carty, R., Riley, J. T., and Pan, W.-P., Factors affecting mercury speciation in a 100-MW coal-fired boiler with low-NO ${ }_{x}$ burners. Energy and Fuels. 2005, 19(3), p. 800-806.

61. Kellie, S., Duan, Y., Cao, Y., Chu, P., Mehta, A., Carty, R., Liu, K., Pan, W.-P., and Riley, J. T., Mercury emissions from a 100-MW wall-fired boiler as measured by semicontinuous mercury monitor and Ontario Hydro Method. Fuel Processing Technology. 2004, 85(6-7), p. 487-499.

62. Kolker, A., Senior, C. L., and Quick, J. C., Mercury in coal and the impact of coal quality on mercury emissions from combustion systems. Applied Geochemistry. 2006, 21(11), p. 1821-1836.

63. Blythe, G., DeBerry, D., Marsh, B., Paradis, J., Range, J., and Rhudy, R. Benchscale evaluation of the fate of mercury in wet FGD systems. in Combined Power Plant Air Pollutant Control Mega Symposium. 2004. Washington, DC, United States: Air and Waste Management Association, Pittsburgh, PA 15222, United States. 